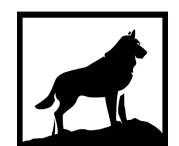

Michigan

Technological

1 8 8 5 University
Michigan Technological University

Digital Commons @ Michigan Tech

2016

ENERGY JUSTICE AND U.S. ENERGY POLICY: CASE STUDY APPLICATIONS EXPLORING U.S. ENERGY POLICY THROUGH AN ENERGY JUSTICE FRAMEWORK

Emily Prehoda

Michigan Technological University, ewprehod@mtu.edu

Copyright 2016 Emily Prehoda

Recommended Citation

Prehoda, Emily, "ENERGY JUSTICE AND U.S. ENERGY POLICY: CASE STUDY APPLICATIONS EXPLORING U.S. ENERGY POLICY THROUGH AN ENERGY JUSTICE FRAMEWORK", Open Access Master's Thesis, Michigan Technological University, 2016.

https://doi.org/10.37099/mtu.dc.etdr/243

Follow this and additional works at: https://digitalcommons.mtu.edu/etdr

Part of the Environmental Studies Commons 
ENERGY JUSTICE AND U.S. ENERGY POLICY: CASE STUDY APPLICATIONS EXPLORING U.S. ENERGY POLICY THROUGH AN ENERGY JUSTICE FRAMEWORK

By

Emily W. Prehoda

\begin{abstract}
A THESIS
Submitted in partial fulfillment of the requirements for the degree of MASTER OF SCIENCE

In Environmental and Energy Policy
\end{abstract}

MICHIGAN TECHNOLOGICAL UNIVERSITY

2016

(C) 2016 Emily W. Prehoda 
This thesis has been approved in partial fulfillment of the requirements for the Degree of MASTER OF SCIENCE in Environmental and Energy Policy.

\title{
Department of Social Sciences
}

\author{
Thesis Advisor: Chelsea Schelly \\ Committee Member: Joshua Pearce
}

Committee Member: $\quad$ Roman Sidortsov

Department Chair: Hugh Gorman 
Table of Contents

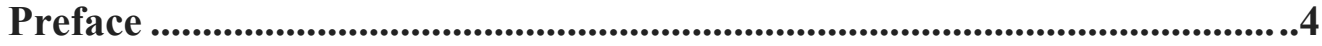

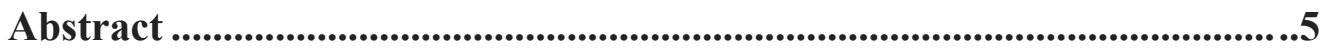

1. Chapter 1 ......................................................................................6

1.1 Existing U.S. Energy Policy ....................................................9

1.2 Energy Policy and Energy Justice............................................11

1.3 Organization of Thesis ........................................................................14

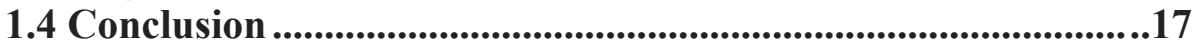

1.5 References .......................................................................................18

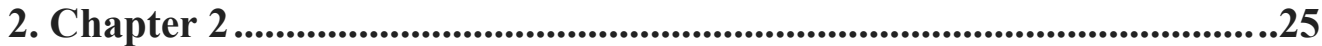

2.1 Introduction ..............................................................................26

2.2 Methods and Calculations .......................................................31

2.3 Results...................................................................................34

2.4 Discussion .........................................................................42

2.5 Conclusions ................................................................................48

2.6 References .......................................................................50

2.7 List of Figures ...................................................................59

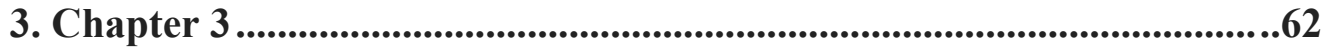

3.1 Introduction ............................................................................63

3.2 Background and Review ..............................................................66

3.3 Data and Methods........................................................................74

3.4 Results...................................................................................79

3.5 Discussion ..............................................................................884

3.6 Conclusion and Policy Implications ...........................................85

3.7 References .................................................................................89

4. Chapter 4 ....................................................................................96

4.1 Introduction ..................................................................................997

4.2 Methods ...............................................................................100

4.3 Results............................................................................104

4.4 Discussion ................................................................................ 107

4.5 Conclusion ..................................................................................... 113

4.6 References .......................................................................115

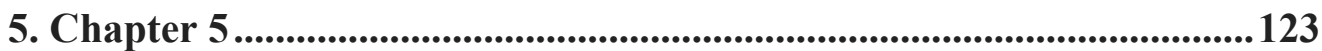

5.1 Turning to Cosmopolitan Justice ................................................ 124

5.2 Policy Recommendations and Implications ...........................125

5.3 Future Work .............................................................................129

5.4 References ................................................................................131 


\section{Preface:}

Chapter 2 consists of a paper that was co-authored by Chelsea Schelly and Joshua Pearce, and is currently submitted to Renewable and Sustainable Energy Reviews. As first author on this paper, I was responsible for gathering background information and data on current U.S. military renewable energy installations, U.S. budget allocated to defense contracting, top U.S. defense contractors, and costs of solar PV systems. I calculated potential nameplate capacity for the entire U.S. military. I created all the graphs and figures in the paper and was responsible for drafting the paper, with editorial and technical assistance from my co-authors.

Chapter 3 includes a paper that was co-authored by Ahbilash Kantamneni and Chelsea Schelly, and will be submitted for review in Energy Policy. Target date for submission is December 2016. For this paper, data were collected from the Michigan Public Service Commission, the 2010 U.S. Census, and National Renewable Energy Lab (NREL), and Michigan Secretary of State Office. Analyses were conducted at the zip code level. I was responsible for data cleaning, variable construction, and statistical analysis. I was also responsible for drafting the paper, with editorial and technical assistance from my co-authors.

Chapter 4 includes a paper that was co-authored by Joshua Pearce and was submitted to the journal Renewable and Sustainable Energy Reviews. I was responsible for collecting background data on coal air pollution at the global and national levels, number of U.S. deaths due to coal-fired electrical production, and current U.S. solar PV capacity. These variables were used to calculate death rate of coal electrical production, death rate of solar PV production, and the number of U.S. lives saved by replacing $100 \%$ of coal electricity with solar PV. I created all figures and graphs in the paper and was responsible for drafting the paper, with editorial and technical assistance from my coauthor. 


\section{Thesis Abstract:}

This thesis presents three examples of U.S. energy policy and demonstrates how these policies violate the principles of energy justice. First, requiring only Federal agencies to obtain a percentage of energy production from renewables violates the distributive energy justice principle through a lack of a federal renewable energy policy which distributes the potential for unequal electrical grid failure to populations. Second, U.S. energy policy violates the procedural energy justice principle through inequitable participation and poor knowledge dissemination that, in some cases, contributes to stagnant renewable targets during the decision-making process and inequitable distribution of the benefits associated with renewable energy arguably resulting from differential representation of economic groups in policy decision making. Third, the United States' continued reliance on and subsidization of fossil fuel extraction and use, violates the prohibitive energy justice principle by causing physical harm to humans and the environment. Finally, a lack of federal renewable energy policy hinders comprehensive energy policy including diversifying the U.S. renewable energy portfolios. Considering energy policy through the framework of energy justice offers a means of evaluating existing policy and can improve future energy policy decisionmaking. Demanding energy justice ensures that all populations have equitable distribution, participation, and access to affordable, efficient, and clean energy technologies that contribute to obtaining basic needs. 
Chapter 1: How does U.S. energy policy reconcile with the principles of energy justice? Introduction

Energy embodies a number of dimensions rather than being limited to the simplistic explanation of the capacity or power to do work. Energy is broken up between primary energy (the energy found in natural resources), end-use energy (the product supplied to consumers from primary energy), useful energy, and energy services (Goldthau and Sovacool, 2012). Scholars define energy services as any benefits provided by the energy industry that functions to support human wellbeing (Sovacool and Mukherjee, 2011). Many argue that energy is the essence of the commodity industry (Schumacher, 1982). While energy is not considered a commodity itself, it provides the pathway for which commodities are made. Taking this one step further, energy is the "lifeblood of the economy and human existence" (Goldthau and Sovacool, 2012: 1). Thus, how energy plays a role in distributing benefits becomes both an economic and political question. Energy security, energy accessibility, and entering the new transition to low carbon energy sources are all important energy issues that move beyond energy as simply an available stock of capacity. Energy has become a "mega-issue" that requires governance at all levels - local, regional, national, and global (Goldthau, 2014, Lesage et al, 2010).

The current energy electrical grid is centralized and integrated, heavily interconnected, and automated. As a result, a democratic majority has less influence than technical experts who control production when any challenge threatens the status quo of U.S. energy production (Winner, 1980). As technology scholar Langdon Winner suggests, development of energy systems is a process that includes scientific knowledge 
and technological development but also political and economic power (Winner, 1980). Individuals less wealth, access to information, and resources have little power in energy system decision-making. Fossil fuel companies spend billions to convince the public that our current system is technologically and economically necessary (Jones et al, 2015). Yet in reality, continued fossil fuel extraction results in collateral damage that affects humanenvironment relationships. Specifically, human's continued dependence on fossil fuels results in environmental problems such as air pollution (Goldberg, 1985), oil spills (Blumer et al, 1973), acid rain (Patel et al, 1974), biodiversity loss (Vitousek et al, 1997), and climate change (Wuebbles and Jain, 2001). These externalities are unjust in that the corporate actors in our current energy market do not incur the costs associated with environmental ills produced from fossil fuel extraction, distribution, and generation (McKibben, 2012). Outdoor air pollution comes in many forms such as ozone, particulate matter, sulfur and nitrogen oxides, carbon monoxide, hydrocarbons, and mercury. These air pollutants are highly correlated with public health issues, chronic disease, morbidity, and mortality effects (Curtis et al, 2006, Yim et al, 2012). Catastrophic accidents such as oil spills continue to happen (Gorman, 2001). Acid rain effects span across ecosystems, damaging fisheries, forests, agriculture and livestock, as well as man-made structures (Likens et al 1979, Likens et al, 1996). Destruction via direct land use for mining practices, waste storage, power plants, and dam infrastructure can decrease biodiversity in affected areas (Cardinale et al, 2012). Finally, human actions, such as industrial practices, energy production, and transportation (to name a few) increase the magnitude of global climate change effects (Lockwood et al, 2009, Smith et al, 2013). U.S. reliance on fossil fuel extraction, distribution, and combustion contribute to these negative 
environmental impacts. While many government strategies, pollution regulations, cap and trade, taxes, and subsidies work to restructure environmental degradation and subsequent human impacts, they do not promote the investment in a fuel source that offers an opportunity for more just distribution of energy systems and services (Winner, 1980 and Lovins, 1976): renewable energy technologies.

Renewable energy sources can be considered a just technology, in that they have the potential to promote social justice (Lovins, 1977). Renewable energy sources provide customers with energy that produces little to no emissions (Panwar et al, 2011) of outdoor air pollutants or greenhouse gases. Full life cycle assessments of energy technologies illustrate renewable energy sources produce a fraction of the externalities (emissions and environmental degradation) associated with fossil fuels (Epstein et al, 2011, Fthenakis et al, 2008, Fthenakis and Kim, 2011, Evans et al, 2009). Fossil fuels distribute these harms to the environment and humans, while renewable technologies knowingly reduce the impacts of energy production and consumption.

Consequently, the environmental and energy justice fields originated from these ethical and moral implications of human's energy decisions (Sovacool and Dworkin, 2015). Injustice becomes an even more salient issue as a resource becomes scarce (Lerner, 1981, Clayton, 2000). Alongside this, energy justice issues are most notable when society experiences severe environmental degradation, human rights violations, or severe accidents (Sidortsov and Sovacool, 2015). The energy justice concept is still in its infancy and scholars do not yet have a general consensus on a definition of energy justice (Sidortsov and Sovacool, 2015). However, many definitions have been proposed and include themes of equitable distribution, equal right to access, and minimal damage to 
human life of and by energy systems (Heffron and McCauley, 2014, Jones et al, 2015, Goldthau and Sovacool, 2012). Decision-makers continually use technical and economic considerations alone when designing energy production, generation, and distribution (Sovacool et al, 2011). When scholars discuss energy justice or injustice, it is often in concert with issues of environmental justice (Sovacool et al, 2013, Goldthau and Sovacool, 2012, Sovacool et al, 2011, Sovacool and Dworkin, 2014). The focus is on communities that are threatened by polluting energy and wasteful technologies. (Energy Justice Network, 1999) Equitable distribution of environmental benefits and burdens along with equitable participation in decision-making and equitable consideration of alternatives can help create a "clean energy, zero-emission, zero-waste" future (Energy Justice Network, 1999). Finding coordination of effective policies with federal assistance, private investment, and nonprofit initiatives can provide access to resources to improve energy efficiency and affordability, decrease externalities, and tackle other energy injustices (Jenkins et al, 2016).

\subsection{Existing US Energy Policy}

The U.S. does not have a federal umbrella renewable energy policy. The Energy Policy Act of 2005 sets requirements for federal agencies to obtain a certain percentage of energy generation from renewables (DOE, 2005). President Barack Obama instituted an "All of the Above Energy Strategy," which targets American energy production domestically, to increase our energy independence (Executive Office of the President, 2014). Specifically targeting clean energy fuels, the U.S. Government focuses renewable energy development on federal agencies, public lands, and military installations. Federal 
incentives to promote renewable energy generation include: investment tax credits, production tax credits, a clean power plan, and DOE loan program (NREL, 2015). Prior to taking office, President Obama proposed a federal renewable portfolio standard (RPS) that would require $25 \%$ of American electrical generation come from renewable energies by 2025 (Office of President, 2014), yet this policy has not been implemented, and federal energy regulation changed focus to regulate $\mathrm{CO} 2$ emissions instead (Bochner, 2014). Although there is no federal policy to focus efforts, half of U.S. states have voluntary or mandatory renewable portfolio standards programs. A RPS places obligations on utility companies within each state to produce a minimum fraction of electricity from renewable resources. Thirty-five states currently hold either renewable portfolio standards or goals that were established through legislation or ballot initiatives (DSIRE, 2016). This suggests large bipartisan support to move in the direction of alternative energy.

As part of the Clean Power Plan (EPA, 2016), the Environmental Protection Agency sets state-by-state rate-based carbon dioxide emission targets. States then receive guidelines on how to design and implement plans to reduce carbon dioxide emissions. The Clean Power Plan does not oblige heavy fossil fuel using states to invest in or generate energy through renewable sources (EPA, 2014). While the Clean Power Plan attempts to reduce carbon dioxide emissions at the state level, it does not provide an avenue to reduce the dependency on long-term fossil fuel usage within the U.S. The lack of U.S. energy policy that includes renewables in the portfolio is an example of energy injustice by failing to address distributive and procedural justice concerns and failing to consider issues related to affirmative and prohibitive justice principles. 


\subsection{Energy Policy and Energy Justice}

Scholars have identified several forms of energy injustice, including three justice theories that form the foundation for an energy justice framework. Distributive justice considers "how social goods are allocated across society" (Sovacool et al, 2013:23). The main scope of distributive justice includes how goods are distributed, what populations receive the distributed goods, and through what approach are these goods distributed? These approaches come in many forms, including decisions based on economic status, necessity, property rights, etc. (Jenkins et al, 2016). Distributive justice is concerned with the benefits and burdens of energy to different social groups. More specifically, considering distributive justice shifts decision making to include an equitable sharing of outcomes (Gross, 2007). Equitable or inequitable distribution of energy and energy impacts can shape a society's educational opportunities, accessibility to natural resources, health and human services, along with economic and political advantages or disadvantages. An equitable distribution of energy thereby distributes economic and politic power. There are social costs that result from the distribution patterns of energy. Relating to energy justice, distributive justice considers the distribution of goods and ills from energy production and use.

Procedural justice reflects the idea of an imbalance of power in the processes that allocate resources. It also comprises the consideration of how decision makers engage with their communities (Jenkins et al, 2016). The main concern is with how decisions are made. This includes rights of participation and access to information (Gross, 2007). The focus is on the fairness of the process (Lind and Tyler, 1988). To achieve fairness in 
procedural justice, decision-making must involve full participation, allow full expression of opinions, provide sufficient information, and involve a maintained level of impartiality of decision makers. Some scholars argue procedural justice is more significant than equitably distributed outcomes in regards to perceptions; MacCoun (2005) suggests that citizens care more about a fair process as it can lead to fair outcomes. Criticisms of fairness in the decision-making process concern parties without social power. These parties have the potential to be excluded from participation and decision-making regarding environmental matters (Clayton, 2000). Tying this to energy systems, procedural energy justice examines the domination of "social, industrial, and political elites" (Sovacool et al, 2013, Dworkin and Sovacool, 2014, Kramer and Tyler, 1996) who maintain control in the extraction, distribution, and generation of fossil fuel sources.

Finally, cosmopolitan justice is concerned with the global and intergenerational distribution of burdens and benefits (Caney, 2005). Conventional energy infrastructure and policies have global impacts in the form of both environmental and human costs. The externalities associated with fossil fuel use are not limited by borders and span the globe, distributing damages to other nations. The continued extraction of fossil fuels decreases fossil fuel reserves, leaving fewer resources for future generations.

Recent extensions of the energy justice theories related to distributive and procedural principles reviewed above resulted two additional concepts, prohibitive and affirmative energy justice principles (Sovacool et al, 2013). The prohibitive principle considers energy system infrastructure designs that hinder a person's ability to acquire basic energy goods. More specifically, this principle involves consideration of level of risk experienced by populations as a result of polluting energy technologies energy 
systems that inflict damage onto people (i.e. pollution morbidity and mortality effects) and/or future generations violate their entitlement to basic goods. The prohibitive principle goes beyond a simple "access to energy" issue. It pulls external costs of energy services into the equation. If the design of the energy infrastructure system violates the prohibitive principle, society bears external costs. The affirmative principle states "if any basic good to which every person is justly entitled can only be secured through energy services, then there is also a derivative right to the energy service" (Sovacool et al, 2013:46, Hernandez, 2015). The affirmative energy justice principle is concerned with attainment of basic goods. If these goods can only be obtained through energy services, then individuals have an established right to energy. In this instance, energy serves as a necessity to satisfy or obtain other basic needs. The affirmative principle considers alternative options of energy services because people have a "derivative entitlement" (Jones et al, 2015:165) to obtain these basic needs. Alongside alternative sources, affirmative justice speaks to those populations living in energy or fuel poverty. Availability of an alternative technology is useless with limited means to invest in these renewable sources.

Given this context of contemporary energy policy in the United States, this thesis explicates theories and principles of energy justice and applies these frames to existing U.S. energy policy. Through the lens of theories and principles mentioned above, (Jenkins et al, 2016, Jones et al, 2015), U.S. energy policy, arguably presents opportunities for analysis and recommendations for future change given the lack of federal, substantive, and equitable pursuit of cleaner energy production and distribution. This application allows for examination of how specific U.S. energy policies reconcile 
with energy justice, the consequences of these violations, and the possibilities for changing and improving policy by using an energy justice framework to guide policy development.

Borrowing from Lakatos (1970), a framework is a basic structure underlying a system or a concept. Frameworks function to provide researchers with a platform to describe or explain phenomena in particular contexts. Frameworks also afford researchers a common language for interdisciplinary communication. While frameworks may not be directly testable (Jenkins-Smith et al, 2014), they can provide guidance towards descriptive and/or explanatory inquiries. For the purpose of this thesis, an energy justice framework provides an innovative means of identifying policy weaknesses and a potential tool for improving the social implications of energy policy. Three case studies are presented below via co-authored manuscripts currently in preparation.

\subsection{Organization of the Thesis}

The papers are presented here in an order that corresponds to the conceptual development of the energy justice field. Deutsch (1975), Rawls (1971) and Dworkin (1985) provide early descriptions of distributive (Chapter 2) and procedural (Chapter 3) justice concepts. These theories were later adapted to describe inequalities in environmental and energy studies (Dobson, 1998, Schlosberg, 2004, Schrader-Frechette, 2002, Cole, 2001, Socavool and Dworkin, 2015). Sovacool et al later developed the prohibitive and affirmative energy justice principles (Sovacool et al, 2013) building upon the theories of distributive and procedural justice. 
Chapter 2 presents a case study of the potential for solar PV scale up for U.S. military facilities. This chapter addresses the energy justice theory regarding the distribution of benefits and burdens by energy systems. The literature surrounding distributive energy justice focuses on direct impact of energy systems. This chapter considers the role of existing energy policies and the consequences (environmental goods and bads) of the distribution (or lack thereof) of these policies, specifically considering the feasibility for addressing existing U.S. policy aimed at military facilities while also drawing attention to the inequitable distribution of targeted energy policies for utilities renewable energy systems for energy security across critical infrastructures and for community resilience. A major social cost of continued reliance and subsidies of fossil fuels is the potential for massive electrical grid failure. Due to its highly interconnected and interdependent nature, electric grid failure has the potential to impair economic and social functions in the event of a power outage. Yet renewable energy policies are being inequitably distributed among end users; while the U.S. has no federal renewable energy target, military facilities must obtain $25 \%$ of energy generation from renewable energy resources by 2025 (ACORE, 2016). The distributive energy justice principle speaks to not only a physical equitable distribution of environmental benefits and burdens, but also distribution of "responsibilities" (McCauley, 2013). This includes a population's exposure to a certain level of risk. The gap lies in a mandate to secure the grid to protect the general public from effects of accidental or intentional grid failure. Considering distributional energy justice into the U.S. renewable energy portfolio will allow decisionmakers to enact policies that equitably distribute environmental goods and burdens across the nation, and ultimately move toward protecting U.S. citizens from major grid failure. 
Chapter 3 offers a state level analysis of solar PV adoption in Michigan. This paper acknowledges the reality of fuel poverty in Michigan, pointing to both procedural justice and the affirmative energy justice principle. Chapter 3 attempts to situate sustainable consumers in an energy policy context to understand other factors that may shape their ability to adopt solar PV technology. This study uses predictors including socioeconomic indicators (median home value, education, unemployment rate, fuel poverty), political affiliations (\% republican), and utility policy (utility rates) to understand what predicts residential adoption of solar PV technology. This information can inform decision-makers about the context of decision making shaping technology choices in residential households. This paper will assist policy development by suggesting the importance of including procedural and affirmative justice in the policymaking process, considering equitable representation and full public participation when developing and evolving Michigan's renewable energy portfolio that might support and incentivize residential solar technology use. Individuals who live in or near fuel poverty have difficulty obtaining energy services, and are less likely to adopt residential PV technology. According to the affirmative principle of energy justice, these individuals have a basic right to energy; the inability to afford alternative options violates this principle. The issue of fuel poverty relates to procedural energy justice because individuals living in or near fuel poverty have unequal access and representation in the energy decision-making process (Kramer and Tyler, 1996).

Chapter 4 presents a second national level case study to address opportunities for policy change within the scope of the prohibitive energy justice principle. The U.S. reliance on fossil fuels for energy brings many externalities. Poor air quality from coal 
combustion adversely impacts human health including mortality and morbidity effects on respiratory, cardiovascular, nervous, urinary, and digestive systems. Energy development must take into account the people and the community first in decision-making. For chapter 4 , the prohibitive principle speaks to a larger issue of infrastructure design. Externalities must be factored into the equation to provide adequate energy justice. This case illustrates how current U.S. energy policy violates the prohibitive principle. The U.S. spends roughly $\$ 4.7$ billion to subsidize the fossil fuel industry (U.S. Department of Treasury, 2014). Conventional fossil fuels have great externalities ranging from environmental degradation in the extraction process (Sims, 2003), to harmful emissions during the combustion/energy generation process (Epstein et al, 2011), to further climate disruption (Lockwood, 2009). The current system has externalities that harm humans and this paper shows the number of deaths per year in the U.S. due to coal-fired electrical combustion. The nature and infrastructure design of the current U.S. energy extraction, transmission, and generation does not factor externalities into energy costs.

\subsection{Conclusion}

Based on each empirical investigation, this thesis stresses the importance of utilizing an energy justice framework in policy decisions regarding energy production and consumption. By moving the focus from a purely economic and/or technical perspective to social justice concepts, we can transform the way policy makers and deliberators form U.S. energy policy. Policy recommendations are further explored in the conclusion chapter of the thesis to aid decision-making in the energy policy arena. 


\subsection{References:}

American Council on Renewable Energy. "National Defense and Security Initiative." Last modified, 2016. http://www.acore.org/programs/member-initiatives/nationaldefensesecurity?highlight=WyJkb2QiLCJkb2QncyIsMjUsInJlbmV3YWJsZSIsIidyZW51 d2FibGUiXQ $==$.

Amin, M. "Energy infrastructure defense systems." Proceedings of the IEEE 93, 5 (2005): 861-875.

----------. "Challenges in Reliability, Security, Efficiency, and Resilience of Energy Infrastructure: smart self-healing electric power grid. Power and Energy Society General Meeting, (2008): 1-5.

Barbose, Galen. "Renewables portfolio standards in the United States: a status update." Lawrence Berkeley National Laboratory. September (2014).

Blumer, Max, M. Ehrhardt, and J. H. Jones. "The environmental fate of stranded crude oil." In Deep Sea Research and Oceanographic Abstracts, vol. 20, no. 3, pp. 239259. Elsevier, 1973.

Bochner, Francesca F. "Water, Wind, and Fire: A Call for A Federal Renewable Portfolio Standard." Duke Envtl. L. \& Pol'y F. 25 (2014): 201.

Caney, Simon. "Cosmopolitan justice, responsibility, and global climate change." Leiden journal of international law 18, no. 04 (2005): 747-775.

Cardinale, Bradley J., J. Emmett Duffy, Andrew Gonzalez, David U. Hooper, Charles Perrings, Patrick Venail, Anita Narwani et al. "Biodiversity loss and its impact on humanity." Nature 486, no. 7401 (2012): 59-67.

Center for Energy and Environmental Policy. "Policies for achieving energy justice in society: best practices for applying solar energy technologies to low-income housing." Last modified, 2010. http://ceep.udel.edu/wpcontent/uploads/2013/08/2010 es READY AchievingEnergyJusticewithSolar1.p df

Chen, G., Dong, Z., Hill, D., Zhang, G., Hua, K. "Attack on structural vulnerability of power grids: a hybrid approach based on complex networks." Physica A 389, 3 (2010): 595-603.

Clayton, Matthew, and Andrew Williams. "The ideal of equality." (2000). 
Cole, Luke W., and Sheila R. Foster. From the ground up: Environmental racism and the rise of the environmental justice movement. NYU Press, 2001.

Cowell, Richard. "Global Energy Justice: Problems, principles, and practices." Journal of Environmental Policy \& Planning 18, 2 (2016):253-255

Curtis, Luke, William Rea, Patricia Smith-Willis, Ervin Fenyves, and Yaqin Pan. "Adverse health effects of outdoor air pollutants." Environment international 32, no. 6 (2006): 815-830.

Deutsch, Morton. "Equity, equality, and need: What determines which value will be used as the basis of distributive justice?." Journal of Social issues 31, no. 3 (1975): 137-149.

Dobson, Andrew. Justice and the environment: Conceptions of environmental sustainability and theories of distributive justice. Clarendon Press, 1998.

DSIRE. Renewable Portfolio Standard Policies. Accessed Aug 20, 2016. http://ncsolarcen-prod.s3.amazonaws.com/wpcontent/uploads/2014/11/Renewable-Portfolio-Standards.pdf

Dworkin, Ronald. A matter of principle. OUP Oxford, 1985.

U.S. Department of Energy. "Energy Policy Act of 2005." Last modified, 2005. http://energy.gov/sites/prod/files/2013/10/f3/epact_2005.pdf.

U.S. Department of Treasury. "Progress Report on Fossil Fuel Subsidies." Last modified, 2014.

https://www.treasury.gov/open/Documents/USA\%20FFSR\%20progress\%20repor t\%20to\%20G20\%202014\%20Final.pdf.

Elliot, E.D. "Why the United States does not have a renewable energy policy." $\mathrm{PhD}$ diss., Yale Law School, 2013.

Energy Justice Network. Energy Justice Platform. Accessed Aug, 15, 2016. http://www.energyjustice.net/platform

EPA. Clean Power Plan. Accessed on Oct 24, 2016. https://www.epa.gov/cleanpowerplan.

Epstein, P., Buonocore, J., Eckerle, K., Hendryx, M., Stout, B., Heinberg, R., Clapp, R., May, B., Reinhart, N., Ahern, M., Doshi, S., Glustrom, L. "Full cost accounting for the life cycle of coal." Ecological Economics Reviews 1219 (2011): 73-98. 
Evans, Alexander M., Robert T. Perschel, and Brian A. Kittler. "Overview of forest biomass harvesting guidelines." Journal of sustainable forestry 32, no. 1-2 (2013): 89-107.

Executive Office of the President. "The All-Of-The-Above energy strategy as a path to sustainable economic growth." Last modified, 2014. https://www.whitehouse.gov/sites/default/files/docs/aota energy strategy as a p ath_to_sustainable_economic_growth.pdf.

Farrell, A., Zerriffi, H., Dowlatabadi, H. "Energy infrastructure and security." Annual Review of Environmental Resources. 29 (2004): 421-469.

Fthenakis, Vasilis M., Hyung Chul Kim, and Erik Alsema. "Emissions from photovoltaic life cycles." Environmental science \& technology 42, no. 6 (2008): 2168-2174.

Fthenakis, V. M., and Hyung Chul Kim. "Photovoltaics: Life-cycle analyses." Solar Energy 85, no. 8 (2011): 1609-1628.

Goldberg, Edward. "Black carbon in the environment." (1985).

Goldthau, A. and Sovacool, B. "The uniqueness of the energy security, justice, and governance problem.” Energy Policy 41 (2012):232-240.

Goldthau, Andreas. "Rethinking the governance of energy infrastructure: Scale, decentralization and polycentrism." Energy Research \& Social Science 1 (2014): 134-140.

Gorman, Hugh S. Redefining Efficiency. The University of Akron Press, 2001.

Hall, Peter A. "Policy paradigms, social learning, and the state: the case of economic policymaking in Britain." Comparative politics (1993): 275-296.

Hall, S.M., Hards, S., Bulkeley, H. "New approaches to energy: equity, justice, and vulnerability. Introduction to the special issue." Local Environment 18, 4 (2013): 413-421.

Heffron, R. and McCauley, D. "Achieving sustainable supply chains through energy justice.” Applied Energy 123 (2014): 435-437.

Hernandez, D. "Sacrifice along the energy continuum: a call for energy justice." Environmental Justice 8, 4(2015): 151-156.

Herrick, Sarah, Joe Kovach, Eunice Padley, Carmen Wagner, and Darrell Zastrow. "Wisconsin's forestland woody biomass harvesting guidelines." WI DNR Division of Forestry and Wisconsin Council on Forestry, Madison, WI(2009). 
Institute for Energy Innovation. "Barriers to Advanced Energy in Michigan." http://www.instituteforenergyinnovation.org/?objectid=E1B873C0-A4E7-11E486CF0050569A5318.

Jenkins, K., McCauley, D., Heffron, R., Stephan, H. "Energy justice: a whole systems approach.” Queen's Political Review 2, 2 (2014): 74-87.

Jenkins, K., McCauley, D., Heffron, R., Stephan, H., Rehner, R. "Energy Justice: A conceptual review." Energy Research and Social Science 11 (2016): 174-182.

Johansson, J., Jonsson, H., Johansson, H. "Analysing the vulnerability of electric distribution systems: a step towards incorporating the societal consequences of disruptions." International Journal of Policy Management 4, 1 (2007): 4-17.

Jones, Benjamin R., Sovacool, Benjamin K, Sidortsov, R. "Making ethical and philosophical case for "energy justice"." Environmental Ethics 37, 2(2015): 145168.

Kramer, Roderick M., and Tom R. Tyler, eds. Trust in organizations: Frontiers of theory and research. Sage Publications, 1995.

Lakatos, Imre. "History of science and its rational reconstructions." In PSA 1970, pp. 91136. Springer Netherlands, 1971.

Lerner, Melvin J. "The justice motive in human relations." In The justice motive in social behavior, pp. 11-35. Springer US, 1981.

Lesage, Dries, and Thijs Van de Graaf. Global energy governance in a multipolar world. Routledge, 2016.

Lewis, T. G. Critical infrastructure protection in homeland security: defending a networked nation. John Wiley and Songs, 2014.

Likens, Gene E., Richard F. Wright, James N. Galloway, and Thomas J. Butler. "Acid rain." Sci. Am.;(United States) 241, no. 4 (1979).

Likens, Gene E. "Acid Precipitation." Chemical and Engineering News 54, no. 48 (1976): $29-44$.

Lockwood, A., Welker-Hood, K., Rauch, M., Gottlieb, B. "Coal's assault on human health.” Report from Physicians for Social Responsibility, 3-16.

Lovins, Amory B. "Energy strategy: the road not taken." Foreign Aff. 55 (1976): 65.

"Soft energy paths: Toward a durable peace." (1977). 
McCauley, D., Heffron, R., Stephan, H. Jenkins, K. "Advancing energy justice: the triumvirate of tenets." International Energy Law Review 32, 3 (2013): 107-110.

McKibben, Bill. "Global warming's terrifying new math." Rolling Stone 19, no. 7 (2012): 2012.

Michaels, Robert J. "National renewable portfolio standard: smart policy or misguided gesture." Energy LJ 29 (2008): 79.

Michigan Public Service Commission. "Michigan's new net metering program.” Last modified, 2015.

https://www.michigan.gov/documents/mpsc/net_metering_handout_final_307847 7.pdf.

Michigan Public Service Commission. "2015 report on energy optimization programs and cost-effectiveness of PA 295 standards." Last modified, 2015. http://www.michigan.gov/documents/mpsc/2015_Energy_Optimization_Report_5 01548 7.pdf.

Miller, C.A., Iles, A., Jones, C. "The social dimensions of energy transitions." Science as Culture 22, 2 (2013): 135-148.

Moellendorf, Darrel. “Cosmopolitan Justice.” (2002).

Motter, A. and Lai, Y. "Cascade-based attacks on complex networks. Physical Review 66, 6(2002):65102-1-4.

Nye, David, Consuming Power: A social history of American Energies. MIT Press, 1999.

O'Brien, G., Hope, A. 'Localism and Energy: negotiating approaches to embedding resilience in energy systems. Energy Policy 38, 12(2010): 7550-7558.

Panwar, N. L., S. C. Kaushik, and Surendra Kothari. "Role of renewable energy sources in environmental protection: a review." Renewable and Sustainable Energy Reviews 15, no. 3 (2011): 1513-1524.

Patel, C.K.N., Burkhardt, E.G., Lambert, C.A. “Acid rain: a serious regional environmental problem." Science, 184(1974): 1176-1179.

Rawls, John. "A theory of justice." (1971).

Reed, D. "Beyond the War on Terror: into the 5th generation of war and conflict." Studies in Conflict and Terrorism 31, 8 (2008): 684-722. 
Sahu, A., Shandilya, A., Bhardwaj, S.K. "Rural electrification: issues and challenges of sustainable development." International Journal of Emerging Technology and Advanced Engineering 4, 8(2014): 240-246.

Salmeron, J., Wood, K., Baldick, R. "Analysis of electric grid security under terrorist threat. Transactions on Power Systems 19, 2(2004): 905-912.

Schlosberg, David. "Reconceiving environmental justice: global movements and political theories." Environmental politics 13, no. 3 (2004): 517-540.

Schumacher, Ernst Friedrich. Schumacher on energy: Speeches and writings of EF Schumacher. Jonathan Cape, 1982.

Shrader-Frechette, Kristin. Environmental justice: Creating equality, reclaiming democracy. Oxford University Press, 2002.

Sims, R., Rogner, H., Gregory, K. "Carbon emission and mitigation cost comparisons between fossil fuel, nuclear, and renewable energy sources for electricity generation. " Energy Policy 31, 13(2003): 1315-1326.

Smith, Keith. Environmental hazards: assessing risk and reducing disaster. Routledge, 2013.

Sovacool, Benjamin K. "The cultural barriers to renewable energy and energy efficiency in the U.S.," Technology in Society 31, 4(2009): 365-373.

Sovacool, Benjamin K., and Ishani Mukherjee. "Conceptualizing and measuring energy security: a synthesized approach." Energy 36, no. 8 (2011): 5343-5355.

Sovacool, Benjamin K., Sidortsov, Roman, Jones, Benjamin. Energy Security, equality, and justice. Routledge, 2013.

Sovacool, B.K., Heffron, R., McCauley, D., Goldthau, A. "Energy decisions reframed as justice and ethical concerns." Nature Energy 1 (2016): 16024.

Wang, J. and Rong, L. "Cascade-based attack vulnerability on the U.S. Power grid. Safety Science 7, 10 (2009): 1332-1336.

Vitousek, Peter M., Harold A. Mooney, Jane Lubchenco, and Jerry M. Melillo. "Human domination of Earth's ecosystems." Science 277, no. 5325 (1997): 494-499.

Winner, L. "Do artifacts have politics?.” Daedalus (1980): 121-136.

Wuebbles, D. and Jain, A. "Concerns about climate change and the role of fossil fuel use.” Fuel Processing Technology, 71(2001): 99-119. 
Yim, Steve HL, and Steven RH Barrett. "Public health impacts of combustion emissions in the United Kingdom." Environmental science \& technology 46, no. 8 (2012): 4291-4296. 
Chapter 2: U.S. Strategic Solar Photovoltaic- Powered Microgrid Deployment for

\title{
Enhanced National Security $^{1}$
}

\section{U.S. Strategic Solar Photovoltaic-Powered Microgrid Deployment for Enhanced National Security}

\author{
Emily W. Prehoda ${ }^{a}$, Chelsea Schelly ${ }^{a}$, Joshua M. Pearce ${ }^{b, c, *}$ \\ a Department of Social Sciences, Michigan Technological University, 1400 Townsend \\ Drive, Houghton, Michigan 49931-1295, USA; ewprehod@mtu.edu, cschelly@mtu.edu \\ $\mathrm{b}$ Department of Materials Science and Engineering, Michigan Technological \\ University, 1400 Townsend Drive, Houghton, Michigan 49931-1295, USA; \\ pearce@mtu.edu \\ ${ }^{\mathrm{c}}$ Department of Electrical and Computer Engineering, Michigan Technological \\ University, 1400 Townsend Drive, Houghton, Michigan 49931-1295, USA; \\ pearce@mtu.edu \\ *Corresponding author. E-mail: pearce@mtu.edu. Telephone: (906) 487-1466.
}

\begin{abstract}
The U.S. electrical grid, the largest and most complex man-made system in the world, is highly vulnerable to three types of external threats: 1) natural disasters, 2) intentional physical attacks, and 3) cyber-attacks. The technical community has recommended hardening the grid to make it more resilient to attack by using distributed generation and microgrids. Solar photovoltaic (PV) systems are an ideal distributed generation technology to provide power for such microgrids. However, both the deployment velocity and the policy of how to implement such technical solutions have been given far less attention than would be normally considered adequate for a national security risk. To address this threat, this paper investigates the technical and economic viability of utilizing defense contracting for the beginning of a national transition to distributed generation in the U.S. First, the technical scale of electrical demand and the solar PV system necessary is analyzed in detail to meet the first level of strategic importance: the U.S. military. The results found that a little over $18 \mathrm{GW}$ of PV would be needed to fortify the U.S. military domestically. The current domestic geographic deployment of microgrid installations in the critical U.S. defense infrastructure were reviewed and compared to historical grid failures and existing and planned PV installations to mitigate that risk. The results showed a minimal number of military bases have introduced solar PV systems, leaving large parts of Department of Defense electrical infrastructure vulnerable to attack. To rectify this situation, the technical skills of the top 20 U.S. defense contractors is reviewed and analyzed for a potential contracting transition to grid fortification. Overall the results indicate that a fortified U.S. military
\end{abstract}

1 The material contained in this chapter has been submitted to Renewable and Sustainable Energy Reviews 
grid made up of PV-powered microgrids is technically feasible, within current contractors skill sets and economically viable. Policy recommendations are made to accelerate U.S. military grid fortification.

Keywords: national security; photovoltaic; resilience; microgrid; defense; distributed generation

\subsection{Introduction}

The U.S. electrical grid, the largest and most complex man-made system in the world today (Chen et al, 2010), is an interconnected network for delivering electricity from generally centralized suppliers to distributed consumers. This electrical system architecture is comprised of substations with variable carrying capacities of electrical load, which are susceptible to widespread cascading failures (Chen et al, 2010, Wang and Rong, 2009, O’Brien and Hope, 2010). Every U.S. sector (military, economy, government, health care, education, etc.) depends on the grid to deliver essential electrical services. Due to its highly interconnected and interdependent nature, electric grid failure has the potential to impair economic and social functions in the event of a power outage (Johansson et al, 2007, Amin, 2005, Amin, 2008). The interdependencies of the power grid and other critical infrastructures are illustrated in Figure 1. The general consensus in the energy community is that the electrical grid is highly vulnerable to three types of external threats: 1) natural disasters (Little, 2002, Albert et al, 2004, Brown et al 2014), 2) intentional physical attacks (Amin, 2005, Amin, 2002, Motter and Lai, 2002, Salmeron et al 2004, Kinney et al, 2005), and 3) cyber-attacks

(Watts, 2003, Fovino et al, 2011, Sridhar et al, 2012, Hebert, 2013, Aitel, 2013, Umbach, 2013, Onyeji et al, 2014). 
The first threat of natural disasters caused by severe weather is responsible for $\$ 18$ to $\$ 33$ billion every year in power outages and damages to U.S. infrastructure (Gent and Costantini, 2003, Brummitt et al, 2012, Office of President, 2013). These disasters tend to be widespread, with an average of 700,000 consumers impacted per weatherinduced power outage annually (Amin, 2005). The impacts of past major U.S. power outages are summarized in Table 1. The majority of economic costs result from spoiled inventory, delayed production, and damage to grid infrastructure (Office of President, 2013).

The second threat of physical attacks includes traditional acts of terrorism such as bombing or sabotage (Watts, 2003) (e.g. an electromagnetic pulse attack (Bernstein et al, 2012, FERC, 2015, Detwiler, 2014). The traditional power grid infrastructure is incapable of withstanding intentional physical attacks (NRC, 2012). Damage resulting in physical attack could be long lasting, as power plants operate with large transformers that are difficult to move and source. Custom rebuilt transformers require time for replacement ranging from months and even up to years (NRC, 2012). For example, a 2013 sniper attack on California's Pacific Gas and Electric (PG\&E) substation disabled 17 transformers supplying power to Silicon Valley. Repairs and improvements cost PG\&E roughly \$100 million and lasted 27 days (Avalos, 2014, CNN, 2015, Memmott, 2014). 
In addition to physical attacks, the electrical grid is also exposed to cyber-attacks. The Pentagon reports spending roughly $\$ 100$ million to repair cyber-related damages to the electric grid in 2009 (WSJ, 2009). The U.S. electric grid, along with other critical infrastructure systems, is growing increasingly dependent upon the Internet and other network connections for data communication and monitoring systems (Sridhar et al, 2012, Wu et al, 2005, Schainker et al, 2006, Ulieru, 2007, Bessani et al, 2008). While this allows electrical suppliers convenient operation and management of systems, it increases the grid's susceptibility to cyber-attack, which exploit critical infrastructure systems, causing denial of webpage services to consumers, disruption to supervisory control and data acquisition (SCADA) operating systems, or sustained widespread power outages (Sridhar et al, 2012, Aitel, 2013, Krotofil et al, 2014, Wooi Ten et al, 2010). Unlike a physical attack, cyber attackers are capable of penetrating critical electric infrastructure from remote regions of the world, requiring only an Internet connection to gain pathways and install malware into the electric power grid's control systems. Many efforts are underway to harden the grid from such attack (Hebert, 2013, Gent and Costantini, 2003, Bessani et al, 2008). However, the integrated nature of the grid, which is based on centralized generation, but diffuse transmission, makes the entire system vulnerable to a concentrated attack, in contrast to a natural disaster that may have local or regional impacts. The U.S. Department of Homeland Security reports responding to approximately 200 cyber incidents in 2012 across critical infrastructure sectors, of which $41 \%$ involved the electrical grid (BPC, 2014). Economic impacts of a successful breach are estimated to cost $\$ 243$ billion mounting to roughly $\$ 1$ trillion in an extreme case (Dipietro, 2015). According to senior intelligence officials, various 
nation states (e.g. China, Russia, North Korea) have made attempts to map current critical infrastructure for future navigation and control of the U.S. electrical system (WSJ, 2009).

Due to such offensive efforts, several other countries, including the U.S., have added cyber-attacks into their current military defense preparations (Schainker et al, 2006). As cyber-attacks are becoming increasingly prevalent, it is necessary to recognize the unpreparedness of critical infrastructure operators. In 2008, the Federal Energy Regulatory Commission (FERC) alongside the North American Electric Reliability Corporation (NERC) implemented a mandatory Critical Infrastructure Protection (CIP) Reliability Standards program (Aradau, 2010). Then an Executive Order (EO 13636) was implemented in 2013, in effort to address additional protection measures not listed in the CIP Standards program (Spina and Skees, 2013). Other proposed policy solutions to electric grid cyber vulnerability include better assessment of vulnerabilities and increased cyber security control through strong firewalls and monitoring systems [Chen et al, 2002, Bessina et al, 2008, Aradau, 2010).

The technical community has recommended a more direct solution to all of these threats for some time: distributed generation and microgrids (Colson et al, 2011, Shahidehpour and Khodayar, 2013, Che and Shahidehpour, 2014). Microgrids allow the generation system to separate from distribution during disturbance events. The system maintains a high level of service and performance while decreasing the chances of cascading failures and enables distributed generation without grid redesign (Lasseter 
and Paigi, 2004, Pearce, 2002), thereby making the entire grid more resilient. Solar photovoltaic (PV) systems, which generate electricity directly from sunlight (Pearce, 2002), are an ideal distributed generation technology to provide power for such microgrids (Maity and Rao, 2010). PV costs have dropped significantly (Barbose et al, 2014, Reichelstein and Yorston, 2013), due to technical evolution, large-scale manufacturing (Zweibel et al, 2008) and a substantial learning curve (Van Der Zwaan and Rabl, 2003, Nemet, 2006, Candelise et al, 2013). Coupled with current decreasing battery costs (DOE, 2013, Tesla, 2015), the transition to solar PV distributed generation microgrid systems can be highly economical (Chaurey and Kandpal, 2010, Abu-Sharkh et al, 2006, Su et al, 2014).

The policy of how to implement such technical solutions has been given far less attention than would be normally considered adequate for a national security risk as demonstrated by the dearth in the literature as compared to more conventional national security threats. To address this threat, this paper investigates the technical and economic viability of utilizing defense contracting for a start of a national transition to distributed generation in the U.S. First, the technical scale of electrical demand and the necessary solar PV system is analyzed in detail to meet the first level of strategic importance: the U.S. military. The current domestic geographic deployment of microgrid installations in the critical U.S. defense infrastructure is reviewed and compared to historical grid failures and existing and planned PV installations to mitigate that risk. Then the technical skills of the top 20 U.S. defense contractors is reviewed and analyzed for a potential contracting transition to grid fortification. Three 
case studies are presented (Lockheed Martin, Bechtel, and GE) to demonstrate how this transition could take place. A cost sensitivity is performed and the potential revenue increase for the current defense contracts of the top 20 U.S. contractors for 2014 is presented. Then, each of the remaining levels the current grid vulnerabilities is summarized and policy recommendations are made to demonstrate a path to a secure and hardened U.S. electric system made up of PV-powered microgrids.

\section{$\underline{2.2}$ Methods and Calculations}

Electric load data for fiscal year 2014 was obtained from the U.S. Energy Information Administration (EIA) for: (1) military, (2) government, (3) critical infrastructure (systems defined as electric power, natural gas/oil production, telecommunications, transportation, water supply, banking and finance, transportation, emergency and government services, and agriculture (Rinaldi et al, 2001), (4) industrial, (5) commercial, and (6) residential (EIA, 2015) to determine the scale of PV-powered microgrid fortification needed at each level of strategic importance. For level 1 (military) facilities, the Department of Defense (DOD) Title 10 USC 2911 requires military operations to obtain $25 \%$ of energy generation from renewable energy resources by 2025 (GPO, 2011). Along with the DOD Title 10 USC 2911, the DOD implemented a secondary initiative of $3 \mathrm{GW}$ of renewable capacity by 2025 (DOD, 2015).

To determine the percentage of military facilities meeting national security thresholds, operational military bases (Army, Air Force, Navy, and Marine) were identified from 
military databases (U.S. Army, 2015, U.S. Navy, 2015, U.S. Air Force, 2015) and cross-referenced with current Department of Defense solar renewable energy existing installations and upcoming projects (U.S. Army, 2015, U.S. Navy, 2015, U.S. Air Force, 2015). Information was tabulated to provide base location, PV installation capacity, and base population.

Next, data on past major U.S. power blackouts were collected (Amin, 2005) and geolocated with the following data: cost in damages, amount of states and customers affected, and the cause of blackout. Two shapefiles were obtained to analyze the national solar electrical security for strategic level 1 facilities: 1) a shapefile of the United States was obtained from the ArcGIS database (Fitzpatrick, 2012), 2) a point shapefile of 2015 military bases was obtained from the DOD (DOD, 2015). Power outage locations military bases were then transcribed to a map utilizing ArcMap version 10.3.1, and this geographic information systems (GIS) data was then overlaid with current military solar-PV installations to provide a map of national solar electrical security for strategic level 1 facilities.

In order to gauge the difficulty in obtaining $25 \%$ (required by 2025 ), $50 \%$, and $100 \%$ compliance with hardening of electrical security at these strategic level 1 facilities, FY 2014 Federal spending budget was collected to determine funds allocated towards DOD federal contracting services. A list of the top 25 federal contractors was obtained from the Federal Procurement Data System and is arranged by the total federal contracting spending (and percentage) on services for each company for fiscal year 
2014 (FPDS, 2015). Technical skills of three of the top 25 U.S. defense contractors (Lockheed Martin, GE and the Bechtel Group) is reviewed and analyzed for a potential contracting transition to grid fortification and case studies are presented. A cost sensitivity is performed and the potential revenue increase for the current defense contracts of the top 20 U.S. contractors for 2013 is presented. Then, reviewing policy relevant to military deployment of $\mathrm{PV}$, policy recommendations are summarized to demonstrate a path to PV-powered microgrids for the necessary national security measures made possible by grid fortification.

Nameplate capacity $(\mathrm{Np})$ in $\mathrm{GW}$ for $\mathrm{p}=25 \%, 50 \%$, and $100 \%$ solar PV generation is given by:

$$
\begin{array}{ccc}
\underline{P}_{C} & (p * C) & -6 \\
-6 & \\
N_{p}=(f)^{* 10} & {[G W / k W]=\left(\begin{array}{lll} 
& & \\
& &
\end{array}\right)^{* 10}} & {[G W / k W]}
\end{array}
$$

Where the percent capacity (PC) $[\mathrm{MWH} /$ day], is given by $\mathrm{p}$ is the percent calculated here for 25,50 , and $100 \%$ of the total capacity $(\mathrm{C}$, in $\mathrm{kWh} /$ day from Table 1$)$. Assuming that the average solar flux (f) in the U.S. is approximately $4.5 \mathrm{kWh} / \mathrm{m}^{2} /$ day for non-tracking flat plate PV tilted south at the latitude to optimize yearly energy production (NREL, 2015), the investment (I) sensitivity for $25 \%, 50 \%$, and $100 \%$ solar PV generation was given by: 
$\mathrm{I}=\mathrm{Npw}[\mathrm{US} \$]$

Where $\mathrm{N}$ is given by equation 1 , and $\mathrm{w}$ is the cost per Watt, which ranges from $\$ 4.00 / \mathrm{W}$ to $\$ 0.50 / \mathrm{W}$ in

$\$ 0.25 / \mathrm{W}$ increments.

\subsection{Results}

Historic Effects of U.S. Blackouts and Scale of Strategic Components

Table 1 illustrates the impact of four major U.S. grid failures along with the number of states effected, economic damages, population affected, cause of grid failure, and average number of days without power.

Table 1. Recent Major U.S. Power Blackouts. Compiled from (Andersson et al, 2005, Blake et al, 2013).

\begin{tabular}{|l|l|l|l|l|l|}
\hline Year & $\begin{array}{l}\text { Number } \\
\text { of States } \\
\text { Affected }\end{array}$ & $\begin{array}{l}\text { Affected } \\
\text { Population } \\
\text { (Millions) }\end{array}$ & $\begin{array}{l}\text { Costs (U.S. } \\
\text { \$ Billions) }\end{array}$ & Cause & $\begin{array}{l}\text { Days } \\
\text { without } \\
\text { Power }\end{array}$ \\
\hline 2003 & 8 & 50 & 6 & $\begin{array}{l}\text { Tree } \\
\text { Trimming }\end{array}$ & 4 \\
\hline 2011 & 13 & 3 & 15 & $\begin{array}{l}\text { Early Snow } \\
\text { Strom }\end{array}$ & 10 \\
\hline 2012 & 14 & 8.2 & 65 & Hurricane & 14 \\
\hline 2012 & 7 & 4.2 & 2.9 & Wind & 10 \\
\hline
\end{tabular}

Table 1 illustrates the electrical use for six levels of strategic importance. Data were obtained from the EIA for Fiscal Year (FY) 2013. Table 2 shows solar-PV capacity (in GW) required to provide $100 \%$ of the electrical needs by each military branch.

Overall, to meet the electrical needs of the three branches, about 2,140 GW is needed. To put these values in perspective, the U.S. solar industry has installed a total 22.7

GW of solar capacity across the U.S (SEIA, 2014). There are currently 216 microgrid 
deployments across the U.S. with $1.948 \mathrm{GW}$ renewable energy capacity (Saadeh, 2015). This represents $0.09 \%$ of the U.S. total installed solar capacity.

Table 2. Electrical use size and calculated PV capacity for six levels of strategic importance in the U.S. for Fiscal Year 2013.

\begin{tabular}{|l|l|l|l|}
\hline Level & Electrical Load & $\begin{array}{l}\text { Electricity } \\
\text { Uses } \\
{[\mathbf{M W H} / \mathbf{d a y}]}\end{array}$ & $\begin{array}{l}\text { Calculated PV } \\
\text { to Meet } \\
\text { Demand } \\
{[\mathbf{G W}]}\end{array}$ \\
\hline 1 & Militar & 81399.4 & 16.3 \\
\hline 2 & Government & $*$ & \\
\hline 3 & $\begin{array}{l}\text { Critical } \\
\text { Infrastructure }\end{array}$ & $*$ & \\
\hline 4 & Industrial & 2620000 & 524 \\
\hline 5 & Commercial & 3720000 & 744 \\
\hline 6 & Residnetial & 3840000 & 768 \\
\hline
\end{tabular}

Military electrical use was obtained from the 2014 DOD Annual Energy Report (DOD, 2015), Electrical consumption for Industry, Commercial, and Residential sectors was obtained from (EIA, 2015). * Electrical consumption alone is not available for the Federal Government and Critical Infrastructure, but divisions of each are included in industrial and commercial values.

The technical solutions to obtain compliance with hardening of electrical security at critical facilities is discussed below. For this review study, only level 1 (military base) loads are analyzed in more depth.

\section{Department of Defense}

The DOD operates over 300 military installations (not including air strips, outlying airfields, and training ranges) within the continental U.S. Of these, 27 active bases (9\%) have implemented or have current plans to implement solar-PV systems for onsite renewable energy generation (Table 3).

Table 3. Current Military Bases Solar-PV Systems 


\begin{tabular}{|c|c|c|}
\hline & Power (MW)* & $\begin{array}{l}\text { Population } \\
\text { (Thousands)** }\end{array}$ \\
\hline \multicolumn{3}{|l|}{ Army } \\
\hline Fort Benning & $30^{\prime}$ & 110 \\
\hline Fort Campbell & 5 & 84 \\
\hline Fort Carson & 2 & 124 \\
\hline Fort Detrick & 15 & 10 \\
\hline Fort Dix & 0.8 & 7 \\
\hline Fort Gordon & $30^{`}$ & 94 \\
\hline Fort Hood & 1 & 322 \\
\hline Fort Huachuca & 17.2 & 33 \\
\hline Fort Rucker & 0.051 & 24 \\
\hline Fort Stewart & $30^{\prime}$ & 54 \\
\hline Presidio & 0.37 & 5 \\
\hline West Point & 0.56 & 10 \\
\hline \multicolumn{3}{|l|}{ Navy } \\
\hline China Lake & 13.78 & 5 \\
\hline Coronado & 0.924 & 27 \\
\hline Kings Bay & 30 & 16 \\
\hline Pearl Harbor & 2.4 & 58 \\
\hline Saufley Field-Pensacola & $50^{`}$ & 14 \\
\hline Holley Field- Whiting & $40^{\prime}$ & 16 \\
\hline \multicolumn{3}{|l|}{ Air Force } \\
\hline U.S. AFA & 6 & 7 \\
\hline Davis-Monthan & 16.4 & 16 \\
\hline Edwards AFB & 3.39 & 22 \\
\hline Eglin AFB & $30^{*}$ & 17 \\
\hline Hill AFB & 0.22 & 24 \\
\hline LA AFB & 0.36 & 5 \\
\hline Luke AFB & 15 & 12 \\
\hline Nellis AFB & 14.2 & 29 \\
\hline \multicolumn{3}{|l|}{ Marine Corps } \\
\hline Albany MC Logistics & 46 & 23 \\
\hline Twenty-Nine Palms & $4.5^{\prime}$ & 58 \\
\hline MC Air Station Miramar & 0.204 & 12 \\
\hline Barstow MCLB & 1.2 & 2 \\
\hline
\end{tabular}

* Data obtained from respective division databases (U.S. Army, 2015, U.S. Navy, 2015, U.S. Air Force, 2015). 
** Data obtained from DOD Military Installations data bank represents proposals for upcoming solar PV generation capacities.

'Future plans to increase current solar PV capacity.

Following the renewable energy production mandates noted above, each branch generated individual renewable energy generation goals to improve efficiency and national security. For example, the Department of Navy plans to generate $50 \%$ of their electricity needs from renewable energy by 2020 (U.S. Navy, 2015) and the Army's goal is $1 \mathrm{GW}$ by 2025 (U.S. Army, 2015). By 2013, the DOD had 0.13GW of solar power up and running (SEIA, 2015) and by 2015, the DOD deployed $0.583 \mathrm{GW}$ of renewable energy with microgrids (Saadeh, 2015). Current solar energy generations for each military branch are as follows: Navy with $0.058 \mathrm{GW}$, Army with $0.036 \mathrm{GW}$, Air Force with 0.036 GW, and Marine Corps with 0.05194 (SEIA, 2015). With the addition of $0.12 \mathrm{GW}$ in upcoming solar projects (U.S. Navy, 2015, U.S. Army, 2015, U.S. Air Force, 2015), the U.S. DOD solar capacity accounts for only a small fraction, $1.1 \%$, of the current total U.S. solar capacity. This accounts for only a fraction $(10 \%)$ of the $3 \mathrm{GW}$ solar capacity goal.

\section{Current Defense Vulnerabilities to Grid Failure}

The DOD is heavily reliant on the electrical grid; DOD operations and facilities' electrical consumption is approximately $80 \%$ of total Federal energy consumption (DOD, 2015). Along with high energy costs, the DOD obtains a majority of its energy from foreign fossil fuels with vulnerable supply lines. Nearly all current bases are vulnerable to electricity generation disruption. Many bases are located within regions that have already experienced major power outages, as can be seen in Figure 2. 
Extended power outages affect military operations: Failure in the electric grid renders equipment, weapons, and personnel defenseless to external attacks (U.S. Navy, 2015, U.S. Army, 2015, U.S. Air Force, 2015).

\section{Projected Solar PV Requirements for Military Grid Fortification}

Nameplate solar capacity was calculated utilizing previous DOD electrical demand (FY 2014). The varying percent capacities, 25\% (required by 2025), 50\%, and $100 \%$, represent the solar capacity necessary for the DOD to transition to grid fortification. The solar PV nameplate capacities are: N25=4.50GW, N50=9.04GW, and $\mathrm{N} 100=18.09 \mathrm{GW}$.

\section{U.S. Military Microgrid Cost Sensitivity}

A cost-sensitivity analysis was performed to illustrate the expected costs of implementing a renewable energy policy or program for the U.S. DOD. Costsensitivities were performed as a function of dollar per watt at each \% capacity $(25$, 50 , and $100 \%$ ). The linear curve begins at $\$ 4.00 / \mathrm{W}$ and decreases by $\$ 0.25 / \mathrm{W}$ until it reaches $\$ 0.50 / \mathrm{W}$ to reflect potential future market costs of a microgrid system (SEIA, 2014). It should be noted here that these are projects as the cost of a large scale purchase of PV- powered microgrids on the order of tens of GW would benefit from considerable economics of scale both for the PV, storage system and any electronics or backup systems.

\section{Potential Microgrid Transition DOD Contractors}


A list of funds allocated to the top twenty-five DOD contractors was compiled to gauge the potentiality of transitioning to a solar PV microgrid system. In FY 2014, the DOD awarded $\$ 286.41$ billion, of total $\$ 526.6$ billion (FY 2014) budget, in funds to 100 contractors (SEIA, 2014). The top 25 are listed in Table 4, with the top awardee, Lockheed Martin Corporation, receiving over US\$25 billion. Bechtel Group Inc. was awarded almost US $\$ 2.5$ billion, followed by General Electric Company with US\$2.2 billion (SEIA, 2014). These three contractors were selected due to their existing penetration in renewable energy development programs and to illustrate existing specialized skills developed by defense contractors needed to aid the ease of transition to military grid fortification.

Table 4. Top 25 Federal Defense Contractors by funding

\begin{tabular}{|c|c|c|}
\hline DOD Contractor & $\begin{array}{l}\text { Financial Obligation } \\
\text { (USD) }\end{array}$ & $\begin{array}{l}\text { Number of } \\
\text { Projects }\end{array}$ \\
\hline LOCKHEED MARTIN CORPORATION & $\$ 25,065,461,247.84$ & 18,634 \\
\hline THE BOEING COMPANY & $\$ 18,005,350,332.68$ & 12,663 \\
\hline GENERAL DYNAMICS CORPORATION & $\$ 13,630,604,800.84$ & 16,329 \\
\hline RAYTHEON COMPANY & $\$ 11,816,577,883.63$ & 10,275 \\
\hline NORTHROP GRUMMAN CORPORATION & $\$ 9,213,821,365.01$ & 10,194 \\
\hline UNITED TECHNOLOGIES CORPORATION & $\$ 6,117,086,747.69$ & 9,296 \\
\hline L-3 COMMUNICATIONS HOLDINGS INC. & $\$ 5,288,631,065.98$ & 8,499 \\
\hline BAE SYSTEMS PLC & $\$ 4,876,213,940.43$ & 9,340 \\
\hline HUNTINGTON INGALLS INDUSTRIES INC. & $\$ 4,025,292,235.52$ & 3,116 \\
\hline HUMANA INC. & $\$ 3,527,209,086.24$ & 231 \\
\hline UNITEDHEALTH GROUP INCORPORATED & $\$ 3,203,771,598.01$ & 243 \\
\hline HEALTH NET INC. & $\$ 3,086,459,475.28$ & 129 \\
\hline SAIC INC. & $\$ 2,988,612,860.95$ & 13,789 \\
\hline UNITED LAUNCH ALLIANCE L.L.C. & $\$ 2,519,158,433.33$ & 89 \\
\hline BECHTEL GROUP INC. & $\$ 2,476,019,275.51$ & 153 \\
\hline GENERAL ELECTRIC COMPANY & $\$ 2,200,317,806.74$ & 4,649 \\
\hline $\begin{array}{l}\text { BOOZ ALLEN HAMILTON HOLDING } \\
\text { CORPORA- }\end{array}$ & $\$ 2.166 .187 .575 .84$ & 4.507 \\
\hline EXELIS INC. & $\$ 2,105,471,497.30$ & 2,583 \\
\hline BELL BOEING JOINT PROJECT OFFICE & $\$ 2,018,971,983.94$ & 2,859 \\
\hline HEWLETT-PACKARD COMPANY & $\$ 1,766,447,587.13$ & 42,041 \\
\hline MCKESSON CORPORATION & $\$ 1,663,708,861.81$ & 16,139 \\
\hline ROYAL DUTCH SHELL PLC & $\$ 1,606,631,098.63$ & 489 \\
\hline TEXTRON INC. & $\$ 1,584,800,612.37$ & 3,717 \\
\hline
\end{tabular}


GENERAL ATOMIC TECHNOLOGIES

CORPORA-

$\$ 1,577,207,888.26$

707

Data was collected from the FY 2014 Federal Procurement data system (FPDS, 2015).

The report includes the top 100 DOD contractors.

Many current DOD contractors already have a proven capacity for designing, building and commissioning PV-powered microgrids. Here, three cases studies of companies that currently contract with the U.S. military on renewable energy projects and thus have demonstrated capacity for these projects are reviewed in order to clarify the ability of defense contractors to provide these services to the U.S. military. These companies were selected only to demonstrate the vast array of all defense contractor's potential to bid on U.S. military solar PV research and development projects.

\section{Lockheed Martin Corporation}

Lockheed Martin, a global security and aerospace company that provides a plethora of services to the DOD, has a Microgrid Development Center to improve efficiency, reliability, and security of microgrid systems. A demonstration project was implemented at Fort Bliss with expectations to decrease energy consumption by $20 \%$ (Lockheed Martin, 2013, U.S. Army, 2013). Along with microgrid systems, Lockheed Martin has launched several solar power projects, including a back-up generation and storage unit for Fort Bliss. Lockheed Martin currently receives $8.7 \%$ funding of the total DOD Federal contracting budget. This amount of funding is significant when compared to the costs of U.S. military grid fortification. Even if this amount is held constant and shifted to microgrid deployment, as can be seen in Figure 3, Lockheed 
could fortify the entire U.S. military electrical infrastructure in a single year of expenditures if the system costs can be reduced to US $\$ 1.50$ or less.

\section{General Electric Company}

GE provides, among its diverse portfolio of electric energy technologies, clean energy technology and solutions, and has been involved in solar PV research for decades. More recently, GE has evolved to provide funding for solar projects as well as partnering with solar manufacturers to bring realized solar projects to customers. GE worked with DOD to develop a demonstration microgrid project at the Twentynine Palms Marine Corps Base. GE has opened the door to DOD installations, partnering with SunPower to build a 14.2 MW solar-PV system on the Nellis Air Force Base (Kwartin, 2011, GEC, 2015). General Electric currently receives $0.8 \%$ funding from the DOD Federal contracting budget.

\section{Bechtel Group Inc.}

Bechtel Group is a worldwide engineering, construction, and project management company, with expertise in infrastructure, defense and security, and power. A leader in nuclear fuel for over 70 years, Bechtel has introduced renewable technologies into their engineering profile. Bechtel has completed three major solar generating facilities across California, each above $100 \mathrm{MW}$ capacity, delivering power to a collective 275,000 homes (Bechtel, 2015). Bechtel currently receives $0.9 \%$ funding from the DOD Federal contracting budget.

The DOD awards approximately $\$ 30$ billion (10.4\%) of the DOD Federal contracting budget to these three companies annually. Even using a relatively 
conservative cost figure of US $\$ 4.00 / \mathrm{W}$ for an installed system of approximately $18 \mathrm{GW}$, these three companies working together could complete $100 \%$ U.S. military grid fortification in less than 2.5 years of current funding allotments. More realistically, such a massive infrastructure project would need to be spaced out over several years to control costs. Figure 4 illustrates a hypothetical model to fund compliance with $100 \%$ solar PV generation microgrids for U.S. military installations over 10 years. It should be noted the careful balance that must be determined between limiting costs by extending the installation period and maintaining military grid vulnerability for an extended time and the effects on national security interests is left for future work. The figure demonstrates projected financial obligations necessary to design and deploy renewable energy installations (utilizing Lockheed Martin, GE, and Bechtel Inc. as an example) to meet 100\% solar PV capacity by 2025.

\subsection{Discussion}

This study found the lack of electrical grid security poses significant risk to critical infrastructure systems. This section will discuss results that point to a need for increasing the U.S. military's electrical system resilience. The limitations of the study are included along with proposals for necessary future studies. Policy suggestions are included to assist the U.S. military's transition to aggressive solar PV generation. This review unveils one potential avenue to the military could take to improve components of national security, energy security, and energy costs. 


\section{Expanding U.S. Military Electrical System Resilience}

There are significant threats of natural disaster, physical attack, and cyberattack to the U.S. electrical grid, as previously noted. Failures in the power system can result in detrimental supply shortages, economic impacts (Arianos et al, 2009) and social costs (O'Brien and Hope, 2010). It is important to design resilient infrastructure systems to recover service levels in a timely manner (Avritzer et al, 2015) and address mitigation of these extreme events (McDaniels et al, 2008). Resilient technological systems are flexible, robust, prepared for change, and are essential to prosperous development of society (Marshall et al, 2007). Electrical system technology must improve, to provide increased energy security by preventing cascading grid failures (Ang et al, 2015).

The majority of military bases are still connected to the U.S. electrical grid and the vulnerable nature of the grid poses a serious threat to national security as personnel, daily operations, weapons, and essential equipment can be compromised in a power outage (U.S. Army, U.S. Navy, U.S. Air Force, 2015). The DOD spends billions of dollars in annual energy costs with the current electrical system model (DOD, 2015). The DOD can transition to a more resilient system by installing decentralized automated microgrids primarily powered with solar PV at a one time, up front cost. This cost can be spread out over several years of deployment. If this is done, the cost of implementing solar PV installations will likely decrease because of the aggressive and protracted PV learning curve (Van der Zwaan and Rabl, 2003, Nemet, 2006, Candelise et al, 2013). It is important to note that regardless of the deployment schedule these upfront costs will be recouped within a few years from avoided annual 
energy expenditures. The economics of this scale of deployment is left for future work as the focus of this study in on enhancing national security. Once disconnected, military base microgrids can provide sufficient generation by supplying enough energy to meet their electrical load and remain islanded in the event of grid failure (Katiraei et al, 2008). Additionally, with appropriate planning, military bases can extend grid protection to surrounding communities. In the event of a power outage, military solar PV powered microgrids can act as a backup system and export surplus power to surrounding communities, helping regional resilience to grid disruption.

During times of low solar insolation, military operations still require power, and thus military microgrids will require adequate storage. Battery technology has been advancing rapidly, and now higher energy density $(700 \mathrm{Wh} / \mathrm{l})$ storage with Li-ion is beginning to dominate. However, theoretical energy densities point to future improvements with nanostructures and new materials using abundant materials such as $\mathrm{LiS}(2600 \mathrm{Wh} / \mathrm{kg})$ and Li-air $(11,000 \mathrm{Wh} / \mathrm{kg})$ technologies (Amine et al, 2014). Along with these technological advancements, battery costs are dropping, with current costs being between $\$ 600-1,000 / \mathrm{kWh}$, and the DOE expects them to fall further to reach $\$ 225 / \mathrm{kWh}$ in 2020 and $\$ 150 / \mathrm{kWh}$ in the longer term (DOE, 2013). Economies of scale will also factor into future battery prices, especially with Tesla's increased battery manufacturing plans through its GigaFactory, which plans to produce 500,000 batteries a year starting 2017 (Tesla, 2014). Shortly, battery packs (like the Power Wall), which will be ideal modular storage building blocks, are expected to be available for $\$ 350 / \mathrm{kWh}$ for home use (Tesla, 2014). Until Tesla 
batteries become available at the scale needed for the U.S. military, one temporary solution is the use of hybrid renewable energy systems to improve system efficiency and energy supply reliability (Erdinc and Uzunoglu, 2012). More specifically, military installations can use combined heat and power (CHP) systems. During these low solar influx times, a CHP system turns on to maintain constant load (Pearce, 2009) sufficient to cover even the most dynamic loads (e.g. a single family residences) (Nosrat et al, 2013, Shah et al, 2015). Although the economics of hybrid PV+CHP+battery systems are attractive (Aishwarya et al, 2016), CHP systems, are still subject to supply chain disruptions of the fuel source and should only be considered as temporary solutions. In addition, it is advisable to reduce loads as much as possible by instituting energy efficiency measures (as have been successful in the past at military bases) (NREL, 2015) and look at the potential for passive solar retrofits, which for example have worked for Department of Navy, creating energy savings (Wray and Miles, 1981, DOD, 2004). Although thermal savings are not directly equivalent to electric load demand reductions, they do result in savings, for example, from reduced blower loads.

The DOD mandates $25 \%$ renewable generation by 2025 , along with a goal of $3 \mathrm{GW}$ across three branches. In Fiscal Year 2014, the DOD spent $\$ 18.2$ billion on all energy expenditures (DOD, 2015). A significant fraction of these operating expenses would be offset by the capital expenditure of a PV- powered microgrid. Roughly $54 \%$ of the DOD budget is allocated to DOD contracting. As can be seen from the results, utilizing current skills of top defense contractors, the DOD could shift funds to 
convert to $100 \%$ solar-PV microgrid systems across Army, Navy/Marine Corps, and Air Force military bases, resulting in decreased costs. The remaining budget excess could be allocated to further harden energy security. The DOD can submit request for proposals (RFPs) to current DOD contractors that include research into optimal physical and cyber protection of solar-PV microgrid farms.

\section{Limits of Study and Future Work:}

The military is the first line of strategic importance for energy security. The results in this paper show that the overall expense is manageable within existing total budgets, but more granular estimates of costs are needed. A major limitation to this study is lack of data to calculate, on a case-by-case basis, solar PV generation capacity. Detailed work is needed at each installation to determine the optimal solution for each base, which must take into account appropriate available areas for solar collection, current and future load profiles in small time steps and potential to reduce loads with energy efficiency retrofits. More precise and accurate estimates on the cost of PV-powered microrid system are needed at the GW scale, where, for example, industrial symbiosis benefits (Pearce, 2008) are likely to occur. Careful ramping up of scale could produce templated (or even open source (Buitenhuis and Peace, 2012)) designs that could be replicated in the future at much lower costs than the first round of demonstration systems. In addition, this analysis focused only on domestic DOD facilities and thus it should be expanded to all DOD facilities internationally.

Future work must address the feasibility of converting energy generation to a renewable solar source to meet the needs of critical infrastructures beyond military 
facilities addressing the other strategic areas shown in Figure 1. It is important to note that total Federal Government and Critical infrastructure electrical use is missing from the data set (Table 2) and future work is needed to quantify those values for strategic planning purposes. After this data is acquired, the additional loads and thus systems sizes for other government facilities would again increase the total scale of such systems, helping to attract more competition for contracts and better economies of scale on prices for both the defense and non- defense wings of the U.S. government.

\section{Policy}

Renewable energy policy in the DOD is still in its infancy, as Title 10 USC 2911 was implemented only in 2011 (GPO, 2011). The DOD partnered with the Department of Energy and the National Renewable Energy Lab to develop renewable energy technology to cut costs, provide energy security, and comply with DOD mandates (NREL, 2012). The DOD provides awards for research through the Strategic Environmental Research and Development program and energy projects through the Environmental Security Technology Certificate Program to fund military penetration into the renewable energy market (DOD, 2015). A majority of current PV at military bases are grid-tied, and the majority of the power generated leaves DOD facilities through power purchase agreements. There are limited policies in place to facilitate a transition to a dominant renewable energy generation system. Incentives to go off grid to owning, operating, and generatig DOD's own capacity through distributed microgrid technology would allow the military independence, reliability, and energy efficiency. Due to the critical nature of electrical power for the DOD policies should be examined to 1) minimize DOD electrical use by increasing efficiency wherever it 
would not hamper operations, 2) on the shortest time line possible transition to distributed PV-powered microgrid systems domestically wherever technically feasible. Policies to either increase DOD contractor rates to accomplish these two goals or shift current allotments to these priorities should be investigated both for DOD infrastructure domestically, but also internationally. Additional funding opportunities could be obtained by reforming allocation of funds. Chief of Naval operations, Admiral Jonathan Greenert and Chief of Staff General, Raymond Odierno argue the military is required to spend millions on unnecessary equipment and machinery (Carter, 2015, Cox, 2015). The equipment accrues additional storage and maintenance costs. Suspending earmarked legislation would also provide funds to use for military solar PV development and implementation (Thornberry, 2015, Bucci et al, 2015). It is well recognized that prioritization of defense contractor spending is a difficult task, but one that must occur while considering microgrids for U.S. military installations in order to achieve a better fortified electrical system.

\section{$\underline{2.5 \text { Conclusions }}$}

The technical community recognizes the lack of electrical grid security and risks posed to critical infrastructure systems. Cascading grid failures elicit threats to national security, economic damages, and disruption to critical infrastructure systems. This paper compared the current geographic deployment of military installations to historical grid failures. A review of current solar-PV penetration into United States Military bases illustrates the potential to mitigate future power outages by (1) maintaining an independent energy source and (2) providing a backup of surplus 
energy supply to civilians. The scale of electrical energy consumption and solar PV system necessary to meet electrical needs was analyzed for the United States Military. A minimal number of military bases have introduced solar PV systems to operate military operations, leaving large room for growth. A cost sensitivity was performed to estimate costs and potential savings in energy expenditures if the military transitions to $100 \%$ solar-PV energy generation. Three of the top 25 defense contractors were reviewed due to their penetration in renewable energy generation markets. These companies represent U.S. defense contractors' potential to respond to bids to complete solar PV research and development projects. The DOD can utilize a number of defense contracting companies technical skills to facilitate a national transition to renewable distributed generation microgrid systems. The technical and economic viability of this transition from the results of this review, indicate the DOD should investigate allocation of additional funds or shifting funds to utilize top defense contractors to begin a national transition to distributed solar PV generation. As the calculated costs of solar PV microgrid systems are a one-time upfront cost, the DOD can easily allocate funds across contracting companies, over ten years to meet $100 \%$ distributed renewable generation (rather than $25 \%$ ) compliance by 2025 . The military can evolve their energy system to protect national security, provide energy security, and decrease energy costs. 


\subsection{References}

Abu-Sharkh, Suleiman, R. J. Arnold, J. Kohler, R. Li, T. Markvart, J. N. Ross, Koen Steemers, P. Wilson, and R. Yao. "Can microgrids make a major contribution to UK energy supply?." Renewable and Sustainable Energy Reviews 10, no. 2 (2006): 78-127

Aitel, Dave. "Cybersecurity essentials for electric operators." The Electricity Journal 26, no. 1 (2013): 52-58.

Albert, Réka, István Albert, and Gary L. Nakarado. "Structural vulnerability of the North American power grid." Physical review E 69, no. 2 (2004): 025103.

Amin, Massoud. "Energy infrastructure defense systems." Proceedings of the IEEE 93, no. 5 (2005): 861-875.

Massoud. "Challenges in reliability, security, efficiency, and resilience of energy infrastructure: Toward smart self-healing electric power grid." In Power and Energy Society General Meeting-Conversion and Delivery of Electrical Energy in the 21st Century, 2008 IEEE, pp. 1-5. IEEE, 2008.

-------- Massoud. "Security challenges for the electricity infrastructure." Computer 35, no. 4 (2002): 8-10.

Amine, Khalil, Ryoji Kanno, and Yonhua Tzeng. "Rechargeable lithium batteries and beyond: Progress, challenges, and future directions." Mrs Bulletin 39, no. 05 (2014): 395-401.

Ang, Beng Wah, W. L. Choong, and T. S. Ng. "Energy security: Definitions, dimensions and indexes." Renewable and sustainable energy reviews 42 (2015): 1077-1093.

Arianos, Sergio, E. Bompard, A. Carbone, and Fei Xue. "Power grid vulnerability: A complex network approach." Chaos: An Interdisciplinary Journal of Nonlinear Science 19, no. 1 (2009): 013119.

Avritzer, Alberto, Laura Carnevali, Hamed Ghasemieh, Lucia Happe, Boudewijn R. Haverkort, Anne Koziolek, Daniel Menasche, Anne Remke, Sahra Sedigh Sarvestani, and Enrico Vicario. "Survivability evaluation of gas, water and electricity infrastructures." Electronic Notes in Theoretical Computer Science 310 (2015): 5-25.

Aradau, Claudia. "Security that matters: Critical infrastructure and objects of protection." Security Dialogue 41, no. 5 (2010): 491-514. 
ArcGis Database, Fitzpatrick, C. US 50 States + DC shapefile. Acccessed on Oct 4, 2015.

https://www.arcgis.com/home/item.html?id=f7f805eb65eb4ab787a0a3e1116ca

7e5.

Andersson, G., P. Donalek, R. Farmer, N. Hatziargyriou, I. Kamwa, P. Kundur, N. Martins et al. "Causes of the 2003 major grid blackouts in North America and Europe, and recommended means to improve system dynamic performance." IEEE transactions on Power Systems 20, no. 4 (2005): 1922-1928.

Barbose, Galen, Naïm Richard Darghouth, Samantha Weaver, David Feldman, Robert Margolis, and Ryan Wiser. "Tracking US photovoltaic system prices 1998-2012: a rapidly changing market." Progress in Photovoltaics: Research and Applications 23, no. 6 (2015): 692-704.

Bechtel Corporation. Ivanpah Solar Electric Generating System California. Accessed on Oct 10, 2015. http://www.bechtel.com/projects/ivanpah-solar-electricgenerating- system/.

Bernstein, Andrey, Daniel Bienstock, David Hay, Meric Uzunoglu, and Gil Zussman. "Sensitivity analysis of the power grid vulnerability to large-scale cascading failures." ACM SIGMETRICS Performance Evaluation Review 40, no. 3 (2012): 33-37.

Bessani, Alysson Neves, Paulo Sousa, Miguel Correia, Nuno Ferreira Neves, and Paulo Verissimo. "The CRUTIAL way of critical infrastructure protection." IEEE Security \& Privacy 6, no. 6 (2008): 44-51.

Bipartisan Policy Center; Hayden, M, Hebert, C, Tierney,S. Cybersecurity and the North American Electric Grid: Washington, DC: 2014. Print. New Policy Approaches to Address An Evolving Threat.

Brown, Gerald, Matthew Carlyle, Javier Salmeron, and Kevin Wood. "Analyzing the vulnerability of critical infrastructure to attack and planning defenses." Tutorials in Operations Research: Emerging Theory, Methods, and Applications (2005): 102-123.

Brummitt, Charles D., Raissa M. D’Souza, and E. A. Leicht. "Suppressing cascades of load in interdependent networks." Proceedings of the National Academy of Sciences 109, no. 12 (2012): E680-E689.

Buitenhuis, A. J., and Joshua M. Pearce. "Open-source development of solar photovoltaic technology." Energy for Sustainable Development 16, no. 3 (2012): 379-388. 
Candelise, Chiara, Mark Winskel, and Robert JK Gross. "The dynamics of solar PV costs and prices as a challenge for technology forecasting." Renewable and Sustainable Energy Reviews 26 (2013): 96-107.

Chaurey, A., and T. C. Kandpal. "A techno-economic comparison of rural electrification based on solar home systems and PV microgrids." Energy Policy 38, no. 6 (2010): 3118-3129.

Che, Liang, and Mohammad Shahidehpour. "Dc microgrids: Economic operation and enhancement of resilience by hierarchical control." IEEE Transactions on Smart Grid 5, no. 5 (2014): 2517-2526.

Chen, Guo, Zhao Yang Dong, David J. Hill, Guo Hua Zhang, and Ke Qian Hua. "Attack structural vulnerability of power grids: A hybrid approach based on complex networks." Physica A: Statistical Mechanics and its Applications389, no. 3 (2010): 595-603.

CNN, Pagliery, J, editor. Sniper attack on California power grid may have been 'an insider,' DHS says. Accessed on Oct 30, 2015. http://money.cnn.com/2015/10/16/technology/sniper-power-grid/.

Colson, C. M., M. H. Nehrir, and R. W. Gunderson. "Distributed multi-agent microgrids: a decentralized approach to resilient power system self-healing." In Resilient Control Systems (ISRCS), 2011 4th International Symposium on, pp. 83-88. IEEE, 2011.

DOD. Military Installations, Ranges, Training Areas. Data Catalog. Accessed on Oct 10, 2015. http://catalog.data.gov/dataset/military-installa- tions-rangesand-training-areas.

------- Unified Facilities Criteria Report. Passive Solar Buildings. 2004.

------ Carter, Ash. Secretary of Defense Congressional Testimony. Accessed on Dec 30, 2015. http://www.defense.gov/News/Speeches/SpeechView/Article/606647/submitted-statement-senate- armed-services-committeebudget-request.

Erdinc, O., and M. Uzunoglu. "Optimum design of hybrid renewable energy systems: Overview of different approaches." Renewable and Sustainable Energy Reviews 16, no. 3 (2012): 1412-1425. 
Executive Office of the President Report. Economic Benefits of Increasing Electric Grid Re- silience to Weather Outages. 2013.

Federal Procurement Data System. Top 100 Contractors Report. Accessed on Oct 2, 2015.https://www.fpds.gov/fpdsng_cms/index.php/en/reports/62-top-100contrac- tors-report3.html.

Forbes, Detwiler, PK. Failure to Protect U.S. Against Electromagnetic Pulse Threat Could Make 9/11 Look Trivial Someday. Accessed on Oct 17, 2015]. http://www.forbes.com/sites/peterdetwiler/2014/07/31/protecting-the-u-s-againstthe-electromagnetic- pulse-threat-a-continued-failure-of-leadership-could-make911-look-trivial-someday/.

Fovino, Igor Nai, Luca Guidi, Marcelo Masera, and Alberto Stefanini. "Cyber security assessment of a power plant." Electric Power Systems Research 81, no. 2 (2011): 518-526.

General Electric Company. Solar 101: The Power of the Sun. Accessed on Oct 10, 2015. https://renewables.gepower.com/solar-energy/overview/solar-101.html.

Gent, Michehl R., and Lynn P. Costantini. "Reflections on security [power systems]." IEEE Power and Energy Magazine 1, no. 1 (2003): 46-52.

Hébert, Curt. "The Most Critical of Economic Needs (Risks): A Quick Look at Cybersecurity and the Electric Grid." The Electricity Journal 26, no. 5 (2013): 1519.

The Heritage Foundation. Bucci, S, Slattery, B, Maine, E. Progress is coming on defense acquisition reform. Accessed Dec 30, 2015.

http://www.heritage.org/research/reports/2015/04/progress-is-coming-on-defenseacquisition- reform\#_ftn.

House of Representatives. Thornberry, M. DOD Reform: Highlights of the Thornberry Reform Effort. Accessed Dec 30, 2015. http://armedservices.house.gov/index.cfm?a=Files.Serve\&File_id=6BA527388917-46EB-8777-84B1E6A704C4

Johansson, Jonas, Henrik Jonsson, and Henrik Johansson. "Analysing the vulnerability of electric distribution systems: a step towards incorporating the societal consequences of disruptions." International Journal of Emergency Management 4, no. 1 (2007): 4-17.

Katiraei, Farid, Reza Iravani, Nikos Hatziargyriou, and Aris Dimeas. "Microgrids management." IEEE Power and Energy Magazine 6, no. 3 (2008): 54-65. 
Kinney, Ryan, Paolo Crucitti, Reka Albert, and Vito Latora. "Modeling cascading failures in the North American power grid." The European Physical Journal BCondensed Matter and Complex Systems 46, no. 1 (2005): 101-107.

Krotofil, Marina, Alvaro Cardenas, Jason Larsen, and Dieter Gollmann. "Vulnerabilities of cyber-physical systems to stale data-Determining the optimal time to launch attacks." International journal of critical infrastructure protection 7, no. 4 (2014): 213-232.

Kwartin, Robert. Solar Energy Development on DoD Installations in the Mojave \& Colorado Deserts. ICF INTERNATIONAL INC FAIRFAX VA, 2011.

Lasseter, Robert H., and Paolo Paigi. "Microgrid: a conceptual solution." In Power Electronics Specialists Conference, 2004. PESC 04. 2004 IEEE 35th Annual, vol. 6, pp. 4285-4290. IEEE, 2004.

---------- Robert H. "Microgrids and distributed generation." Journal of Energy Engineering 133, no. 3 (2007): 144-149.

Little, Richard G. "Toward more robust infrastructure: observations on improving the resilience and reliability of critical systems." In System Sciences, 2003.

Proceedings of the 36th Annual Hawaii International Conference on, pp. 9-pp. IEEE, 2003.

Lockheed Martin. Intelligent Microgrid Solutions; U.S. Army and Lockheed Martin Commission microgrid at Fort Bliss. Accessed on Oct 10, 2015.http:/www.lockheedmartin.com/us/news/press-releases/2013/may/mfc051613-us-armyand-LM.html.

Maity, Indrani, and Shrisha Rao. "Simulation and pricing mechanism analysis of a solarpowered electrical microgrid." IEEE Systems Journal 4, no. 3 (2010): 275-284.

Marshall, Nadine A., David M. Fenton, Paul A. Marshall, and S. G. Sutton. "How resource dependency can influence social resilience within a primary resource industry." Rural Sociology 72, no. 3 (2007): 359-390.

McDaniels, Timothy, Stephanie Chang, Darren Cole, Joseph Mikawoz, and Holly Longstaff. "Fostering resilience to extreme events within infrastructure systems: Characterizing decision contexts for mitigation and adaptation." Global Environmental Change 18, no. 2 (2008): 310-318.

Military, Cox, M. Pentagon Tells Congress to Stop Buying Equipment it Doesn't Need. Accessed on Dec 23, 2015 Dec 23. http://m.military.com/daily- 
news/2015/01/28/pentagon-tells-congress-to-stop-buying-equipment-itdoesnt-need.html.

Motter, Adilson E., and Ying-Cheng Lai. "Cascade-based attacks on complex networks." Physical Review E 66, no. 6 (2002): 065102.

Mundada, Aishwarya S., Kunal K. Shah, and J. M. Pearce. "Levelized cost of electricity for solar photovoltaic, battery and cogen hybrid systems." Renewable and Sustainable Energy Reviews 57 (2016): 692-703.

National Hurricane Center, Blake ES, Kimberlain TB, Berg RJ, Cangialosi JP, Beven JL. Tropical Cyclone Report Hurricane Sandy. Accessed on Dec 3, 2015. http://www.nhc.noaa.gov/data/tcr/AL182012_Sandy.pdf.

National Research Council. Terrorism and the Electric Power Delivery System. Accessed on Oct 17, 2015. http://www.wiresgroup.com/docs/reports/WPF Terrorism\%20and\%20The \%20Electric\%20Power\%20Delivery\%20System.pdf.

Nemet, Gregory F. "Beyond the learning curve: factors influencing cost reductions in photovoltaics." Energy policy 34, no. 17 (2006): 3218-3232.

Nosrat, Amir, and Joshua M. Pearce. "Dispatch strategy and model for hybrid photovoltaic and trigeneration power systems." Applied Energy 88, no. 9 (2011): 3270-3276.

Amir H., Lukas G. Swan, and Joshua M. Pearce. "Improved performance of hybrid photovoltaic-trigeneration systems over photovoltaic-cogen systems including effects of battery storage." Energy 49 (2013): 366-374.

NPR, Memmott, M, editor. Sniper attack on California power station raises terrorism fears. Accessed on Oct 12, 2015. http://www.npr.org/sections/thetwoway/2014/02/05/272015606/sniper-attack-on-calif-power-station-raisesterrorism-fears.

NREL. Energy Projects. Accessed Nov 11, 2015. http://www.nrel.gov/defense/projects.html\#army.

-------- Department of Defense Energy Programs. Accessed on Dec 3, 2015. http://www.nrel.gov/defense/projects.html.

O’Brien, Geoff, and Alex Hope. "Localism and energy: Negotiating approaches to embedding resilience in energy systems." Energy policy 38, no. 12 (2010): 75507558. 
Onyeji, Ijeoma, Morgan Bazilian, and Chris Bronk. "Cyber security and critical energy infrastructure." The Electricity Journal 27, no. 2 (2014): 52-60.

Pearce, Joshua M. "Photovoltaics—a path to sustainable futures." Futures34, no. 7 (2002): 663-674.

Joshua M. "Expanding photovoltaic penetration with residential distributed generation from hybrid solar photovoltaic and combined heat and power systems." Energy 34, no. 11 (2009): 1947-1954.

-------- Joshua M. "Industrial symbiosis of very large-scale photovoltaic manufacturing." Renewable Energy 33, no. 5 (2008): 1101-1108.

Reichelstein, Stefan, and Michael Yorston. "The prospects for cost competitive solar PV power." Energy Policy 55 (2013): 117-127.

Rinaldi, Steven M., James P. Peerenboom, and Terrence K. Kelly. "Identifying, understanding, and analyzing critical infrastructure interdependencies." IEEE Control Systems 21, no. 6 (2001): 11-25.

Saadeh, O. "North American microgrids 2015: Advancing beyond local energy optimization." GTM Research (2015).

Salmeron, Javier, Kevin Wood, and Ross Baldick. "Analysis of electric grid security under terrorist threat." (2004).

San Jose Mercury News, Avalos, G, editor. PG\&E substation in San Jose that suffered a sniper attack has a new security breach. Accessed on Oct 12, 2015.

http://www.mer- curynews.com/business/ci 26419083/pg-e-substation-san-josethat-suffered-sniper.

Schainker, Robert, John Douglas, and Thomas Kropp. "Electric utility responses to grid security issues." IEEE Power and Energy Magazine 4, no. 2 (2006): 30-37.

Shah, Kunal K., Aishwarya S. Mundada, and J. M. Pearce. "Performance of US hybrid distributed energy systems: Solar photovoltaic, battery and combined heat and power." Energy Conversion and Management 105 (2015): 71-80.

Shahidehpour, Mohammad, and Mohammad Khodayar. "Cutting campus energy costs with hierarchical control: The economical and reliable operation of a microgrid." IEEE Electrification Magazine 1, no. 1 (2013): 40-56.

Solar Energy Industries Association. http://www.seia.org/research-resources/solarindustry-data, accessed 10/30/2015. 
Spina, Stephen M., and J. Daniel Skees. "Electric Utilities and the Cybersecurity Executive Order: Anticipating the Next Year." The Electricity Journal 26, no. 3 (2013): 61-71.

Sridhar, Siddharth, Adam Hahn, and Manimaran Govindarasu. "Cyber-physical system security for the electric power grid." Proceedings of the IEEE100, no. 1 (2012): 210-224.

$\mathrm{Su}$, Bin, Tong $\mathrm{Wu}$, and Zhenya Zhan. "The Optimal Allocation Model of Microgrid Based on Economic Benefits." In Intelligent Human-Machine Systems and Cybernetics (IHMSC), 2014 Sixth International Conference on, vol. 1, pp. 300303. IEEE, 2014.

Ten, Chee-Wooi, Govindarasu Manimaran, and Chen-Ching Liu. "Cybersecurity for critical infrastructures: attack and defense modeling." IEEE Transactions on Systems, Man, and Cybernetics-Part A: Systems and Humans 40, no. 4 (2010): 853-865.

Tesla. Energy storage for a Sustainable home. PowerWall. Accessed on Nov 23, 2015. http://www.teslamotors.com/powerwall.

- Planned 2020 Gigafactory Production Exceeds 2013 Global Production.

Accessed on Nov 23, 2015.

http://www.teslamotors.com/sites/default/files/blog_attach-

ments/gigafactory.pdf.

Ulieru, Mihaela. "Design for resilience of networked critical infrastructures." In 2007 Inaugural IEEE-IES Digital EcoSystems and Technologies Conference, pp. 540545. IEEE, 2007.

Umbach,F. "Energy infrastructure targeted as cyber attacks increase globally." World Review 5, no. 3 (2013).

U.S. Army. Accessed on Oct 2, 2015. Available from: www. http://www.goarmy.com/.

Army moves toward renewable energy goal for 2025. Accessed on Dec 7, 2015.

http://www.army.mil/article/94756/The_Army_Moves_Toward_Renewable_Ener gy_Goal_for_2025/.

Fort Bliss unveils Army's first microgrid. Accessed on Dec 7, 2015. http://www.army.mil/article/103577/Fort_Bliss_unveils_Army_s_first microg $\underline{\mathrm{rid} /}$. 
U.S. Air Force. Accessed on Oct 2, 2015. Available from: www. http://www.airforce.$\mathrm{com} /$.

U.S. Navy. Accessed on Oct 2, 2015. www. http://www.navy.mil/.

U.S. Navy Energy, Environment, and Climate Change. Accessed on Dec 7, 2015. http://greenfleet.dodlive.mil/energy/.

U.S. Energy Information Administration. Short-Term Energy Outlook. Accessed on Nov 10, 2015]. http://www.eia.gov/forecasts/steo/re- port/electricity.cfm.

U.S. Federal Energy Regulatory Commission. Electromagnetic Pulse: Effects on the U.S. Power Grid. Accessed on Dec 7, 2015. http://www.ferc.gov/industries/electric/indusact/reliability/cybersecurity/ferc executive summary.pdf.

U.S. Government Publishing Office. Title 10 U.S.C. 2911. Accessed on Oct 2, 2015. http://www.gpo.gov/fdsys/granule/USCODE-2010-title10/USCODE-2010title10-subtitleA-partIV-chap173-subchapI-sec2911

Van der Zwaan, Bob, and Ari Rabl. "Prospects for PV: a learning curve analysis." Solar energy 74, no. 1 (2003): 19-31.

Wall Street Journal; Gorman, S, editor. Electricity grid in U.S. penetrated by spies. Accessed on Oct 02, 2015]. http://www.wsj.com/articles/SB123914805204099085.

Wall Street Journal, Dipietro, B. Risk and Compliance Journal. Accessed on Oct 17, 2015. http://blogs.wsj.com/riskandcompliance/2015/07/08/attack- on-u-selectrical-grid-could-cost-1-trillion/.

Wang, Jian-Wei, and Li-Li Rong. "Cascade-based attack vulnerability on the US power grid." Safety Science 47, no. 10 (2009): 1332-1336.

Watts, David. "Security and vulnerability in electric power systems." In 35th North American power symposium, vol. 2, pp. 559-566. 2003.

Wray, W. O., and C. R. Miles. Passive-solar retrofit study for the United States Navy. No. LA-UR-81-2500; CONF-810865-3. Los Alamos National Lab., NM (USA); Naval Civil Engineering Lab., Port Hueneme, CA (USA), 1981.

Wu, Felix F., Khosrow Moslehi, and Anjan Bose. "Power system control centers: Past, present, and future." Proceedings of the IEEE 93, no. 11 (2005): 1890-1908. 
Zweibel, Ken, James Mason, and Vasilis Fthenakis. "A solar grand plan." Scientific American 298, no. 1 (2008): 64-73.

\subsection{List of Figures}

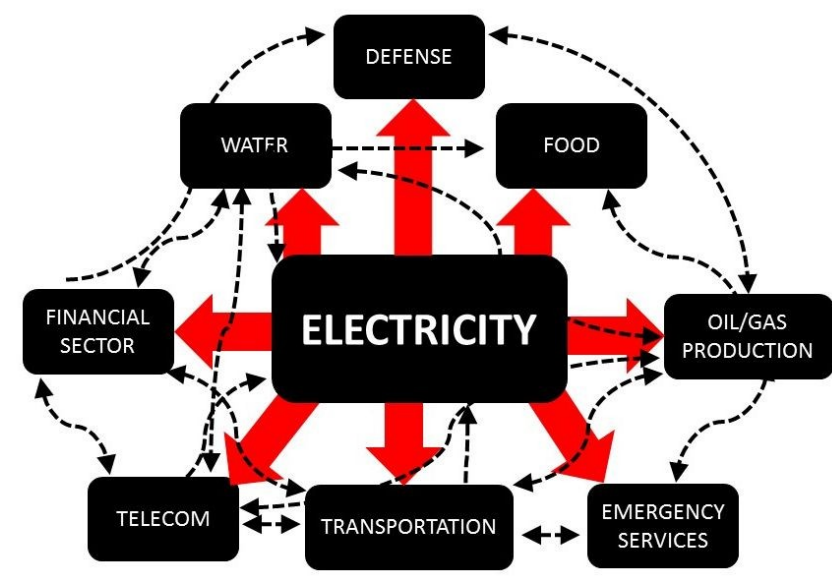

Figure 1. Interdependency of infrastructure systems and electrical grid. Data compiled from literature on critical infrastructure industries [7, 9, 12, 14, 21, 22].

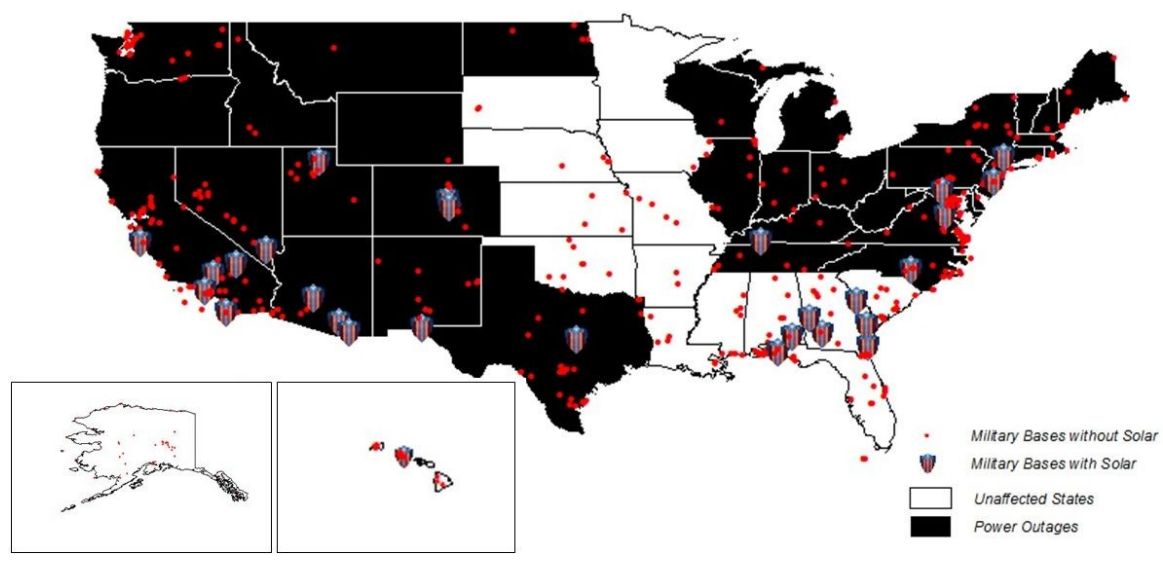

Figure 2. Map of United States Military Bases with Solar-PV systems in historically vulnerable blackout zones. 


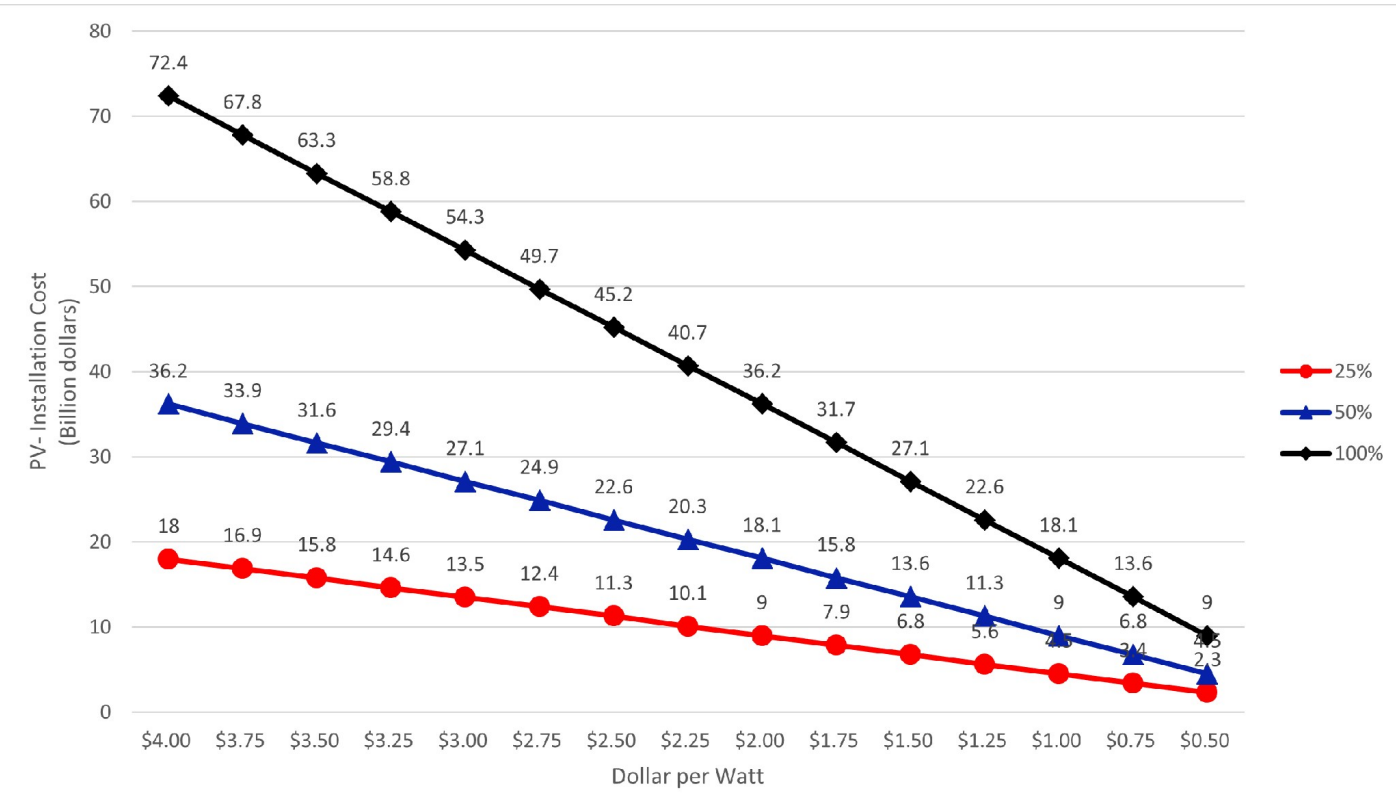

Figure 3. Total installation cost sensitivity as a function of installed cost and percent PV capacity on U.S. domestic military bases. Estimated solar PV costs were calculated as a function of cost per watt from $\$ 4.00-\$ 0.50$ reflecting current and expected market values for each percent capacity: $a=25 \%, b=50 \%, c=100 \%$.

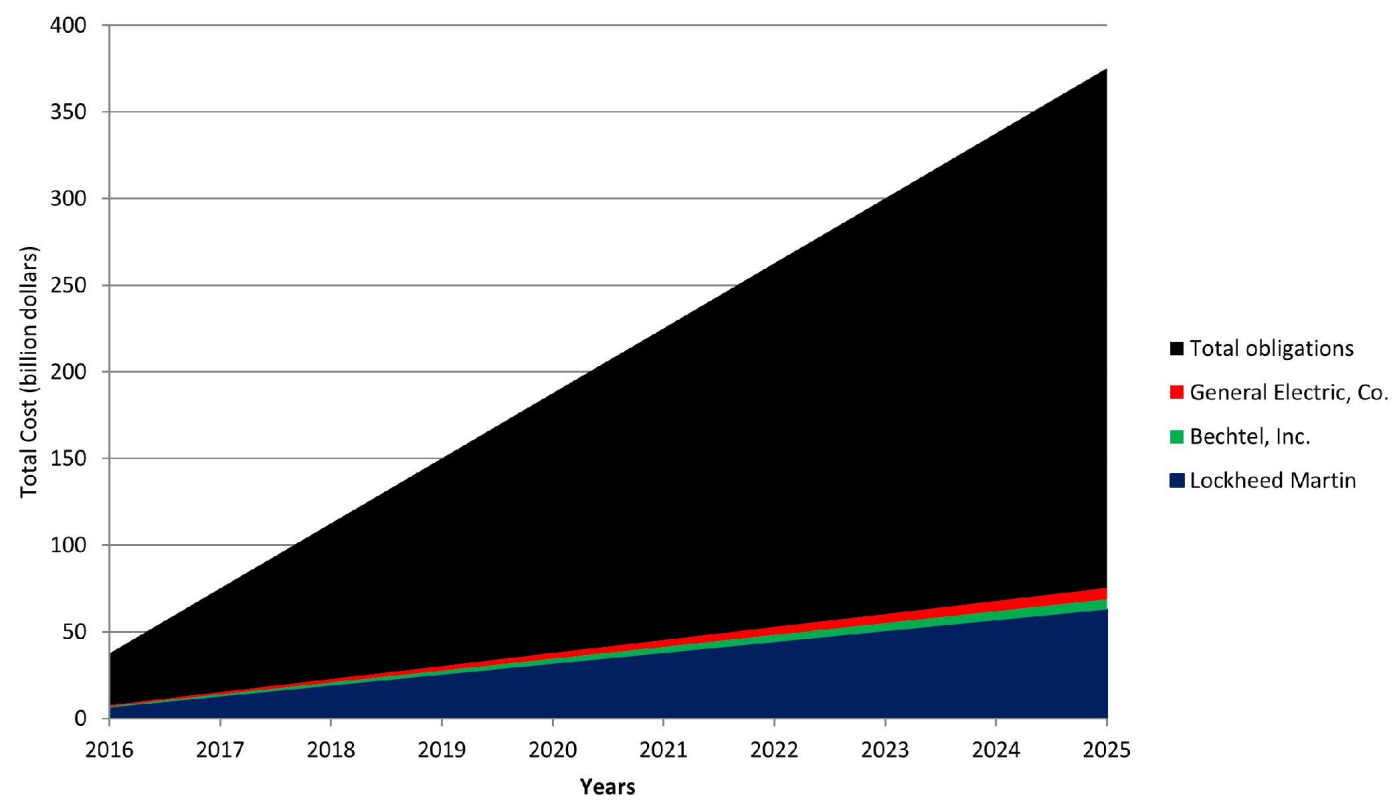

Figure 4. Total financial obligation spread across 10 years to design and deploy $100 \%$ solar PV capacity system. Total was calculated using US\$72.4 billion (as a function of US\$4.00/W in Figure 3. Projected DOD allocations include: US\$ 6.29 billion to 
Lockheed Martin, US\$579 million to General Electric Co., and US\$652 million to Bechtel Inc. each year for ten years. Total current obligations for the three companies totals $\$ 30$ billion per year, reaching $\$ 300$ billion after ten years. 


\section{Chapter 3: Placing Residential Solar Technology Adoption in Situated Policy Context: A Case Study of Michigan Adopters ${ }^{2}$}

\section{Placing Residential Solar Technology Adoption in Situated Policy Context:}

\section{A Case Study of Michigan Adopters}

Emily Prehoda $^{\mathrm{a}^{*}}$, Abhilash Kantamneni ${ }^{\mathrm{b}}$, Chelsea Schelly ${ }^{\mathrm{a}}$

${ }^{a}$ Michigan Technological University, Department of Social Science, 1400 Townsend

Drive, Houghton, Michigan, 49930

${ }^{\mathrm{b}}$ University of Guelph, Department of Geography, 50 Stone Road East, Guelph, Ontario, N1G 2W1

*Corresponding author. Email: ewprehod@mtu.edu. Telephone:(906) 487-2113.

Abstract: Adopters of residential PV systems are often conceptualized as sustainable consumers, meaning they are viewed as likely to be both environmentally motivated and economically advantaged. Conceptualizing the sustainable consumer as motivated by individual environmental values and mobilized through availability of individual economic resources fails to consider how the sustainable consumer is spatially and temporally situated within a particular policy context. By applying a logistic regression model to predict residential PV adoption in Michigan, this study attempts to examine regulatory and policy differences in utilities and the ways individual socioeconomics are contextualized via these utility policy contexts. This paper contributes to a broader conceptualization of energy policy as an issue of import for considerations of social

2 The material contained in this chapter is in preparation for submission to Energy Policy 
justice, as these structural economic and utility policy factors that shape PV adoption point to issues of procedural injustice, suggesting a need to include a procedural justice framework in the energy decision-making process.

Keywords: solar energy; PV technology adoption; electric utilities; energy justice

\subsection{Introduction}

Solar photovoltaic (PV) technology is a popular and promising source of renewable energy production (Greenberg, 2009). Solar photovoltaic technology converts sunlight into electricity and it can be developed at various scales, from centralized utility scale plants to small-scale distributed systems. Distributed solar power refers to energy or electricity that is produced near the customers who use it, for example, rooftop or ground mounted installations (Pepermans et al, 2003). Solar radiation is widely abundant, yet both utility scale and residential solar PV adoption lags behind solar PV technology development (Reece, 1979, EIA, 2010). One reason for the relatively low rates of adoption of distributed residential solar is the high initial capital cost to purchase and install home PV systems (Branker et al, 2011, Borenstein, 2015).

In recent years, however, the solar market has seen expedited growth along with dropping system costs (SEIA, 2016). Overall, the U.S. solar market saw an annual growth rate of 60\% between 2006 and 2016 (SEIA, 2016), which corresponds to the 2006 passage of the Solar Investment Tax Credit (ITC). However, utility scale solar PV installations represent 74\% of solar installed capacity (GW) in 2015 (SEIA, 2016).

Residential solar PV saw its largest growth rate of 66\% between 2014 and 2015 (SEIA, 2015) through mechanisms such as increased producer competition that facilitates decreasing costs and improved customer awareness of alternative energy options 
(Sherwood, 2011). U.S. residential solar PV installations reached 1.1 million homes in 2015 (SIA, 2016). The total solar market forecast is expected to grow $119 \%$ in 2016 , with utility scale systems leading the way (SEIA, 2016).

Utility scale PV systems result in substantial monetary savings compared to the construction of conventional fossil fuel production facilities (IEA, 2010, IRENA, 2014). However, residential distributed generation has many uniquely valuable qualities (Borenstein, 2015). These include the evident increasing cost-effectiveness of residential PV compared to utility sourced electricity (Kantamneni et al, 2016), contributions to climate change mitigation through reduced carbon emissions (Heidari and Pearce, 2016), and energy security achieved through localized generation (Lovins, 1976; 1977; 1978; Schelly and Banerjee, 2016; Kantamneni et al, 2016).

In many states, residential solar technology is made possible through multiple ownership structures that include customers with diverse economic backgrounds (Rabago, 2013). These include owner financing (consumer purchase of residential solar PV system), third party ownership (solar lease or power purchase agreement with utility) (Davidson et al, 2014), the property tax assessment model (Coughlin and Cory, 2009), or monetizing the value of solar renewable energy credits creating monetary influx that can be used to repay solar loans (Coughlin and Cory, 2009). California, New York, Massachusetts, and Washington D.C., among others, instituted a solar initiative to fund solar energy (both PV and thermal) to customers on fixed or low incomes (Browning et al, 2016). These are only a few financial options that allow residents to lower the upfront financial burden associated with solar PV installations. Finally, policies can provide incentives to residential consumers that result in compensation for excess generation 
(Rabago, 2013). While these policies present options that promote increased development of residential solar PV, limitations for expansion do exist. Government policies and falling investment costs can either facilitate or hinder widespread solar PV adoption (Bahadori and Nwaoha, 2013). High investment or capital costs may still play a role in limiting residential solar PV adoption if government policies fail to provide financial incentives for residential renewable projects (Bazen and Brown, 2009).

Adopters of residential PV systems are often conceptualized as sustainable consumers, which means they are viewed as likely to be both environmentally motivated and economically advantaged. However, thinking about adopters as sustainable consumers fails to conceptualize them as actors spatially and temporally situated in a policy context. Policy here is used specifically to refer to policies that shape the PV adoption context, including the utility rates and regulations set by state policy as put forth by agencies such as state public service or public utility commissions. Utility rates, which are set by state regulatory policy, become meaningful to actual energy users only in the context of energy expenditures, more specifically the percentage of income dedicated to meeting energy provision needs. Therefore, this paper examines the extent to which utility structures operate as policy contexts, how utility type represents the kinds of requirements via renewable portfolio standards (RPS) or Public Service Commission (PSC) regulation utilities face, how utility type is related to income, and how utility rates become meaningful through a measure of energy expenditure via energy poverty. These measures allow us to situate the PV adopter in a utility policy context to understand the extent to which these local utility policy factors matter for predicting and shaping PV adoption at the residential scale. 
This paper thus contributes to further understanding the motivations of residential PV adopters by situating them within a particular regulatory and policy context. This paper also contributes to a broader conceptualization of just energy policy, as these structural economic and utility policy factors that shape PV adoption point to potential issues related to procedural justice (Sovacool et al, 2013, Sovacool and Dworkin, 2014, Kramer and Tyler, 1996), suggesting the need to develop a procedural justice framework in the energy decision-making process. There is an established link between poverty and political disenfranchisement (Naples, 1998, Shipler, 2004), which illustrates a procedural injustice (MacCoun, 2005, Maguire and Lind, 2003) in energy policy decision-making because people who are living in energy poverty are less likely to have access to both the long term cost saving provided via PV adoption and are less likely to have access to influencing policy decision making processes. Given the role of situated policy context in shaping PV adoption, specifically the significance of energy poverty, these issues of procedural social justice should be considered when it comes to utility rate decision making and consideration of policies that would make savings on energy costs via solar PV leasing programs more accessible. Recommendations are made to facilitate policy decision making at the state level to further diversify Michigan's renewable energy portfolio through residential PV adoption and to address issues of procedural injustice in utility regulatory regimes that shape possibilities for residential PV use.

\subsection{Background and Review}

From 2013-2015, Michigan fell from $32^{\text {nd }}$ to $34^{\text {th }}$ in a national state ranking of solar PV adoption levels (SEIA, 2016). This is despite the 2008 Michigan legislation 
Public Act 295, a renewable portfolio standard program that requires utility companies to obtain $10 \%$ of electrical generation from renewable sources by 2015 . While most Michigan utilities have far surpassed this goal, and done so with lower costs than expected, critics argue Michigan's renewable portfolio standard is among the weakest in the nation (Institute for Energy Innovation, 2015). A component to P.A. 295 is net metering, which allows customers who wish to install an on-site renewable energy system to obtain compensation for any net excess generation. However, some utilities operating in the state are no longer allowing net metering access, based on interpretation of the regulatory provision provided by the state RPS (Maloney, 2016). Further, some Michigan residents pay utility rates that are very high, compared to US residents everywhere except Hawaii, given the complicated regulatory and geographical context in which electricity is supplied (EIA, 2014, MPSC, 2013; see Figure 1 below). This policy context makes the state a unique case study for studying PV adopters, as the regulatory environment first promoted and now works to limit the benefits of adoption, while the variation in utility rate pricing means that $\mathrm{PV}$ adoption creates differential amounts of long term savings via self-generation for state residents in different regions.

The analysis here builds on previous analyses of structural and value-oriented factors and their ability to predict solar adoption in the U.S. (Zahran et al, 2008; Schelly, 2010). Previous work focuses on solar thermal technology, as the US Census only collects information about solar technology used for water heating. However, as solar electric PV adoption becomes more widespread, data accessibility is improving, allowing for investigation into the predictors of residential PV adoption. Data regarding individual 
net-metered PV installations is now available from the state of Michigan, although is not available for all US states.

PV adopters are often viewed as environmentally motivated and economically secure enough to commit large upfront investments costs for PV installation (Zahran et al, 2008; Schelly 2010, and Kwan, 2012). In this way, they are often conceptualized as similar to other sustainable consumers (Truffer et al, 2001, Faiers and Neame, 2006). Utilizing the adoption and diffusion of innovations theory, several studies model the diffusion of solar power systems as they relate to attributes of the technology and the individual's inclination towards acceptance of solar (Kaplan, 1999, Labay and Kinnear, 1981, Velayudhan, 2002). The early adopting sustainable consumer is someone who incorporates improved social and environmental performance into his or her purchasing choices (Belz and Peattie, 2009). Gilg et al (2005) discuss three dimensions that ultimately help to characterize a "green" or sustainable consumer (2005). These include (1) environmental values and concerns, which focus on individual values that are strongly linked to considering the natural environment as extremely significant in someone's life (Steel, 1996), (2) psychological factors, i.e. personal attitudes, sustainable consumption behaviors, and their impacts (Azjen and Fishbein, 1973, Heberlein, 2012), and (3) sociodemographic variables, such as age, sex, education, political affiliation, and wealth that contribute to sustainable consumption (Hines et al, 1987).

There is a large body of scholarship on the link between individual behaviors perceived as environmentally responsible, individual personal values, and variables related to individual political orientation (Van Liere and Dunlap, 1980, Lorenzoni et al, 2005, Dunlap, 2008, Blankenkau et al, 2008, Kwan, 2012). Particularly in the U.S. 
context, where environmental issues are highly polarized (Dunlap, 2016, McCright et al, 2014, Gershtenson et al, 2006, Dunlap et al, 2001), individuals are not likely to engage in behaviors that are perceived as environmentally responsible if they do not identify with the politics of environmentalism (Gromet, Kunreuther, and Larrick, 2013; Goldstein et al, 2008). Thus, the link between political orientation, environmental values, and behaviors perceived to be environmentally responsible is fairly well established, and is often conceptualized in terms of the sustainable consumer. In this study, the link is captured via a measure of political voting behavior; given the highly polarized context regarding environmental issues in the U.S. (Dunlap, 2016) and the framing of PV as an environmentally responsible technology (Schelly, 2014a), political behavior is used as a proxy measure to capture the relationship between individual values and adoption.

Hypothesis 1: Zip codes with a higher Republican voting percentage will result in lower likelihood of adopting solar PV

The sustainable consumer is also often characterized in terms of structural factors such as socio-demographics. The sustainable consumer must be economically secure enough to have income to expend on products considered to be more environmentally sustainable, which are often more expensive. In the case of residential PV adoption, while there are options for leasing panels and thus decreasing or eliminating the upfront costs, these options are not available in the case study state of Michigan, USA. Thus, it is consistent to view economic wellbeing as a predictor for residential PV adopters in Michigan, as they can be conceptualized as sustainable consumers who have the 
expendable income to invest in sustainable electricity generation. The literature surrounding purchasing behaviors, including that reviewed above, suggests that sociodemographic factors contribute to sustainable consumption (Gilg et al, 2005).

Characteristics of a sustainable consumer include a higher education when compared to other consumers. Education provides an avenue to expand knowledge about the environment and technology. Increased education also results in a variety of job opportunities with higher income. Education has been indirectly but positively linked to income (Ganzeboom et al, 1992, Martinez et al, 1998). Higher education and wealth tend to align with characteristics found in sustainable consumers (Dunlap, 1975, Hines et al, 1987). Median home value can be used as a general measure of disposable income. It has also been shown that sustainable consumers tend to be homeowners. This suggests the importance of using a home value measure (Gilg et al, 2005). Employment provides the economic means to purchase goods, including residential PV technology. Unemployed individuals in the U.S. receive only a tiny fraction of the monetary benefits when compared to working individuals (BLS, 2016). Thus, higher rates of unemployment result in a lower means for purchasing solar PV.

Hypothesis 2: Higher education levels result in higher odds of adopting solar Hypothesis 3: Higher rates of home ownership and higher home values result in higher odds of adopting solar Hypothesis 4: Higher unemployment rate results in lower odds of adopting solar 
Yet the characterizations of a sustainable consumer listed above do not consider the policy context (i.e. federal, state, or local regulations and policies) in which a consumer chooses alternative technological development. Policy functions to influence or determine the behavior of a system, organization, or individual (Lewis, 2007, Collins et al, 2003). Governments utilize policy tools, legislation, regulations, sanctions, and incentives (Briggs, 2007) to influence behavior and societal outcomes. The purpose of this study is to interrogate the extent to which understandings of the sustainable consumer are improved by placing PV adoption decisions within a spatially and contextually specific policy context.

Michigan energy policies are designed and implemented by a public utility commission and the state legislature. The Michigan Public Service Commission (MPSC) regulates investor-owned utilities. MPSC responsibilities include establishing utility rates, ensuring utilities provide reliable and adequate services, and ensuring fair conditions of service for utility customers. Regulated utilities can request approval from the MPSC to increase utility rates to compensate a rise in business costs. Municipal (cityowned) and cooperative (member-owned) utilities set rates through elected board of directors. In most cases municipal and cooperative utilities are not regulated by the MPSC. In this study, utility rates are used as a proxy for energy policy context. As utility rates rise, individuals may search for alternative electrical options to help offset highenergy costs (Sahu, 2008). Michigan residents (particularly in the Upper Peninsula) pay a higher (on average) utility rate for electrical services (see Figure 1 below). Residents may seek out alternative options (i.e. solar PV), to combat these high costs (see Kantamneni et al, 2016). 
Hypothesis 5: Higher utility rates results in higher likelihood of adopting solar

Further, we examine how utility rates become meaningful for consumers via utility expenditures as a percentage of income. Electricity provides individuals within a household a comfortable living space. In some instances, homes are unable to maintain a level of comfort, and are defined as living in fuel poverty. Fuel poverty is a calculation based on a household's energy expenditure as a fraction the household income (Liddell and Morris, 2010). The World Health Organization defines the fuel poverty threshold as $10 \%$ : any household that requires $10 \%$ or more of their income to meet their energy needs is in fuel poverty (Boardman, 1991, WHO, 2005). Households living in fuel poverty have limited means to purchase a residential solar PV system. Alongside this, those living in fuel poverty are unequally represented in energy and electricity discussions (Sovacool and Dworkin, 2014).

State legislature and public utilities have the power to enact policies to make solar PV accessible to everyone. Yet there is a large discrepancy between existing legislation in states with growing residential solar adoption and those without. This is especially true in Michigan with the absence of state solar PV incentives such as tax exemptions, tax credits, or solar PV rebates (DSIRE, 2016). Arguably, policies should be targeted to address issues of procedural injustice (Sovacool et al, 2013), so that those living in fuel poverty can benefit from the distributed generation provided by residential PV technology. However, given the current policy context, we hypothesize that fuel poverty within a particular zip code will be associated with lower PV adoption rates. 
Hypothesis 6: As fuel poverty within a zip code increases, there will be a lower likelihood of solar PV adoption in those zip codes.

Conceptualizing the sustainable consumer as motivated by individual environmental values and mobilized through availability of individual economic resources to expend fails to consider how the sustainable consumer is spatially and temporally situated within a particular policy context. This policy context arguably is also likely to matter for shaping the decision to adopt residential PV technology (Schelly, 2014a; Schelly, 2014b). This paper aims to understand residential PV adoption in Michigan in terms of the role of the established individual values and structural economic factors, but also in terms of the utility policy factors that create a situated context in which homeowners make decisions, including decisions about PV adoption. This study attempts to demonstrate how utility policy factors function to affect the sustainable consumer.

This paper contributes to further theorizing of the sustainable consumer by considering the relative significance of local utility policy and utility context in predicting residential PV adoption, considering regulatory context as a system of provision (Spaargaren, 2003) that shapes the decision making of homeowners considering enacting their values as sustainable consumers via installation of solar technology. Findings do confirm that while solar PV adopters generally have individual values and economic correlating with sustainable consumption, the policy context (specifically operationalized here in terms of a descriptive analysis of utility type and an applied logistic regression 
model considering utility rate and utility rate as made meaningful via fuel poverty) within which sustainable consumers make decisions also shapes solar PV adoption. Utilizing the findings from this study, Michigan energy policy can evolve to provide solar PV adoption opportunities to all Michigan residents, addressing issues of procedural injustice (Sovacool et al, 2013) and ultimately increasing the state's use of distributed renewable energy resources.

\subsection{Data and Methods}

The data source for the dependent variable of PV adoption is the 2014 Michigan Public Service Commission net metering report. This is an annual report on net metering data collected from Michigan electric providers. As per Rule 20 (3), Michigan electric providers must submit information regarding their net metering customers, size of system, type of renewable technology, when they joined the net metering program, and geographic location (county and zip code level). This report also provides information based on utility type and utility rates.

Voter information was obtained from the Michigan Secretary of State for the percent Republican variable construction (see below). Population estimates were obtained from the 2010 U.S. Census Bureau. Data on median income, median home value, unemployment rate, and education for Michigan zip codes was obtained through the 2014 American Fact Finder reports through the U.S. Census Bureau. Finally, the average monthly electric bill in the state, used to calculate an estimated fuel poverty level for each Michigan zip code, was obtained from the 2014 Energy Information Administration report. 
The independent variables utilized in the analysis include voter information, education, median income, median home value, unemployment rates, utility rates, and fuel poverty (see Table 1). As noted above, education and home value are highly correlated with and represent indirect measures of income; education functions to influence the level of income and home value represents a measure of disposable income. Therefore, income was not included in the statistical regression model. Further, income only becomes meaningful in lived context, including contextual factors such as cost of living, including costs of utility rates; thus, leaving it out of the regression model is consistent with the argument being made here regarding the spatially contextualized policy factors that shape PV adoption. In this paper, income is used descriptively to consider the relationship between utility type as a measure of utility regulation and income, further demonstrating how income becomes a lived reality when applied to cost of living, more specifically, utility rates. 
Table 5. Comparison of Means

\begin{tabular}{|c|c|c|c|c|}
\hline Variable & $\begin{array}{l}\text { Solar above or } \\
\text { below mean }\end{array}$ & $\underline{\mathbf{N}}$ & Mean & $\begin{array}{l}\text { Standard } \\
\text { Deviation }\end{array}$ \\
\hline Percent Republican & $\begin{array}{l}\text { Above } \\
\text { Below }\end{array}$ & $\begin{array}{l}93 \\
504\end{array}$ & $\begin{array}{l}53.7 \% \\
51.3 \%\end{array}$ & $\begin{array}{l}10.34 \% \\
15.7 \%\end{array}$ \\
\hline Education & $\begin{array}{l}\text { Above } \\
\text { Below }\end{array}$ & $\begin{array}{l}93 \\
504\end{array}$ & $\begin{array}{l}17.2 \% \\
23.9 \%\end{array}$ & $\begin{array}{l}13.2 \% \\
14.9 \%\end{array}$ \\
\hline Home Value & $\begin{array}{l}\text { Above } \\
\text { Below }\end{array}$ & $\begin{array}{l}93 \\
504\end{array}$ & $\begin{array}{l}\$ 118,431.87 \\
\$ 129,603.19\end{array}$ & $\begin{array}{l}\$ 70,669.03 \\
\$ 61,088.80\end{array}$ \\
\hline Unemployment & $\begin{array}{l}\text { Above } \\
\text { Below }\end{array}$ & $\begin{array}{l}93 \\
504\end{array}$ & $\begin{array}{l}11.7 \% \\
11.4 \%\end{array}$ & $\begin{array}{l}7.5 \% \\
5.5 \%\end{array}$ \\
\hline Utility Rates & $\begin{array}{l}\text { Above } \\
\text { Below }\end{array}$ & $\begin{array}{l}93 \\
504\end{array}$ & $\begin{array}{l}\$ 0.14 / \mathrm{kWh} \\
\$ 0.14 / \mathrm{kWh}\end{array}$ & $\begin{array}{l}\$ 0.017 / \mathrm{kWh} \\
\$ 0.018 / \mathrm{kWh}\end{array}$ \\
\hline Fuel Poverty & $\begin{array}{l}\text { Above } \\
\text { Below }\end{array}$ & $\begin{array}{l}93 \\
504\end{array}$ & $\begin{array}{l}2.8 \% \\
2.4 \%\end{array}$ & $\begin{array}{l}1.7 \% \\
0.9 \%\end{array}$ \\
\hline
\end{tabular}

\section{Variable Construction}

To create the dichotomous dependent variable used in this study, PV adoption data were normalized. To normalize, the number of solar customers (MPSC, 2014) was taken as a percentage of the total population of each zip code (U.S. Census, 2010). The dependent variable is dichotomous and was recoded to (0) below mean adoption and (1) above mean adoption $(\mathrm{SD}=0.69)$. Mean adoption by zip code in the state of Michigan is 
$0.18 \%$, meaning that the average level of adoption in each zip code is less than $2 \%$ of all households. The dichotomous dependent variable is defined based on zip copes with residential solar PV installation rates below and above this mean adoption level.

A political orientation variable was used to address hypothesis 1 . Michigan voter information from the 2014 state general election (SOS, 2015) was utilized to create percent Republican for each zip code. Average percent Republican for Michigan zip codes was $52.2 \%$ ( $\mathrm{SD}=15.18 \%$ ). To create the percent Republican variable, data were compiled from the Secretary of State Precinct Voter information online table. The number of individuals who voted for the Republican candidate for State Governor was normalized by population to create a variable of the percentage of the Republican voters in each zip code.

Education was included to address hypothesis 2 and was defined as the percent of the population with a bachelor's degree or higher. Average education for Michigan zip codes was $22.9 \%(\mathrm{SD}=14.9 \%)$. Median home value was included in the logistic regression model to addresses hypothesis 3 . Average median home value was $\$ 127,950.17(\mathrm{SD}=\$ 62,683.93)$. Average unemployment rate for each Michigan zip code, $11.5 \%(\mathrm{SD}=5.9 \%)$, was included to address hypothesis 4 . Utility rates were included to address hypothesis 5 . Rates range from $\$ 0.10 / \mathrm{kWh}$ to $\$ 0.21 / \mathrm{kWh}$, averaging roughly $\$ 0.14 / \mathrm{kWh}(\mathrm{SD}=\$ 0.02 / \mathrm{kWh}$, see Figure 1 below).

A measure of fuel poverty was calculated to address hypothesis 6 . This is a measure of percentage of income spent on electricity. The average yearly Michigan electric bill, $\$ 1,134.24$ (EIA, 2016), was used to determine the percentage of each zip code's median income expenditures on electric bills. A community lives in fuel poverty 
if their electrical expenditure exceeds $10 \%$ of household income (Boardman, 1991). The average level of fuel poverty within Michigan is $2.5 \%(\mathrm{SD}=1.1 \%)$, meaning that a majority of Michigan residents are not defined as living in fuel poverty. Only one zip code (48411 in Michigan lives in fuel poverty, 18.15\%).

\section{Maps: Utility Rates and Solar Customers}

Data on utility rates for each zip code was collected from the 2014 MPSC report. A shapefile of Michigan zip codes was obtained from the ArcGIS database (ArcGIS, 2016). Average Michigan utility rates (investor-owned, municipal, and cooperative) were geolocated with zip codes and transcribed using ArcMap version 10.4.1.

Data on number of solar PV adoption customers was collected from the 2014 Michigan Public Service Commission report (2014 report). A shapefile of the Michigan zip codes was obtained from the ArcGIS database (ArcGIS, 2016). Total population of Michigan zip codes was obtained from the U.S. Census Bureau (U.S. Census, 2010). Dividing the number of solar PV customers by population in each zip code normalized total number of solar PV customers. This normalized data was then geolocated with Michigan zip codes. The data were then transcribed utilizing ArcMap version 10.4.1 to provide a map of percent above and below the average solar PV customers in each Michigan zip code.

Analysis

The final number of zip codes with solar PV adoption is 598 rather than 680 . Some zip codes were omitted due to the lack of a residential population. In some 
instances, a zip code showed solar PV adoption for a 20kw or less system that belonged to a small business, but within a zip code with no reported population. In other cases, a zip code was omitted if it had a renewable installation, but was something other than solar PV (i.e. wind or hydro). A logistic regression was conducted to determine the odds of the independent variables influencing the dependent variable. The results of the logistic regression test are discussed below. The results described below include a descriptive representation of utility types and the economic stratification of their customers, the GIS representation of PV adoption in Michigan, and the logistic regression analysis.

\subsection{Results}

The three main types of utilities in Michigan include (1) investor-owned, (2) cooperative, and (3) municipality. Investor-owned utilities service a larger number of zip codes compared to cooperative and municipal utilities combined. Municipal and cooperative utilities are not-for-profit entities and can structure their utility rates independent from the MPSC. Descriptive statistics illustrate the relationship between utility type as a means of representing utility regulatory regimes and the economic wellbeing of customers as illustrated by average incomes. An aggregate average median income is included for each utility type in Table 2. 
Table 6. Frequency and aggregate average income of utilities in Michigan zip codes.

\begin{tabular}{|l|l|l|}
\hline Utility type & $\begin{array}{l}\text { Frequency (number } \\
\text { of zip codes) }\end{array}$ & Aggregate Average Income \\
\hline Investor Owned & 471 & $\$ 54,702.99$ \\
\hline Cooperative & 97 & $\$ 43,608.51$ \\
\hline Municipal & 30 & $\$ 26,704.97$ \\
\hline
\end{tabular}

Figure 1 illustrates utility rate variation across the state of Michigan. As shown by the map, high utility rates (above the average $\$ 0.14 / \mathrm{kWh}$ ) are concentrated in the Upper Peninsula and southeastern region of the Lower Peninsula. The utility rates correspond to utilities that service these particular areas. Average median income in the Upper Peninsula is $\$ 50,331.67$, compared to $\$ 58,100.88$ in the Lower Peninsula. This spatial representation demonstrates that geographies with the highest utilities rates make on average less than those living in regions with lower, below average utility rates.

Furthermore, this spatial representation does not fully capture the extreme variation in rates across the state; while the state average in Michigan is higher than the US average rate, ${ }^{3}$ customers of the IOU operating in the Upper Peninsula currently pay $\$ .27 / \mathrm{kWh},{ }^{4}$ an extremely high rate that is particularly meaningful in the context of low regional median incomes.

\footnotetext{
${ }^{3}$ https://www.eia.gov/electricity/monthly/epm_table_grapher.cfm?t=epmt 5 _6_a, accessed October 19, 2016.

${ }^{4}$ See http://www.dleg.state.mi.us/mpsc/electric/download/rates1.pdf, accessed October $19,2016$.
} 


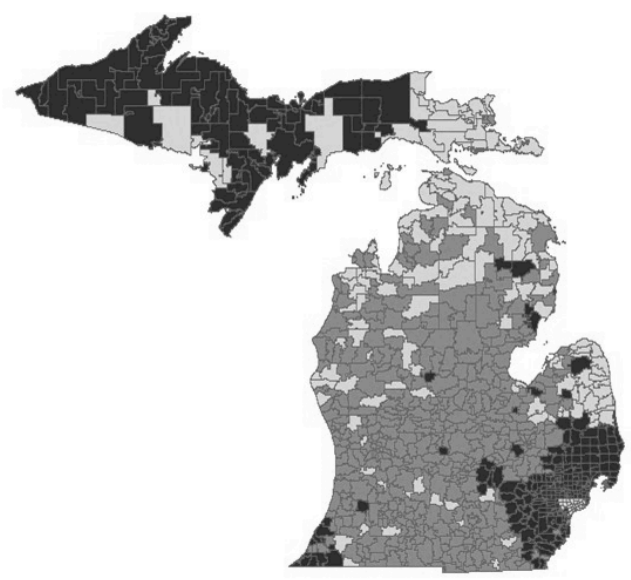

Utility Rates (\$/kWh)

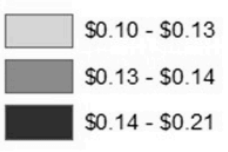

Figure 5: Utility rate variation by Michigan zip code

Figure 2 illustrates the normalized solar PV adoption for each zip code in Michigan. As shown by the map, solar PV adoption is concentrated in mid to eastern regions downstate. This correlates to the concentration of individual wealth in the state but not to the geographies with the highest utility rates. This is consistent with previous literature on the relationship between individual wellbeing and ability to adopt PV technology, supporting hypothesis 3 that zip codes with higher wealth will have a higher likelihood of PV adoption. The map shows lower PV adoption in areas of higher utility rates, contradicting previous literature as well as hypothesis 5. In the Upper Peninsula, 
roughly $0.07 \%$ of zip codes, compared to the Lower Peninsula's $0.14 \%$ of zip codes, are above the mean adoption rates.

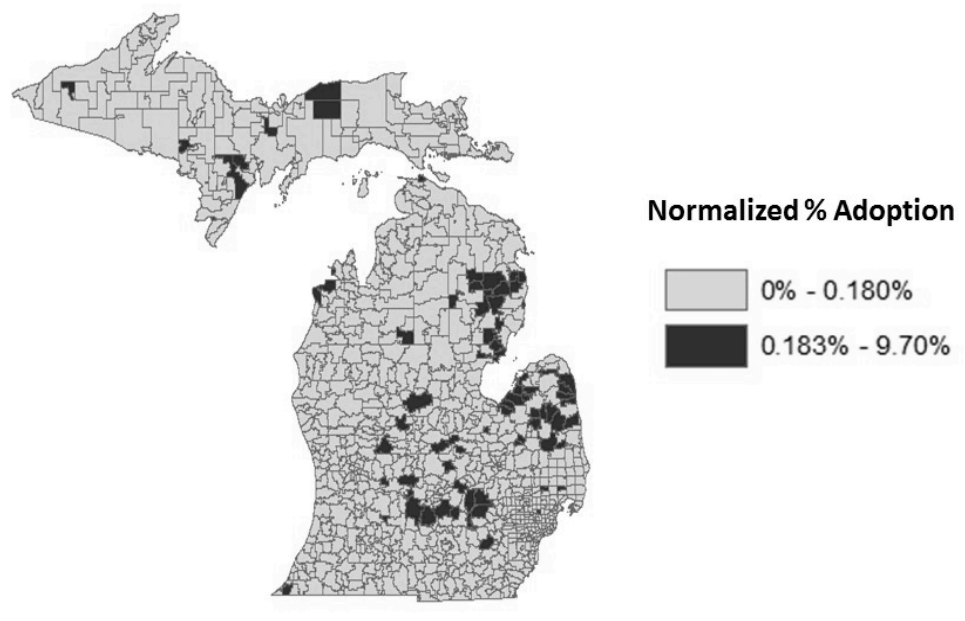

Figure 6: Geography of Household Solar PV Adoption in Michigan

Table 3 reports the summary model for the logistic regression analysis. The analysis indicates that the variables percent Republican, education, median home value, and fuel poverty were significant predictors. This means that hypotheses 1 and 3 are confirmed, while hypotheses 2 and 6 are significant, but not in the hypothesized direction. Unemployment (hypothesis 4) and utility rates (hypothesis 5) were insignificant predictors in this model. 
Table 7. Logistic Regression Output Summary Model

\begin{tabular}{|l|l|l|l|}
\hline Variable & B & S.E. & $\begin{array}{l}\text { Nagelkerke } \\
\text { R-squared }\end{array}$ \\
\hline Percent Republican & $0.049^{*}$ & 0.013 & \\
\hline Education & $-0.076^{*}$ & 0.018 & \\
\hline Median Home Value & $<0.001$ & $<0.001$ & \\
\hline Unemployment Rate & -0.011 & 0.030 & \\
\hline Utility Rates & 10.880 & 2.539 & \\
\hline Fuel Poverty & $0.582^{*}$ & 7.065 & \\
\hline & & & 0.170 \\
\hline
\end{tabular}

*p-value $<0.05$

Each unit increase in the percent Republican within a zip code decreases the odds of moving from the "0-below mean" to " 1 -above mean." Each unit increase in education level resulted in a 0.076 level decrease in solar PV adoption. For median home value, for each unit change, the odds of moving from below average adoption to above average adoption is small but significant. Finally, a one-unit increase in fuel poverty results in a 0.582 level increase in PV adoption.

Zip codes with a higher percentage of republicans result in lower PV adoption, supporting the notion of environmental values in a sustainable consumer. Higher 
education resulting in lower PV adoption suggests a unique case in Michigan. Median home value results are supported by previous literature. The directional change in adoption levels due to fuel poverty suggests consumer's motivation to invest in solar PV, despite being the appearance economically disadvantaged. Overall, these results illustrate political orientation and certain socioeconomic factors predict solar PV adoption in Michigan.

\subsection{Discussion}

Results of this study support previous research on the sustainable consumer by demonstrating that the factors political orientation and median home value are significant in predicting residential PV adoption in predicted directions. In the US context, individuals with a Republican political orientation tend to favor balancing environmental protection with strong economic development (Dunlap, 2008); other research has found that Republicans generally support the development of renewable technology, but not at the expense of the economy or investment by tax payers (Lyon and Yin, 2010). The findings here suggest that political polarization (Dunlap, 2016) continues to shape identification as a sustainable consumer and the context of PV adoption. Median home value was statistically significant, also aligning with previous literature of sustainable consumer characteristics.

Education was significant but in an unexpected direction, contradicting previous literature of characteristics of the sustainable consumer. Perhaps education has a different affect specifically in the state of Michigan. Some studies suggest conceptualizing 
education as a barrier to technological adoption has only marginal effects (Uematsu, 2010, Mwangi et al, 2015).

In the logistic regression model presented above, the fuel poverty predictor was significant. A majority of Michigan zip codes do not live in fuel poverty; however, the relationship was still significant in the model. Yet the model contradicted the hypothesized relationship, that higher fuel poverty results in lower adoption. Perhaps the calculation of fuel poverty may not be capturing real fuel poverty levels in Michigan. Alternatively, residents in higher fuel poverty zip codes may take advantage of the net metering opportunity provided as part of the P.A. 295, contributing to this positive relationship. This is clearly an area for future research, as it demonstrates that the lived policy context as made meaningful through utility expenditures does correlate with residential PV adoption decisions, but in ways not yet fully understood.

\section{$\underline{3.6}$ Conclusion and policy implications}

The weak to moderate overall strength of the regression model presented above indicates the potential role of other factors that may have more explanatory power. Variables not captured in the statistical model include other values-oriented variables, specific beliefs and attitudes towards solar PV, differences between seasonal and permanent residents, and other spending characteristics of zip codes (i.e. mortgage payments) that deplete disposable income stores.

There are potential ways to improve the fuel poverty variable constructed for this analysis. Fuel poverty was calculated from the average Michigan electric bill and median income of each zip code. A more accurate depiction of fuel poverty in Michigan can be 
created from individual utilities average monthly bills. When contacted individually via phone, some utilities indicated they do not collect this type of data.

The results point to several areas for future research. One avenue would be to employ surveys, questionnaires, and/or interviews geared at obtaining information from homeowners. Building on this research would provide insight into the energy decisionmaking process among Michigan residents.

As stated above, policies function to influence behavior at a system, organization, local, or individual scale. The sustainable consumer has the economic means and environmental values to support residential PV technology, and this paper hypothesized that high utility rates would operate as a policy context to further encourage solar adoption. However, the utility rate predictor was insignificant in the regression analyses. Yet looking into how utility rates shape the lived experience of electricity by considering the relationship between utility expenditures and incomes (see Figure 1 and Table 2) suggests a need for further research into the contextualized policy factors that either help or hinder the renewable energy transition.

Michigan's lack of renewable state incentives represents situation of policy lockin, a term describing a system that perpetuates conventional practices, more specifically a continued reliance on policies that support fossil fuels (Unruh, 2000). Michigan's RPS program attempts to promote renewable energy adoption and development at a system level, yet there are minimal incentives to lessen the burden of upfront solar PV system costs at the individual level. As a result, sustainable consumers who wish to adopt solar PV technology are hindered by the policy system in place in Michigan, or are prevented from doing so, either because of lacking economic resources or particularly by the policy 
barriers for those consumers living in territories serviced by utility that are no longer allowing net metered installations (Maloney, 2016).

These results also speak to a procedural energy injustice in Michigan renewable energy policy. Procedural justice considers fairness of the processes used in the decision making process (Kramer and Tyler, 1996). A second component includes the step beyond decision making to implementation of projects or policies. Under procedural justice, all individuals should have equal representation and equal opportunity for consideration in the decision making process (Shrader-Frechette, 2002). Yet in most cases, those with higher wealth have stronger bargaining capacity in decision-making (Sovacool and Dworkin, 2014). Communities, populations, or individuals with lower incomes or living in fuel poverty may not have access to meaningful participation in Michigan's energy decision-making process. If equal access to participation is difficult, it is important to ensure proper representation in energy decision-making.

Energy policies set by the state legislature and public utilities commission determine how easy accessible PV adoption is in each state. A first step to improve the solar PV market in Michigan would be an incremental increase to Michigan's RPS program. Many other states incrementally increase their renewable energy targets with success (California, Massachusetts, Washington, to name a few) (DSIRE, 2015).

Yet a RPS program is only one component of a state's successful clean energy policy. Including state incentives can greatly expand renewable energy adoption (Menanteau, 2003, Butler and Neuhoff, 2008, Johnstone et al, 2010). Michigan currently does not have state incentives in the form of tax credits, tax exemptions, solar rebates, or programs to facilitate solar PV adoption for low-income consumers. Providing incentives 
at the state level will ensure increased solar PV and other renewable energy adoption levels. Finally, providing alternative ownership structures extends solar PV accessibility beyond those with the individual economic means for adoption. Owner financing, third party ownership, property tax assessment model, or monetizing the value of renewable energy credits via solar installation are all possible models. Yet these options do not always extend to low or fixed income households.

One option is to include targets for low and fixed income customers in state renewable energy policy portfolio mandates, by partially or fully funding household solar. Funding for this option could come from Michigan's energy optimization surcharge, utility renewable energy funds strictly used for low-income solar PV installations, or community cooperative initiatives.

This paper attempted to understand the role of utility policy factors in contextualizing potential influences on solar PV adoption. Implementing a procedural justice framework can attempt to close the gaps found in information exchange, full participation, and adequate representation in the energy decision-making process. Without specific procedural justice considerations, certain Michigan populations will continue to be dominated by high utility costs and the lack of state renewable incentives that support residential solar PV adoption. 


\subsection{References}

Ajzen, Icek, and Martin Fishbein. "Attitudinal and normative variables as predictors of specific behavior." Journal of personality and Social Psychology27, no. 1 (1973): 41.

ArcGIS. U.S.A. Zip Code Areas. Accessed on Sept 21, 2016. https://www.arcgis.com/home/item.html?id=8d2012a2016e484dafaac0451f9aea2 $\underline{4 .}$

Bazen, Ernest F., and Matthew A. Brown. "Feasibility of solar technology (photovoltaic) adoption: A case study on Tennessee's poultry industry." Renewable Energy 34, no. 3 (2009): 748-754.

Belz, Frank-Martin, and Ken Peattie. Sustainability marketing: A global perspective. Wiley, 2009.

Bahadori, Alireza, and Chikezie Nwaoha. "A review on solar energy utilisation in Australia." Renewable and Sustainable Energy Reviews 18 (2013): 1-5.

Blankenau, Joe, Monica Snowden, and Marian Langan. "Understanding environmentalism in a red, agricultural state: The impact of political party identification and place of residence." Sociological Spectrum 28, no. 1 (2007): 5580 .

Boardman, Brenda. Fuel poverty: from cold homes to affordable warmth. Pinter Pub Limited, 1991.

Borenstein, Severin, and James Bushnell. The us electricity industry after 20 years of restructuring. No. w21113. National Bureau of Economic Research, 2015.

Branker, Kadra, M. J. M. Pathak, and Joshua M. Pearce. "A review of solar photovoltaic levelized cost of electricity." Renewable and Sustainable Energy Reviews 15, no. 9 (2011): 4470-4482.

Australian Public Service Commission. "Changing Behaviour: a public policy perspective." See: www. apsc. gov. au/publications07/changingbehaviour. htm (accessed January 2012) (2007).

Browning, A., 2016. Low-income solar policy guide. Accessed on Oct 05, 2016. http://www.lowincomesolar.org/wp-content/uploads/2016/03/Low-Income-SolarPolicy-Guide_3.11.16.pdf. 
Butler, Lucy, and Karsten Neuhoff. "Comparison of feed-in tariff, quota and auction mechanisms to support wind power development." Renewable energy 33, no. 8 (2008): 1854-1867.

Chernyakhovskiy, Ilya. "Solar PV Adoption in the United States: An Empirical Investigation of State Policy Effectiveness." (2015).

Collins, Joanna, Gillian Thomas, Rebecca Willis, and James Wilsdon. "Carrots, sticks and sermons: influencing public behaviour for environmental goals." Report version 4 (2003).

Coughlin, Jason, and Karlynn S. Cory. Solar photovoltaic financing: residential sector deployment. National Renewable Energy Laboratory, 2009.

Database of State Incentives for Renewables and Efficiency. Accessed on Oct 10, 2016. http://programs.dsireusa.org/system/program?zipcode $=49930$.

Davidson, Carolyn, Daniel Steinberg, and Robert Margolis. "Exploring the market for third-party-owned residential photovoltaic systems: insights from lease and power-purchase agreement contract structures and costs in California." Environmental Research Letters 10, no. 2 (2015): 024006.

Dunlap, Riley E. "The impact of political orientation on environmental attitudes and actions." Environment and behavior 7, no. 4 (1975): 428.

Riley E., Chenyang Xiao, and Aaron M. McCright. "Politics and environment in America: Partisan and ideological cleavages in public support for environmentalism." Environmental politics 10, no. 4 (2001): 23-48.

- Riley E., and Araon M. McCright. "A widening gap: Republican and Democratic views on climate change." Environment: Science and Policy for Sustainable Development 50, no. 5 (2008): 26-35.

--------- Riley E., Aaron M. McCright, and Jerrod H. Yarosh. "The Political Divide on Climate Change: Partisan Polarization Widens in the US." Environment: Science and Policy for Sustainable Development 58, no. 5 (2016): 4-23.

ELECTRICITY, G., 2014. Projected Costs of Generating Electricity.

EIA. International Energy Outlook 2010, U.S. Department of Energy, USA, 2010, pp. 1338.

------ Accessed on Sept 21, 2016. http://www.eia.gov/electricity/sales_revenue_price/pdf/table5_a.pdf. 
Faiers, Adam, and Charles Neame. "Consumer attitudes towards domestic solar power systems." Energy Policy 34, no. 14 (2006): 1797-1806.

Ganzeboom, Harry BG, Paul M. De Graaf, and Donald J. Treiman. "A standard international socio-economic index of occupational status." Social science research 21, no. 1 (1992): 1-56.

Gershtenson, Joseph, Brian W. Smith, and William R. Mangun. "Friends of the earth? Partisanship, party control of Congress, and environmental legislation in Congress." Politics \& Policy 34, no. 1 (2006): 66-92.

Gilg, Andrew, Stewart Barr, and Nicholas Ford. "Green consumption or sustainable lifestyles? Identifying the sustainable consumer." Futures 37, no. 6 (2005): 481504.

Goldstein, Noah J., Robert B. Cialdini, and Vladas Griskevicius. "A room with a viewpoint: Using social norms to motivate environmental conservation in hotels." Journal of consumer Research 35, no. 3 (2008): 472-482.

Greenberg, Michael. "Energy sources, public policy, and public preferences: Analysis of US national and site-specific data." Energy Policy 37, no. 8 (2009): 3242-3249.

Gromet, Dena M., Howard Kunreuther, and Richard P. Larrick. "Political ideology affects energy-efficiency attitudes and choices." Proceedings of the National Academy of Sciences 110, no. 23 (2013): 9314-9319.

Heberlein, Thomas A. "Navigating environmental attitudes." Conservation Biology 26, no. 4 (2012): 583-585.

Heidari, Negin, and Joshua M. Pearce. "A review of greenhouse gas emission liabilities as the value of renewable energy for mitigating lawsuits for climate change related damages." Renewable and Sustainable Energy Reviews 55 (2016): 899908.

Hines, Jody M., Harold R. Hungerford, and Audrey N. Tomera. "Analysis and synthesis of research on responsible environmental behavior: A meta-analysis." The Journal of environmental education 18, no. 2 (1987): 1-8.

Institute for Energy Innovation. Barriers to advanced energy in Michigan. Accessed on Sept 21, 2016. http://www.instituteforenergyinnovation.org/?objectid=565852005B56-11E2-B865000C29CA3AF3.

Johnstone, Nick, Ivan Haščič, and David Popp. "Renewable energy policies and technological innovation: evidence based on patent counts." Environmental and resource economics 45, no. 1 (2010): 133-155. 
Kantamneni, Abhilash, Richelle Winkler, Lucia Gauchia, and Joshua M. Pearce.

"Emerging economic viability of grid defection in a northern climate using solar hybrid systems." Energy Policy 95 (2016): 378-389.

Kaplan, Abram W. "From passive to active about solar electricity: innovation decision process and photovoltaic interest generation." Technovation 19, no. 8 (1999): 467481.

Kramer, Roderick M., and Tom R. Tyler, eds. Trust in organizations: Frontiers of theory and research. Sage Publications, 1995.

Kwan, Calvin Lee. "Influence of local environmental, social, economic and political variables on the spatial distribution of residential solar PV arrays across the United States." Energy Policy 47 (2012): 332-344.

Labay, Duncan G., and Thomas C. Kinnear. "Exploring the consumer decision process in the adoption of solar energy systems." Journal of consumer research 8, no. 3 (1981): 271-278.

Lewis, Miranda. States of reason: Freedom, responsibility and the governing of behaviour change. Institute for Public Policy Research, 2007.

Liddell, Christine, and Chris Morris. "Fuel poverty and human health: a review of recent evidence." Energy policy 38, no. 6 (2010): 2987-2997.

Lorenzoni, Irene, Nick F. Pidgeon, and Robert E. O'Connor. "Dangerous climate change: the role for risk research." Risk Analysis 25, no. 6 (2005): 1387-1398.

Lovins, Amory B. "Energy strategy: the road not taken." Foreign Aff. 55 (1976): 65.

Amory B. "Soft energy paths: Toward a durable peace." (1977).

-------- Amory B. "Soft energy technologies." Annual Review of Energy 3, no. 1 (1978): 477-517.

Lyon, Thomas P., and Haitao Yin. "Why do states adopt renewable portfolio standards?: An empirical investigation." The Energy Journal (2010): 133-157.

MacCoun, Robert J. "Voice, control, and belonging: The double-edged sword of procedural fairness." Annu. Rev. Law Soc. Sci. 1 (2005): 171-201. 
Maguire, Lynn A., and E. Allan Lind. "Public participation in environmental decisions: stakeholders, authorities and procedural justice." International Journal of Global Environmental Issues 3, no. 2 (2003): 133-148.

Maloney, P., 2016. Upper peninsula utility first in Michigan to hit solar net metering cap. Acessed on Sept 21, 2016. http://www.utilitydive.com/news/upper-peninsulautility-first-in-michigan-to-hit-solar-net-metering-cap/423963/.

Martinez, Eva, Yolanda Polo, and Carlos Flavian. "The acceptance and diffusion of new consumer durables: differences between first and last adopters." Journal of Consumer Marketing 15, no. 4 (1998): 323-342.

McCright, Aaron M., Chenyang Xiao, and Riley E. Dunlap. "Political polarization on support for government spending on environmental protection in the USA, 1974 2012." Social Science Research 48 (2014): 251-260.

Menanteau, Philippe, Dominique Finon, and Marie-Laure Lamy. "Prices versus quantities: choosing policies for promoting the development of renewable energy." Energy policy 31, no. 8 (2003): 799-812.

Moore, Richard. "Definitions of fuel poverty: Implications for policy." Energy Policy 49 (2012): 19-26.

Mwangi, H. W., A. W. Kihurani, J. M. Wesonga, E. S. Ariga, and F. Kanampiu. "Factors influencing adoption of cover crops for weed management in Machakos and Makueni counties of Kenya." European Journal of Agronomy69 (2015): 1-9.

Pepermans, Guido, Johan Driesen, Dries Haeseldonckx, Ronnie Belmans, and William D'haeseleer. "Distributed generation: definition, benefits and issues." Energy policy 33, no. 6 (2005): 787-798.

Rábago, Karl R. "The 'Value Of Solar'Rate: Designing An Improved Residential Solar Tariff." Solar Industry, February (2013).

Reece, Ray. The sun betrayed: A report on the corporate seizure of US solar energy development. South End Press, 1979.

Sawin, Janet L., Eric Martinot, Virginia Brien, Angus McCrone, Jodie Roussell, Douglas Barnes, Christopher Flavin et al. "Renewables 2010-Global status report." (2010).

Rogers, John, and Laura Wisland. "Solar power on the rise: the technologies and policies behind a booming energy sector." Union of Concerned Scientists(2014).

Sahu, Santosh. "Trends and Patterns of Energy Consumption in India." (2008). 
Schelly, Chelsea. "Testing residential solar thermal adoption." Environment and Behavior 42, no. 2 (2010): 151-170.

--------- Chelsea. "Residential solar electricity adoption: what motivates, and what matters? A case study of early adopters." Energy Research \& Social Science 2 (2014): 183-191.

Chelsea. "Implementing renewable energy portfolio standards: The good, the bad, and the ugly in a two state comparison." Energy Policy 67 (2014): 543-551.

--------- Chelsea, and Aparajita Banerjee. "Soft Energy Paths Revisited: Politics and Practice in Energy Technology Transitions." Challenges 7, no. 2 (2016): 16.

Secretary of State. Election Precinct Results Search. Accessed on Oct 7, 2016. http://miboecfr.nictusa.com/cgi-bin/cfr/precinct_srch.cgi.

Sherwood, Larry. "US solar market trends." In Proceedings of the Solar Conference, vol. 2, p. 909. AMERICAN SOLAR ENERGY SOCIETY; AMERICAN INSTITUTE OF ARCHITECTS, 2007.

Shipler, David K. The working poor: Invisible in America. Vintage, 2008.

Shrader-Frechette, Kristin. Environmental justice: Creating equality, reclaiming democracy. Oxford University Press, 2002.

SEIA. Solar Market Sets New Record Installing 73 GW Solar PV. Accessed on Sept 21, 2016. http://www.seia.org/news/us-solar-market-sets-new-record-installing-73gw-solar-pv-2015.

--------U.S. Residential Soalr PV Installations Exceeded Commercial Installations First Time. Accessed Sept 21, 2016. http://www.seia.org/news/us-residential-solar-pvinstallations-exceeded-commercial-installations-first-time-q1-2014.

Sovacool, Benjamin K., Roman V. Sidortsov, and Benjamin R. Jones. Energy security, equality and justice. Routledge, 2013.

---------- Benjamin K., and Michael H. Dworkin. Global energy justice. Cambridge University Press, 2014.

Spaargaren, Gert. "Sustainable consumption: a theoretical and environmental policy perspective." Society \&Natural Resources 16, no. 8 (2003): 687-701. 
Statistics Portal. Number of Households in the U.S. from 1960-2015. Accessed on Oct 5, 2016. https://www.statista.com/statistics/183635/number-of-households-in-theus/.

Steel, Brent S. "Thinking globally and acting locally?: environmental attitudes, behaviour and activism." Journal of environmental management 47, no. 1 (1996): 27-36.

Taylor, Michael, K. Daniel, A. Ilas, and E. So. "Renewable Power Generation Costs in 2014." International Renewable Energy Agency: Masdar City, Abu Dhabi, UAE (2015).

Truffer, Bernhard, Jochen Markard, and Rolf Wüstenhagen. "Eco-labeling of electricity-strategies and tradeoffs in the definition of environmental standards." Energy policy 29, no. 11 (2001): 885-897.

Uematsu, Hiroki, and Ashok K. Mishra. "Can Education Be a Barrier to Technology Adoption?." Selected Paper prepared for presentation at the Agricultural \& Applied Economics Association (2010): 25-27.

Unruh, Gregory C. "Understanding carbon lock-in." Energy policy 28, no. 12 (2000): 817-830.

U.S. Bureau of Labor Statistics. Employment situation summary. Accessed on Oct 5, 2016. www.bls.gov/news.release/empsit.nr0.htm.

U.S. Census Bureau. American Fact Finder. Accessed on Sept 21, 2016. http://factfinder.census.gov/faces/nav/jsf/pages/index.xhtml.

Van Liere, Kent D., and Riley E. Dunlap. "The social bases of environmental concern: A review of hypotheses, explanations and empirical evidence." Public opinion quarterly 44, no. 2 (1980): 181-197.

Velayudhan, S. K. "Dissemination of solar photovoltaics: a study on the government programme to promote solar lantern in India." Energy policy 31, no. 14 (2003): 1509-1518.

World Health Organization. Environment and Health in Developing Countries. Accessed on Oct 1, 2016. http://www.who.int/heli/risks/ehindevcoun/en/index2.html.

Zahran, Sammy, Samuel D. Brody, Arnold Vedlitz, Michael G. Lacy, and Chelsea Lynn Schelly. "Greening local energy: explaining the geographic distribution of household solar energy use in the United States." Journal of the American Planning Association 74, no. 4 (2008): 419-434. 


\title{
Chapter 4: Potential Lives Saved by Replacing Coal with Solar Photovoltaic
}

\section{Electricity Production in the U.S. ${ }^{5}$}

\author{
Potential Lives Saved by Replacing Coal with Solar Photovoltaic Electricity \\ Production in the U.S. \\ Emily W. Prehoda ${ }^{a}$ \& Joshua M. Pearce ${ }^{\text {b,c,* }}$ \\ ${ }^{a}$ Department of Social Sciences, Michigan Technological University, USA \\ ${ }^{b}$ Department of Materials Science and Engineering, Michigan Technological University, \\ USA \\ ${ }^{\mathrm{c}}$ Department of Electrical and Computer Engineering, Michigan Technological \\ University, USA
}

*Corresponding author. E-mail: pearce@mtu.edu. 1400 Townsend Drive, Houghton, Michigan 49931-1295, Telephone: (906) 487-1466.

\begin{abstract}
Poor air quality from coal combustion adversely impacts human health including mortality and morbidity effects on respiratory, cardiovascular, nervous, urinary, and digestive systems. However, the continued use of coal are no longer necessary to provide for society's electrical needs because of advances in solar photovoltaic (PV) technology. In order to inform health policy this paper reviews the data for quantifying the lives saved by a replacement of U.S. coal-fired electricity with solar PV systems. First the geospatial correlation with coal fired power plants and mortality is determined for the U.S. at the state level. Then, current life cycle mortality rates due to coal combustion are calculated and current energy generation data is collated. Deaths/kWh/year of coal and PV are calculated, and the results showed that 51,999 American lives/year could be saved by transitioning from coal to PV-powered electrical generation in the U.S. To accomplish this, $755 \mathrm{GW}$ of U.S. PV installations are needed. The first costs for the approach was found to be roughly $\$ 1.45$ trillion. Over the 25 year warranty on the PV modules the first cost per life saved is approximately $\$ 1.1$ million, which is comparable to the value of a human life used in other studies. However, as the solar electricity has value, the cost per life is determined while including the revenue of the solar electric generation using a sensitivity analysis on the value of the electricity. These results found that for most estimations of the value, saving a life by offsetting coal with PV actually saved money as well, in some cases several million dollars per life. It is concluded that it is profitable to save lives in the U.S. with the substitution of coal-fired electricity with solar power and that the conversion is a substantial health and environmental benefit.
\end{abstract}

5 The material contained in this chapter has been submitted to Renewable and Sustainable Energy Reviews 
Keywords: public health; pollution; photovoltaic; lives; coal; solar energy

\subsection{Introduction}

Coal combustion for electrical generation not only contributes to high levels of carbon dioxide emissions (Sims et al, 2003, Markandya and Wilkinson, 2007, Lockwood et al, 2009) with the concomitant climate disruption (Lockwood et al, 2009, Weisser, 2007, Fenger, 2009, Gohlke et al, 2011), but also to conventional air pollution (Fenger, 2009, Epstein et al, 2011). Coal fired electrical power plants released 23\% of air pollutants [8] and the largest contributors to U.S. carbon dioxide emission is electrical generation (31\%) (EPA, 2014). While coal use is declining due to natural gas resources and renewable energy growth (Reboredo, 2015), coal combustion still accounts for roughly $30-40 \%$ of U.S. carbon dioxide pollution, contributing to ever-expanding climate change (Lockwood et al, 2009). Air pollutants are classified into four groups: gaseous, persistent organic, heavy metals, and particulate matter (Kampa and Castanas, 2008). The literature shows a positive correlation between mortality and morbidity due to outdoor air pollution (Curtis et al, 2006, Hendryx, 2007, Hendryx and Zullig, 2009, Yim et al, 2012). Specifically coal combustion results in emissions of carbon dioxide, methane (gaseous pollutants), particulate matter, nitrogen and sulfur oxides (gaseous), and mercury (heavy metal) (Markandya and Wilkinson, 2007, Weisser, 2007, Epstein et al, 2011, Curtis et al, 2006, Gaffney and Marley, 2009, Smith et al, 2013, Finkelman et al, 2002, Melod and Johnston, 2015). Poor air quality, from coal combustion is well known to adversely affect human health including: mortality and morbidity effects on respiratory, cardiovascular, 
nervous, urinary, and digestive systems is summarized in Table 1. This paper will focus on mortality due to emissions from coal-fired electrical generation.

Table 8. Major health effects from coal combustion emissions.

\begin{tabular}{|c|c|c|c|}
\hline & $\begin{array}{l}\text { Medical } \\
\text { Condition }\end{array}$ & $\begin{array}{l}\text { Estimated } \\
\text { Affected } \\
\text { Individuals* }\end{array}$ & $\begin{array}{l}\text { Coal } \\
\text { Emissions } \\
\text { Responsible }\end{array}$ \\
\hline \multirow{3}{*}{ Respiratory } & Asthma & 22.9 million & $\mathrm{NOx}, \mathrm{PMx}^{*}$ \\
\hline & $\begin{array}{l}\text { Chronic } \\
\text { Obstructive } \\
\text { Pulmonary } \\
\text { Disease }\end{array}$ & 12.1 million & NOx, PMx \\
\hline & Lung Cancer & $159,217 *$ & PMx \\
\hline \multirow{2}{*}{ Cardiovascular } & Heart Attack & 7.9 million & PMx \\
\hline & $\begin{array}{l}\text { Congestive Heart } \\
\text { Failure } \\
\end{array}$ & 5.7 million & PMx \\
\hline \multirow[t]{3}{*}{ Neurological } & Ischemic Stroke & 104,000 & $\begin{array}{l}\mathrm{NOx}, \mathrm{PMx}, \\
\mathrm{SO}_{2}\end{array}$ \\
\hline & $\begin{array}{l}\text { Developmental } \\
\text { delays }\end{array}$ & 637,233 & Mercury $^{70}$ \\
\hline & & & \\
\hline
\end{tabular}

*Estimated affected individuals include both mortality and morbidity rates. PMx (particulate matter) encompasses particulate matter size between 2.5 and 10 micrometers. NOx (nitrogen oxide) (Lockwood et al, 2009, Kampa and Castanas, 2008, Curtis et al, 2006, Hendryx, 2007, Clancy et al, 2002).

A full life cycle accounting of coal reveals an estimated $\$ 523.3$ billion in damages (including social and environmental externalities), which is roughly $\$ 0.27 / \mathrm{kWh}$ generated (Epstein et al, 2011). Thus, the externalities of coal-fired electricity are more than double 
the average cost of residential electricity in the U.S. of $\$ 0.12 / \mathrm{kWh}$ (EIA, 2016). Although coal is detrimental in all stages of its life cycle, combustion is the stage with the heaviest health burden (Gaffney and Marley, 2009) in the form of mortality and morbidity effects due to outdoor air pollutants/emissions.

Most research devoted to addressing issues of coal degraded air quality has focused on mitigation of coal plant emissions using regulations and mechanisms such as cap and trade through permits (Stavins, 2008), which are vigorously opposed by the coal industry (Stavins, 1998). These mechanisms decreased some gaseous pollutants by targeting sulfur and nitrogen oxides through a cap and trade regulatory policy (EPA, 2013). Particulate matter (absorbed through inhalation and ingestion) and carbon dioxide (impacts climate processes) continue to pose severe risks (Smith et al, 2013, O'Neill et al, 2012). Particulate matter is directly linked to increased mortality due to lung cancer and respiratory disease (Curtis et al, 2006, Gohlke et al, 2011).

Fortunately, the continued use of coal and the required complicated emissions controls are no longer necessary to provide for society's electrical needs because of advances in renewable energy sources such as solar photovoltaic (PV) technology (Sims et al, 2003, Weisser, 2007, Pearce, 2002). PV produces no emissions or generate liquid or solid wastes during use and has a well-established environmentally-friendly ecological balance sheet (Pearce and Lau, 2002, Fthenakis et al, 2006, Fthenakis et al, 2008, Evans et al, 2009, Fthenakis and Kim, 2011, Solangi et al, 2011). Integrating rooftop solar has potential to provide $39 \%$ of the total U.S. electrical generation (Gagnon et al, 2016) and with the potential to build solar farms on unused tracks of land (Nguyen and Pearce, 2010), transitioning to solar PV has potential to replace coal as an energy source entirely 
(Zweibel et al, 2008, Duan et al, 2016). Thus, by replacing coal-fired electricity with PVgenerated electricity there is an expected decrease in air and waste emissions (e.g. greenhouse gases and air pollution particulates) that affect overall air quality and would be expected to improve human health. However, how significant this health impact would be is not known.

In order to inform health policy this paper will quantify the American lives saved by a complete elimination of the domestic coal industry with the scale up of solar PV systems. First the geospatial correlation with coal fired power plants and mortality is determined for the U.S. at the state level. Then, current life cycle mortality and morbidity rates due to coal combustion are calculated and current energy generation data is used to determine the current lives saved by PV and the increase in U.S. PV installations to replace coal-fired electrical generation entirely. Then, American deaths/kWh of coal and PV per year are calculated, enabling health policy analysts to determine the number of lives currently saved by existing PV production and the potential for eliminating all premature deaths from coal combustion in the U.S. The first costs for the approach is calculated per lives saved over the life time of the PV systems. Finally, the cost per life is determined while including the revenue of the solar electric generation using a sensitivity analysis on the value of the electricity. Public health impact results and policy interventions are discussed.

\subsection{Methods}

Coal-fired electricity emissions (EIA, 2010) were geolocated in the U.S to illustrate the geospatial relationship between coal emissions related mortality. Two 
shapefiles were obtained from the ArcGis database to analyze current air pollution due to coal-fired electrical production in the United States: (1) a shapefile of the U.S.

(Fitzpatrick, 2015), and (2) a shapefile of the current U.S. coal electrical plants (ArcGIS, 2014). This data was then transcribed on a map utilizing ArcMap 10.3.1 to indicate potential areas for PV penetration. Then annual mortality due to coal emissions per 100,000 people was added to the map (Schneider and Banks, 2010).

Total U.S. electrical generation was obtained to quantify the percentage of $\mathrm{kWh}$ produced by coal and solar PV in the U.S. (EIA, 2013). Current U.S. solar penetration data was obtained to provide for the baseline of PV lives saved now and in order to calculate the amount of PV needed to replace coal-fired electrical generation entirely. Current solar PV penetration has reached roughly $27.4 \mathrm{GW}$ (SEIA, 2015). This aggregate of solar PV produces $2.32 \times 10^{7} \mathrm{kWhrs} /$ year (EIA, 2016).

In order for PV to completely eliminate coal, the total DC rated power of PV needed, $\mathrm{S}_{\mathrm{T}}$, is calculated as follows:

$$
S_{T}=\frac{C_{T}}{(I \times 365)} * 10^{-6} \quad[\mathrm{GW}]
$$

where $\mathrm{C}_{\mathrm{T}}$ is the total amount of coal-fired electricity produced per year $(1.32$ $\mathrm{x} 10^{12} \mathrm{kWh} /$ year) (EIA, 2016), and $\mathrm{I}$, which is measured in $\mathrm{kWh} / \mathrm{m}^{2} /$ day, is the population weighted average U.S. peak sun hours per day that represents solar flux for solar PV generation and is determined by: 


$$
I=\sum_{S=1}^{50} \frac{\left(P_{S} I_{S}\right)}{P_{T}}\left[\mathrm{kWh} / \mathrm{m}^{2} / \text { day }\right]
$$

Where $\mathrm{P}_{\mathrm{s}}$ is the 2015 population of each state (U.S. Census, 2015), $\mathrm{I}_{\mathrm{s}}$ is the average solar flux in each state (NREL, 2007), and $\mathrm{P}_{\mathrm{T}}$ is the total 2015 U.S. population. I was found to be $4.79 \mathrm{kWh} / \mathrm{m}^{2} /$ day.

The contribution to mortality was quantified utilizing secondary sources for coal (Hendryx, 2007, Hendryx and Zullig, 2009,Cohen et al, 2005, Hendryx, 2008, Penney et al, 2009) and PV (Fthenakis et al, 2006, Fthenakis and Kim, 2011, Fthenakis and ChulKim, 2007, Hirschberg et al, 2004). A quantification of emissions throughout the entire life cycle of coal was necessary to determine the average U.S. number of premature deaths per year, $F_{c}$. The coal-fired electricity life cycle is divided into four components: extraction, transport, processing, and combustion (Epstein et al, 2011). The solarphotovoltaic system life cycle is divided into 5 components: mining, purification, manufacturing, operation, and recycling (Fthenakis et al, 2008). Waste, in the form of emissions, is calculated at each stage of the technologies life cycle and is aggregated. Thus, the electricity generation death rate for coal, $r_{c}$ is given by:

$$
r_{C}=\frac{D_{T C}}{C_{T}} \quad[\text { American deaths } / \mathrm{kWh} / \text { year }]
$$


where $\mathrm{D}_{\mathrm{TC}}$ is the total number of deaths due to coal fired electrical emissions, which is 52,000/year (Caiazzo et al, 2013).

The electricity generation death rate for solar photovoltaic technology, $\mathrm{r}_{\mathrm{PV}}$, is given by:

$$
r_{P V}=\frac{D_{T P V}}{E_{T P V}} \quad[\mathrm{U} . \mathrm{S} . \text { deaths } / \mathrm{kWh} / \text { year }]
$$

where the total energy generated by $\mathrm{PV}, \mathrm{E}_{\mathrm{TPV}}$ is $2.32 \times 10^{7} \mathrm{kWh} /$ year $(\mathrm{EIA}, 2016)$ or $2.65 \times 10^{-3} \mathrm{GW}$-year/year. The total deaths per year due to PV is more challenging to determine. For thin film amorphous silicon PV the value is currently zero based on the limited number of cases in the U.S. Environmental Protection Agencies Risk Management Program database (Fthenakis et al, 2006). The actual values of deaths from other PV materials is similarly not available. To remain conservative, the values for crystalline silicon-based PV will be estimated based on the values from a material used weighted number of deaths from chemical accidents in the larger chemical industry involving listed hazardous substances that are also used in solar cell or PV module manufacturing (e.g., $\mathrm{AsH}_{3}, \mathrm{PH}_{3}, \mathrm{SiHCl}_{3}, \mathrm{H}_{2} \mathrm{Se}, \mathrm{HF}, \mathrm{HCl}, \mathrm{SiH}_{4}$ ). This provides less than $10^{-4}$ deaths per GWyr, which is far safer than coal (Fthenakis et a, 2006, Fthenakis and Kim, 2011). The $\mathrm{D}_{\mathrm{TPV}}$, deaths per year from $\mathrm{PV}$, is currently amounts to $2.648 \times 10^{-}$ ${ }^{7}$ deaths/year (e.g. far less than 1). 
The total lives (L) saved per kWh of solar PV electricity production offsetting coal-fired electrical generation is given by:
$L=r_{c}-r_{P V}$
[U.S. lives saved/kWh]

(5)

Utilizing current industrial PV costs, $\mathrm{P}$, of $\$ 1.92 / \mathrm{W}$ (U.S. DOE, 2014), the first cost per life, $\mathrm{C}_{\mathrm{FL}}$, saved by purchasing a PV system to offset coal use nationally is calculated as follows:

$$
C_{F L}=\frac{\left[\left(S_{T} \times 10^{9} \frac{W}{G W} \times P\right)\right]}{\left(l_{p v} \times F_{C}\right)} \quad[\text { First cost } \$ \text { invested/U.S. lives saved in PV }
$$

lifetime]

Where $\mathrm{S}_{\mathrm{T}} \times 10^{9}$ is total solar in $\mathrm{GW}$ converted to $\mathrm{W}$, and $\mathrm{F}_{\mathrm{c}}$ represents the number of fatalities due to coal combustion emissions per year and $l_{\mathrm{pv}}$ is the lifetime of the PV. However, unlike conventional health policy interventions that only have a first cost, this policy would also generate revenue, which must be taken into account, which allows for a cost per life, $\mathrm{C}_{\mathrm{L}}$, over a specific period, $\mathrm{T}$ :

$$
C_{L}(T)=\frac{\left[\left(s_{T} \times 10^{9} \frac{W}{G W} \times P\right)-\left(C_{T} \times T \times v\right)\right]}{\left(T \times F_{C}\right)} \quad \text { [S/U.S. lives saved over T years] }
$$


Where $v$ is the $\$ / \mathrm{kW}$-hrs of the PV generated electricity replacing all of coal. A sensitivity analysis is run on $v$ and to avoid complications the energy cost escalation rate is assumed to track with inflation.

\subsection{Results}

There is a clear correlation between annual mortality due to coal emissions and the geographic locations of coal-fired power plants in the U.S. as can be seen in Figure 1. Dense regions of mortality are correlated with high coal-fired electrical emissions in the central and northeast of the U.S. Emissions from coal-fired electricity total $1.57 \times 10^{9}$ million metric tons in 2013 (EPA, 2014).

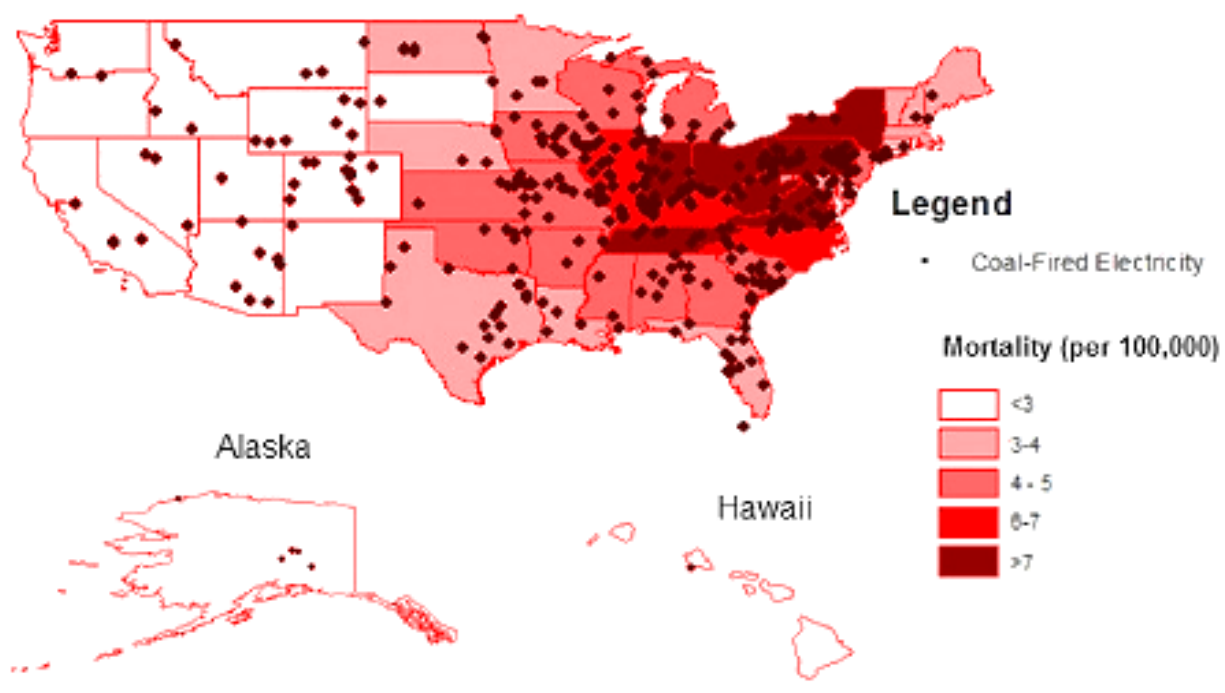

Figure 7. Coal fired electricity facilities located in the U.S. and the annual mortality due to coal emissions per 100,000 people in each U.S. state. 
Using equations 1 and 2, to completely replace coal-fired electricity would require 755 $\mathrm{GW}$ of solar PV. As the death rate from coal is $3.9393939 \times 10^{-8}$ deaths $/ \mathrm{kWh}$ from equation 3 and that of $\mathrm{PV}$ is $1.14 \times 10^{-14}$ deaths/kW-hr from equation 4 . It is clear that from a human mortality standpoint PV is far safer than coal produced electricity. This is quantified in equation 5 , which provides $3.9393927 \times 10^{-8}$ lives saved per $\mathrm{kW}-\mathrm{hr}$ as the respective death rates are 6 orders of magnitude larger for coal than PV. If the entire U.S. coal fired electricity production were switched to PV production. This would result in 51,999 American lives saved per year.

Installing $755 \mathrm{GW}$ of PV in the U.S. at $\$ 1.92 / \mathrm{W}$ (DOE, 2014), would cost the U.S roughly $\$ 1.45$ trillion dollars. Following equation 6 and using a 25 year warranty on the PV modules as the lifetime this results in a first cost per American life saved of roughly $\$ 1.1$ million per life. However, there are several complicating factors, first the output efficiency of PV modules degrades with time. For most technical studies this has been shown to be $0.5 \%$ per year degradation rate or less and that is what is used in PV economic studies (Campbell et al, 2008, Branker et al, 2011). The warranty for PV and its effective lifetime is set at 25 years, although it is clear the real lifetime of the PV would be much greater than that. In general the 25 year warranty for PV guarantees the PV power is performing at $80 \%$ of the initial rated power or better. Thus, to remain conservative these factors both decrease and increase cost per life respectively, they have been assumed to roughly cancel out and be ignored. The far more important complicating factor of using PV replacement of coal as a public health policy measure is the value of 
PV-generated electricity. Using 25 years again and equation 7 the cost per life varies substantially depending on the value assigned to the electricity as seen in Table 2, which ranges from over $\$ 1.1$ million per life saved if the electricity has no value, through coal generation with zero value placed on externalities (IER, 2012), and net metering through various scenarios (EIA, 2016), the calculated value for solar (Farrell, 2014) to $-\$ 4.6 \mathrm{~m}$ per life saved if the residential retail rate is used in an isolated rural community (Kantamneni et al, 2016).

Table 9. The Value of solar PV-generated electricity and the impact on the cost per life saved.

\begin{tabular}{|c|c|c|c|}
\hline $\begin{array}{l}\text { Method of Valuing Solar } \\
\text { Electricity }\end{array}$ & US\$/kWhr & $\begin{array}{l}\text { Solar PV US\$ } \\
\text { value/year }\end{array}$ & $\begin{array}{l}\text { Cost per Life } \\
\text { (US\$/life) }\end{array}$ \\
\hline No value & 0 & 0 & $\$ 1,115,076$ \\
\hline Coal generation only [57] & $\$ 0.0323$ & $\$ 4.26 \times 10^{10}$ & $\$ 295,153$ \\
\hline Net metering industrial [58] & $\$ 0.068$ & $\$ 8.98 \times 10^{10}$ & $-\$ 611,077$ \\
\hline Net metering commercial [58] & $\$ 0.1050$ & $\$ 1.39 \times 10^{11}$ & $-\$ 1,550,308$ \\
\hline Net metering residential [58] & $\$ 0.1261$ & $\$ 1.66 \times 10^{11}$ & $-\$ 2,085,923$ \\
\hline Value of Solar Minnesota [59] & $\$ 0.145$ & $\$ 1.91 \times 10^{11}$ & $-\$ 2,565,693$ \\
\hline $\begin{array}{l}\text { Net metering Houghton, MI } \\
{[60]}\end{array}$ & $\$ 0.2273$ & $\$ 3.00 \times 10^{11}$ & $-\$ 4,654,847$ \\
\hline
\end{tabular}

\subsection{Discussion}


Although, Figure 1 illustrates areas of high emissions due to coal-production, it is important to note that air pollution can be dispersed through the air and affect regions at large distances from the source (Fenger, 2009, Yim and Barrett, 2012). Carbon dioxide indirectly results in premature death due to climate change events and according to WHO analyses, climate change is expected to cause 250,000 additional deaths per year between 2030 and 2050 (Lockwood et al, 2009, Stoppato, 2008). Decreases in sulfur dioxides results from burning "clean coal”, washing coal, and utilizing scrubbers to chemically remove sulfur dioxide from coal burning smokestacks, resulted in decreasing sulfur dioxide levels from $15.7 \mathrm{~m}$ tons in 1990 to $10.2 \mathrm{~m}$ tons in 2005 (EPA, 2005). This was completed through cap and trade-based policy. The EPA issued control standards under clean air act, which includes $\mathrm{NO}_{\mathrm{x}}, \mathrm{SO}_{2}$, and $\mathrm{PM}_{\mathrm{x}}$. Decreases in particulate matter may not be correlated with decreased mortality as there is no well-defined safe threshold for particulate matter (Curtis et al, 2006). Particulate matter made up of smaller particles, which travel deep into respiratory tract and become lodged permanently (Buhre et al, 2005). Thus, despite improvements coal emissions remain a significant threat to mortality rates in the U.S. This paper found that a large number of premature deaths, about 52,000 in the U.S. due to coal-fired emissions during electrical generation, could be eliminated by a conversion to PV-based electrical generation.

To accomplish this national health benefit the amount solar PV needed to mitigate premature death due to coal-fired electrical production was $755 \mathrm{GW} .755 \mathrm{GW}$ is a significant increase over current U.S. PV penetration levels $(27.4 \mathrm{GW})$. Thus, only $3.6 \%$ of the PV necessary to prevent the current life loss from coal pollution is available. It should also be pointed out that there are some lifecycle emissions from PV (Epstein et al, 
2011, Fthenakis et al, 2008, Fthenakis and Chul-Kim, 2007, Sherwani et al, 2010). However, the full life cycle of PV produces a fraction of the carbon dioxide equivalent emissions when compared to coal (Fthenakis et al, 2008, Stoppato, 2008, Katzenstein and Apt, 2009). Air pollution throughout full life cycle of PV tends to vary with materials used during manufacture and mining (Sherwani and Usmani, 2010), however, the negative environmental impacts of PV generally involve accidental operation error (Hernandez et al, 2014, Turney and Fthenakis, 2011). In summary, the substitution of coal-fired electricity with solar power is a substantial health and environmental benefit and clear path towards a more sustainable state (Pearce, 2002).

This study made several estimations to obtain these values, which should be pointed out. First, the population-weighted average of solar flux was used to determine the energy generation rather than a detailed analysis of the geographic variation of PV production potential across the U.S. For the purposes of this study the error introduced with this method is small, but more detailed studies on both the rooftop PV potential (Wiginton et al, 2010, Nguyen and Pearce, 2012, Kodysh et al, 2013) and the solar farm (Nguyen and Pearce, 2010) and even agrivoltaic (Dupraz et al, 2011, Dinesh and Pearce, 2016) potential, would provide a more granular (e.g. including shading losses) estimates for decision makers (e.g. at the state or community level). Second, the premature deaths from coal related emissions are actually conservative. This study provided analyses of only the combustion step in coal electrical generation in the United States. To capture the full scope of mortality rates in the U.S., analyses must be expanded to include the full life cycle of coal; this includes sectors other than electrical (industry, manufacture of synthetic fuel, or manufacturing steel) that utilize coal. Other externalities exist for coal, 
including land use, water pollution, natural resource depletion, habitat destruction (Tsoutsos et al, 2005). These uncertainties must be quantified for both coal and solar PV to determine accurate measure of lives saved by replacing one electrical generation source for another. However, it is clear from the results that the potential American lives at stake, which can be saved by a policy intervention is warranted that encourages more rapid deployment of $\mathrm{PV}$.

Performing a similar analysis at a global scale could be of use to policy makers and the United Nations to satisfy Sustainable Development Goal \#7: Ensure access to affordable, reliable, sustainable, and modern energy for all (UN, 2016), while significantly reducing global lives sacrificed to current coal combustion. Current global outdoor air pollution is concentrated in developing nations due to continued increase of coal use (Finkelman et al, 2002). As a result, larger mortality rates of developing nations are expected to continue (Curtis et al, 2006, Cohen et al, 2005). The World Health Organization estimates 7 million deaths per year due to air pollution (of these 2.6 million are linked to outdoor air pollution), making it the single largest environmental risk today (WHO, 2014). Air pollution related mortality outweighs global car accidents (1.3 million people (ASIRT, 2016)) by a factor of five and natural disasters by a factor of 28 (mortality ranging from 20,000-250,000 people depending on the year) (IFRC, 2014). It can thus be assumed that the deaths per unit energy will be even more extreme on the global scale as the U.S. environmental protection standards are more advanced than much of the world. In addition, this does not take into account the potential premature deaths aggravated by climate change for which the Intergovernmental Panel on Climate Change 
(IPCC) already recommends immediate action to reduce emissions by 2050 (IPCC, 2011).

To meet the health-related demand of eliminating coal pollution with solar power in the U.S., \$1.45 trillion dollars would need to be invested in new PV generation. This is the total cost to save all future lives in the U.S. from coal-related electricity over the next twenty-five years. Even with no value the cost per life is only $\$ 1.1 \mathrm{~m}$, which is on the lower end of the values normally ascribed to human life (between $\$ 1$ and $\$ 9$ million) (Harrington, 2009, DOT, 2015, Partnoy, 2012). However, unlike other health policy interventions, which only cost money up front (Jamison et al, 2006), PV replacement of coal production also has the potential to generate significant revenue as shown in the third column of Table 2 . Table 2 provides a sensitivity analysis on the value of the solar electricity, which is currently under intense debate in the electrical industry. PV is inherently distributed so using the centralized coal value of electricity of $\$ 0.03 / \mathrm{kWhr}$ is misleadingly pessimistic. In most of the U.S. PV is currently net metered making the values between $\$ 0.06-0.12 / \mathrm{kWhr}$ more realistic. As can be seen in Table 2, all of these values actually have a net economic benefit for saving lives from only the value of electricity. There has also been a strong case made (Farrell, 2014) that net metering actually represents a subsidy to electric utilities as the value of solar can be higher (e.g. $\$ 0.14 / \mathrm{kWhr}$ in Minnesota). When looking at the potential for isolated communities to adopt solar the current high costs of electricity turn the potential economic savings per life save truly substantial. As technology has progressed to such a point that PV, battery and cogen units can displace the use of the grid in even the most extreme circumstances (Nosrat et a, 2013, Mundada et al, 2016, Basrawi et al, 2014, Shah et al, 2015), these 
levels of savings are possible for the small populations living in such regions (Kantamneni et al, 2016). The use of PV to offset coal-fired electricity compares exceptionally favorably to more conventional forms of health policy interventions, the best of which (e.g. helping children in developing nations (Murray and Chambers, 2015)) still costs a few thousand per life rather than conserving money.

The results clearly show, premature deaths due to anthropogenic effects (coal combustion and pollution) can be mitigated through anthropogenic efforts (PV electrical energy conversion). Policies can be developed at many scales (international, federal, state, and local levels) to contribute to the concerted climate change mitigation efforts. There are several policy interventions that could accelerate PV adoption: 1) Effective renewable portfolio standards (RPS) programs (Yin and Powers, 2010) and Mandatory Green Power Option (MGPO) (Delmas and Montes-Sancho, 2011) can be implemented at the state level. As air pollution is not limited to state boundaries, as is shown in Figure 1 , requiring states to design RPS programs would decrease emissions from electrical generation. Federal agencies, such as the EPA, can strengthen particle pollution standards, which can indirectly lead the electrical industry to adopt renewable energy generation systems (Fischer and Newell, 2008, Acemoglu et al, 2012). An alternative strategy includes instituting state taxes or carbon trading mechanisms (Convery et al, 2008, Bushnell et al, 2013) on coal usage. States and industries that continue coal usage would pay higher taxes to internalize environmental and health effects. EPA regulations such as Mercury and Air Toxics Standards, are responsible for the decommissioning of $72 \mathrm{GW}$ of coal electrical generating capacity (IER, 2012); this number is expected to rise by 2020 . On the other hand, increasing federal incentives for solar PV will likely result in 
a rapid transition to cleaner energy generation. It is important to note that a portfolio of these policy implementations will be more effective in reducing emissions and promoting renewables than any single policy or program (Fischer and Newell, 2008). In the context of mortality in the U.S., exploring and adapting wartime mobilization strategies (Delina and Diesendorf, 2013) to a national solar PV electrical transition may provide enough emission mitigation to slow anthropogenic climate change effects.

Finally, this study has only explored the impact of coal-fired electricity conversion to solar PV on mortality. However, current air pollution costs also occur in medical costs and lost productivity. In 2010, OECD nations spent roughly $\$ 1.7$ trillion in attempts to combat and treat effects from outdoor air pollution (OECD, 2014). The U.S. spends roughly $\$ 185$ billion per year on coal emission effects; these represent only health related costs (Epstein et al, 2011). California alone spent $\$ 193$ million in hospital care in 2007 due to air pollution effects (Romley et al, 2013). It has long been established that energy policy creates horrendous public health problems and injustices (Wilkinson et al, 2007), and this study makes clear large scale PV deployment to eliminate coal could help alleviate this historical problem. Future work can help quantify the values of these other effects from a transition from coal to solar based electrical generation.

\subsection{Conclusion}

The results of this study showed a clear geospatial correlation between coal fired power plants and mortality from air pollution is the U.S. at the state level. To reduce these deaths coal-fired electricity must be eliminated and the results showed that 51,999 
American lives could be saved per year by transitioning from coal to PV-powered electrical generation in the U.S. To accomplish this, $755 \mathrm{GW}$ of U.S. PV are needed and the first costs for such an national array are $\$ 1.45$ trillion. Over the 25 year warranty on the PV modules the first cost per life saved is approximately $\$ 1.1$ million, which is comparable to the value of a human life used in other studies. However, as the solar electricity has value, the cost per life for offsetting coal with PV actually saved money as well, in some cases several million dollars per life. It is concluded that it is profitable to save lives in the U.S. with the substitution of coal-fired electricity with solar power and that the conversion is a substantial health and environmental benefit. Evolving the U.S. energy system utilizing clean, alternative technology will allow the U.S. to prevent thousands of premature deaths along with becoming a global leader in renewable technology adoption. 


\subsection{References}

Acemoglu, Daron, Philippe Aghion, Leonardo Bursztyn, and David Hemous. "The environment and directed technical change." The American Economic

Review 102, no. 1 (2012): 131-166.

ArcGIS. U.S. Coal Plants, emissions, and attributed health issues. [Internet] 2014 [cited on 3016 Apr 1]. Available at:

http://www.arcgis.com/home/item.html?id=e31814ad804549c987f159e9a2f8eaf4

ASIRT. Annual Global Road Crash Statistics. [Internet]; 2016 [cited on 2016 Apr 20]. Available at: http://asirt.org/initiatives/informing-road-users/road-safetyfacts/road-crash-statistics

Basrawi, Firdaus, Takanobu Yamada, and Shin'ya Obara. "Economic and environmental based operation strategies of a hybrid photovoltaic-microgas turbine trigeneration system." Applied Energy 121 (2014): 174-183.

Branker, Kadra, M. J. M. Pathak, and Joshua M. Pearce. "A review of solar photovoltaic levelized cost of electricity." Renewable and Sustainable Energy Reviews 15, no. 9 (2011): 4470-4482.

Buhre, B. J. P., J. T. Hinkley, R. P. Gupta, T. F. Wall, and P. F. Nelson. "Submicron ash formation from coal combustion." Fuel 84, no. 10 (2005): 1206-1214.

Bushnell, James B., Howard Chong, and Erin T. Mansur. "Profiting from regulation: Evidence from the European carbon market." American Economic Journal: Economic Policy 5, no. 4 (2013): 78-106.

Caiazzo, Fabio, Akshay Ashok, Ian A. Waitz, Steve HL Yim, and Steven RH Barrett. "Air pollution and early deaths in the United States. Part I: Quantifying the impact of major sectors in 2005." Atmospheric Environment79 (2013): 198-208.

Campbell, Matt, P. Aschenbrenner, J. Blunden, E. Smeloff, and S. Wright. "The drivers of the levelized cost of electricity for utility-scale photovoltaics." White Paper: SunPower Corporation (2008).

Clancy, Luke, Pat Goodman, Hamish Sinclair, and Douglas W. Dockery. "Effect of airpollution control on death rates in Dublin, Ireland: an intervention study." The lancet 360, no. 9341 (2002): 1210-1214.

Cohen, Aaron J., H. Ross Anderson, Bart Ostro, Kiran Dev Pandey, Michal Krzyzanowski, Nino Künzli, Kersten Gutschmidt et al. "The global burden of disease due to outdoor air pollution." Journal of Toxicology and Environmental Health, Part A 68, no. 13-14 (2005): 1301-1307. 
Convery, Frank, Denny Ellerman, and Christian De Perthuis. "The European carbon market in action: Lessons from the first trading period." Journal for European Environmental \& Planning Law 5, no. 2 (2008): 215-233.

Curtis, Luke, William Rea, Patricia Smith-Willis, Ervin Fenyves, and Yaqin Pan. "Adverse health effects of outdoor air pollutants." Environment international 32, no. 6 (2006): 815-830.

Delina, Laurence L., and Mark Diesendorf. "Is wartime mobilisation a suitable policy model for rapid national climate mitigation?." Energy policy 58 (2013): 371-380.

Delmas, Magali A., and Maria J. Montes-Sancho. "US state policies for renewable energy: Context and effectiveness." Energy Policy 39, no. 5 (2011): 2273-2288.

Fischer, Carolyn, and Richard G. Newell. "Environmental and technology policies for climate mitigation." Journal of environmental economics and management 55, no. 2 (2008): 142-162.

Dinesh, Harshavardhan, and Joshua M. Pearce. "The potential of agrivoltaic systems." Renewable and Sustainable Energy Reviews 54 (2016): 299-308.

Duan, Hong-Bo, Gu-Peng Zhang, Lei Zhu, Ying Fan, and Shou-Yang Wang. "How will diffusion of PV solar contribute to China' s emissions-peaking and climate responses?." Renewable and Sustainable Energy Reviews 53 (2016): 1076-1085.

Dupraz, C., H. Marrou, G. Talbot, L. Dufour, A. Nogier, and Y. Ferard. "Combining solar photovoltaic panels and food crops for optimising land use: towards new agrivoltaic schemes." Renewable Energy 36, no. 10 (2011): 2725-2732.

EIA. Total Energy. [Internet]; 2013 [cited on 2016 Apr 1]. Available at: http://www.eia.gov/totalenergy/data/monthly/pdf/sec7_5.pdf

------ Net Generation from Renewables. [Internet]; 2016 [cited on 2016 Mar 11]. Available at: http://www.eia.gov/electricity/monthly/epm table grapher.cfm?t=epmt $1 \_01$ a

- What is U.S. Electricity Generation by Source. [Internet]; 2015 [cited on 2016 Apr 1]. Available at: https://www.eia.gov/tools/faqs/faq.cfm?id=427\&t=3

------ Electrical Power Annual 2010. [Internet]; 2011 [cited on 2016 Mar 12]. Available at: http://www.eia.gov/electricity/annual/archive/03482010.pdf

------ Electric Power Monthly. [Internet]; 2016 [cited on 2016 Mar 2]. Available at: https://www.eia.gov/electricity/monthly/epm_table_grapher.cfm?t=epmt 5_6_a 
Short term energy and summer fuels outlook (2016 values) [Internet]; 2016 [cited on 2016 Mar 11]. https://www.eia.gov/forecasts/steo/report/electricity.cfm

EPA. Cap and Trade. [Internet]; 2005 [cited on 2016 Feb 20]. Available at: https:/www3.epa.gov/captrade/

US GHG Inventory Report [Internet]; 2014 [cited on 2016 Feb 12] available at: https://www3.epa.gov/climatechange/ghgemissions/usinventoryreport.html

------ Sources of Greenhouse Gas Emissions. [Internet]; 2014 [cited 2016 Feb 15] available from: https://www3.epa.gov/climatechange/ghgemissions/sources/electricity.html

------ 2013 Progress Reports. [Internet]; 2013 [cited on 2016 Mar 2]. Available at: , https://www3.epa.gov/airmarkets/progress/reports/index.html

Epstein, Paul R., Jonathan J. Buonocore, Kevin Eckerle, Michael Hendryx, Benjamin M. Stout Iii, Richard Heinberg, Richard W. Clapp et al. "Full cost accounting for the life cycle of coal." Annals of the New York Academy of Sciences 1219, no. 1 (2011): 73-98.

Evans, Annette, Vladimir Strezov, and Tim J. Evans. "Assessment of sustainability indicators for renewable energy technologies." Renewable and sustainable energy reviews 13, no. 5 (2009): 1082-1088.

Farrell, John. "Minnesota's Value of Solar: Can a Northern State's New Solar Policy Defuse Distributed Generation Battles?." Institute for Local Self-Reliance Report, April 2014b,(http://www. ilsr. org/wp-content/uploads/2014/04/MN-Value-ofSolar-from-ILSR. pdf) (2014).

Fenger, Jes. "Air pollution in the last 50 years-From local to global." Atmospheric Environment 43, no. 1 (2009): 13-22.

Fitzpatrick, C. US 50 States + DC shapefile. ArcGis Database. 2012 Feb 1 [cited on 2015 Oct 4]. Available from: https://www.arcgis.com/home/item.html?id=f7f805eb65eb4ab787a0a3e1116ca7e 5 .

Fthenakis, V. M., H. C. Kim, A. Colli, and C. Kirchsteiger. "Evaluation of risks in the life cycle of photovoltaics in a comparative context." In 21st European Photovoltaic Solar Energy Conference. 2006.

Fthenakis, Vasilis M., Hyung Chul Kim, and Erik Alsema. "Emissions from photovoltaic life cycles." Environmental science \& technology 42, no. 6 (2008): 2168-2174. 
Fthenakis, V. M., and Hyung Chul Kim. "Photovoltaics: Life-cycle analyses." Solar Energy 85, no. 8 (2011): 1609-1628.

- Vasilis M., and Hyung Chul Kim. "Greenhouse-gas emissions from solar electric-and nuclear power: A life-cycle study." Energy Policy 35, no. 4 (2007): 2549-2557.

Finkelman, Robert B., William Orem, Vincent Castranova, Calin A. Tatu, Harvey E. Belkin, Baoshan Zheng, Harry E. Lerch, Susan V. Maharaj, and Anne L. Bates. "Health impacts of coal and coal use: possible solutions." International Journal of Coal Geology 50, no. 1 (2002): 425-443.

Gaffney, Jeffrey S., and Nancy A. Marley. "The impacts of combustion emissions on air quality and climate-From coal to biofuels and beyond." Atmospheric

Environment 43, no. 1 (2009): 23-36.

Gagnon, Pieter, Robert Margolis, Jennifer Melius, Caleb Phillips, and Ryan Elmore. "Rooftop Solar Photovoltaic Technical Potential in the United States: A Detailed Assessment." Rep. No. NREL/TP-6A20-65298). Retrieved March30 (2016): 2016.

Gohlke, Julia M., Reuben Thomas, Alistair Woodward, Diarmid Campbell-Lendrum, Annette Prüss-Üstün, Simon Hales, and Christopher J. Portier. "Estimating the global public health implications of electricity and coal consumption." Environmental health perspectives 119, no. 6 (2011): 821.

Harrington, L 2009 The Valuation of the Life Shortening Aspects of Work. EPA. Available at: https://yosemite.epa.gov/ee/epa/eerm.nsf/vwAN/EE0297.pdf/\$file/EE-0297.pdf

Hendryx, Michael. "Mortality from heart, respiratory, and kidney disease in coal mining areas of Appalachia." International archives of occupational and environmental health 82, no. 2 (2009): 243-249.

Michael, and Keith J. Zullig. "Higher coronary heart disease and heart attack morbidity in Appalachian coal mining regions." Preventive Medicine 49, no. 5 (2009): 355-359.

Michael. "Mortality rates in Appalachian coal mining counties: 24 years behind the nation." Environmental Justice 1, no. 1 (2008): 5-11.

Hernandez, R. R., S. B. Easter, M. L. Murphy-Mariscal, F. T. Maestre, M. Tavassoli, E. B. Allen, C. W. Barrows et al. "Environmental impacts of utility-scale solar energy." Renewable and Sustainable Energy Reviews 29 (2014): 766-779. 
Hirschberg, Stefan, Roberto Dones, Thomas Heck, P. Burgherr, W. Schenler, and C. Bauer. "Sustainability of electricity supply technologies under German conditions: a comparative evaluation." PSI, 2004.

IER. Electrical Generating Costs 2012. [Internet]; 2012 [cited on 2016 Mar 11]. http://instituteforenergyresearch.org/analysis/electric-generating-costs-a-primer/

----- Power Plant Closures. [Internet]; 2012 [cited on 2016 Apr 24]. Available at: http://instituteforenergyresearch.org/topics/policy/power-plant-closures/

IFRC. World Disasters Report. [Internet]; 2014 [cited on 2016 Apr 20]. Available at: http://www.ifrc.org/world-disasters-report-2014/data

IPCC. Special report on Renewable Energy Sources and Climate Change Mitigation. [Internet]; 2011 [cited on 2016 Apr 1]. Available at: http://www.uncclearn.org/sites/default/files/inventory/ipcc15.pdf .

Jamison, Dean T., Joel G. Breman, Anthony R. Measham, George Alleyne, Mariam Claeson, David B. Evans, Prabhat Jha, Anne Mills, and Philip Musgrove, eds. Disease control priorities in developing countries. World Bank Publications, 2006.

Kampa, Marilena, and Elias Castanas. "Human health effects of air pollution." Environmental pollution 151, no. 2 (2008): 362-367.

Kantamneni, Abhilash, Richelle Winkler, Lucia Gauchia, and Joshua M. Pearce. "Emerging economic viability of grid defection in a northern climate using solar hybrid systems." Energy Policy 95 (2016): 378-389.

Kodysh, Jeffrey B., Olufemi A. Omitaomu, Budhendra L. Bhaduri, and Bradley S. Neish. "Methodology for estimating solar potential on multiple building rooftops for photovoltaic systems." Sustainable Cities and Society 8 (2013): 31-41.

Katzenstein, Warren, and Jay Apt. "Air emissions due to wind and solar power." Environmental science \& technology 43, no. 2 (2008): 253-258.

Lockwood, Alan H., Kristen Welker-Hood, Molly Rauch, and Barbara Gottlieb. "Coal's assault on Human HealtH." Physicians for Social Responsibility Report (2009).

Markandya, Anil, and Paul Wilkinson. "Electricity generation and health." The Lancet 370, no. 9591 (2007): 979-990.

Melody, S. M., and F. H. Johnston. "Coal mine fires and human health: What do we know?." International Journal of Coal Geology 152 (2015): 1-14. 
Mundada, Aishwarya S., Kunal K. Shah, and J. M. Pearce. "Levelized cost of electricity for solar photovoltaic, battery and cogen hybrid systems." Renewable and Sustainable Energy Reviews 57 (2016): 692-703.

Murray, Christopher, and Ray Chambers. "Keeping score: fostering accountability for children's lives." The Lancet 386, no. 9988 (2015): 3-5.

Nguyen, H. T., and Joshua M. Pearce. "Estimating potential photovoltaic yield with r. sun and the open source geographical resources analysis support system." Solar energy 84, no. 5 (2010): 831-843.

Ha T., and Joshua M. Pearce. "Incorporating shading losses in solar photovoltaic potential assessment at the municipal scale." Solar Energy 86, no. 5 (2012): 12451260.

Nosrat, Amir H., Lukas G. Swan, and Joshua M. Pearce. "Improved performance of hybrid photovoltaic-trigeneration systems over photovoltaic-cogen systems including effects of battery storage." Energy 49 (2013): 366-374.

NREL (National Renewable Energy Laboratory). Annual direct normal solar radiation 8 years mean value (1998-2005). SUNY 20km satellite mode 2007.

OECD. The Cost of Air Pollution. [Internet]; 2014 [cited on 2016 Apr 20]. Available at: http://www.keepeek.com/Digital-Asset-Management/oecd/environment/the-costof-air-pollution/summary/english 9789264210448-sum-en\#page1

O'Neill, Brian C., Brant Liddle, Leiwen Jiang, Kirk R. Smith, Shonali Pachauri, Michael Dalton, and Regina Fuchs. "Demographic change and carbon dioxide emissions." The Lancet 380, no. 9837 (2012): 157-164.

Partnoy, F. The Cost of a Human Life, Statistically Speaking. The Globalist. 2012, [Internet]; 2012 [cited on 2016 Apr 10]. http://www.theglobalist.com/the-cost-ofa-human-life-statistically-speaking

Pearce, Joshua M. "Photovoltaics - a path to sustainable futures." Futures34, no. 7 (2002): 663-674.

Pearce, Joshua, and Andrew Lau. "Net energy analysis for sustainable energy production from silicon based solar cells." In ASME Solar 2002: International Solar Energy Conference, pp. 181-186. American Society of Mechanical Engineers, 2002.

Penney, Sarah, Jacob Bell, and John Balbus. "Estimating the health impacts of coal-fired power plants receiving international financing." Report of Environmental Defence Fund (2009). 
Reboredo, Juan C. "Renewable energy contribution to the energy supply: Is there convergence across countries?." Renewable and Sustainable Energy Reviews 45 (2015): 290-295.

Romley, John A., Andrew Hackbarth, and Dana P. Goldman. The Impact of Air Quality on Hospital Spending. RAND Corporation, 2010.

Schneider, Conrad G., Jonathan M. Banks, and Marika Tatsutani. The toll from coal: An updated assessment of death and disease from America's dirtiest energy source. Clean Air Task Force, 2010.

SEIA. Solar Market Insight. [Internet] 2015 [cited on 2016 Mar 4]. Available at:, http://www.seia.org/research-resources/us-solar-market-insight

Shah, Kunal K., Aishwarya S. Mundada, and J. M. Pearce. "Performance of US hybrid distributed energy systems: Solar photovoltaic, battery and combined heat and power." Energy Conversion and Management 105 (2015): 71-80.

Sherwani, A. F., and J. A. Usmani. "Life cycle assessment of solar PV based electricity generation systems: A review." Renewable and Sustainable Energy Reviews 14, no. 1 (2010): 540-544.

Sims, Ralph EH, Hans-Holger Rogner, and Ken Gregory. "Carbon emission and mitigation cost comparisons between fossil fuel, nuclear and renewable energy resources for electricity generation." Energy policy 31, no. 13 (2003): 1315-1326.

Smith, Kirk R., Howard Frumkin, Kalpana Balakrishnan, Colin D. Butler, Zoë A. Chafe, Ian Fairlie, Patrick Kinney et al. "Energy and human health." Annual Review of public health 34 (2013): 159-188.

Solangi, K. H., M. R. Islam, R. Saidur, N. A. Rahim, and H. Fayaz. "A review on global solar energy policy." Renewable and sustainable energy reviews 15, no. 4 (2011): 2149-2163.

Stavins, Robert N. "Addressing climate change with a comprehensive US cap-and-trade system." Oxford Review of Economic Policy 24, no. 2 (2008): 298-321.

--------- Robert N. "What can we learn from the grand policy experiment? Lessons from SO 2 allowance trading." The Journal of Economic Perspectives 12, no. 3 (1998): 69-88.

Stoppato, A. "Life cycle assessment of photovoltaic electricity generation." Energy 33, no. 2 (2008): 224-232. 
Tsoutsos, Theocharis, Niki Frantzeskaki, and Vassilis Gekas. "Environmental impacts from the solar energy technologies." Energy Policy 33, no. 3 (2005): 289-296.

Turney, Damon, and Vasilis Fthenakis. "Environmental impacts from the installation and operation of large-scale solar power plants." Renewable and Sustainable Energy Reviews 15, no. 6 (2011): 3261-3270.

United Nations. Sustainable Development Goals. [Internet]; 2016 [cited on 2016 Apr 20]. Available at: https://sustainabledevelopment.un.org/

U.S. Census. Population Estimates. [Internet]; 2015 [cited on 2016 Apr 15]. Available at: https://www.census.gov/popest/data/counties/totals/2015/index.html

U.S. DOE SunShot. Photovoltaic system pricing trends. [Internet]; 2014 [cited on 2016 Mar 20]. Available at: http://www.nrel.gov/docs/fy14osti/62558.pdf

US DOT. 2015. Treatment of the Value of Preventing Fatalities and Injuries in Preparing Economic Analyses. [cited on 2016 Apr 1]. Available at: https://www.transportation.gov/sites/dot.gov/files/docs/VSL2015 0.pdf

Weisser, Daniel. "A guide to life-cycle greenhouse gas (GHG) emissions from electric supply technologies." Energy 32, no. 9 (2007): 1543-1559.

WHO. 7 Million Premature Deaths Annually Linked to Air Pollution. [Internet]; 2014 [cited on 2016 Feb 20]. Available at: http://www.who.int/mediacentre/news/releases/2014/air-pollution/en/

Wiginton, L. K., H. T. Nguyen, and Joshua M. Pearce. "Quantifying rooftop solar photovoltaic potential for regional renewable energy policy." Computers, Environment and Urban Systems 34, no. 4 (2010): 345-357.

Wilkinson, Paul, Kirk R. Smith, Michael Joffe, and Andrew Haines. "A global perspective on energy: health effects and injustices." The Lancet 370, no. 9591 (2007): 965-978.

Yim, Steve HL, and Steven RH Barrett. "Public health impacts of combustion emissions in the United Kingdom." Environmental science \& technology 46, no. 8 (2012): 4291-4296.

Yin, Haitao, and Nicholas Powers. "Do state renewable portfolio standards promote instate renewable generation?." Energy Policy 38, no. 2 (2010): 1140-1149.

Zweibel, Ken, James Mason, and Vasilis Fthenakis. "A solar grand plan." Scientific American 298, no. 1 (2008): 64-73. 


\section{Chapter 5: Conclusion: Energy Justice and U.S. Energy Policy \\ Introduction}

This thesis applies an energy justice framework to case studies to understand how specific U.S. energy policies reconcile with energy justice. Utilizing an energy justice framework provides guidance to analyzing existing policy to consider opportunities for changing and improving policy. Applying this framework can ultimately highlight opportunities for policy change as well as provide an avenue for a shift in policy goals from profit maximization to considerations of equity and equality in energy decisionmaking.

Chapter 2 presents a case study of distributive energy injustice in U.S. energy policy. Designing and implementing a federal RPS program will not only promote renewable energy adoption, but also to potentially provide equitable distribution of environmental burdens and benefits. While the paper demonstrates the real feasibility of military facilities transitioning to renewable energy sources, it also highlights the inequitable distribution of policies targeting both critical infrastructures and community resilience throughout the U.S.

Chapter 3 discusses procedural and affirmative energy injustice by utilizing a state level case study of residential solar PV adoption in Michigan. While residential PV adopters do largely fit the characteristics of a sustainable consumer, individual value and socioeconomic variables fail to situate potential adopters in a lived policy context, which also influences the prevalence of adoption. Providing and extending renewable energy incentives to all demographics (including low to fixed income households) will begin to reconcile state energy policy with the affirmative principle. Creating a consumer 
advocacy group that works alongside the state's regulatory agencies could provide the opportunity for all relevant stakeholders to be represented in state energy decisionmaking.

Chapter 4 illustrates a violation of the prohibitive energy justice principle through a case study of adverse health affects due to coal-fired electrical production. Utilizing policy instruments such as carbon tax or carbon cap and trade can place responsibility for

emissions on heavy fossil fuel users. Requiring users to account for the full social costs of fossil fuels will promote renewable energy adoption and encourage preliminary steps to restructure the U.S.'s reliance on a centralized, fossil fuel dependent energy infrastructural system.

\subsection{Turning to Cosmopolitan Justice}

Cosmopolitan justice is a concept that highlights environmental burdens and justice as global issues (Caney, 2005). It is focuses on the global scale of the energy systems and their impacts, questioning who should bear the burden of outcomes or consequences of energy production and its consequences in global climate change. This includes a consideration of intergenerational justice.

As this thesis is an analysis of U.S. energy policy, the contention that developing renewable energy policies requires considering cosmopolitan justice applies in the sense that the U.S. can become a global leader in climate change mitigation through enhanced, developed, renewable energy policy. U.S. energy policy represents the consequences of unequal access and power, both internally and internationally. The concept of cosmopolitan justice also allows a re-conceptualization of U.S. energy policy within the 
global scope; pollution that contributes to climate change is not geographically limited to the boundaries of a nation-state. Effects of energy policy and decision-making surrounding American energy usage have huge implications globally.

Scholars posit several explanations as to why the U.S. does not have a federal renewable energy policy (Elliot, 2013, Bochner, 2014, Sovacool and Cooper, 2009, Michaels, 2008). These explanations revolve mainly around the deep seeded political structure, political culture (Elliot, 2013), and interstate economics (Michaels, 2008). This thesis does not attempt to provide insight as to why the U.S. is reluctant to instate a national renewable energy policy, but rather cite, with specific case studies, how a lack thereof does not reconcile with the energy justice theories and principles explained above.

\subsection{Policy Recommendations and Implications}

The first case study (Chapter 2) looks at renewable energy at domestic military installations. The U.S. military must comply with a federal mandate to begin adopting renewable energy systems ( $3 \mathrm{GW}$ by 2025$)$. This case study speaks to the distributive principle. The centralized U.S. electrical grid is vulnerable to external threats. In the event of a physical, natural, or cyber-attack, the electrical system failure can impair social and economic functions of the nation. National and energy security in energy policy designs must incorporate an energy justice framework in the decision-making process, which would suggest a need for a policy that applies to all critical infrastructures or even all communities, not just military facilities. There are limited policies in place to facilitate a transition to a dominant renewable energy generation system and this lack of policies functions to potentially distribute environmental harms inequitably to U.S. citizens. The 
Federal government needs to explore options that protect all citizens, including protection from grid vulnerabilities. The mandate for the military represents only a localized corporate interest that does not reflect the interest of the entire United States population. A proposed solution looks at creating a federal RPS program. There is speculation regarding utilizing a uniform national RPS (Michaels, 2008). Issues include the potential for some participants to free ride within a national system or interstate disruption due to enactment of a uniform RPS program. Therefore, legislation could mandate a federal RPS program that allows states flexibility in designing the RPS program specific to those state's resources and needs.

The second study (Chapter 3) focuses on procedural and affirmative energy injustice in adopting renewable energy systems, by examining regional issues with utilities and residential PV adoption in the context of existing utility policies in the state of Michigan. Understanding what predicts solar PV adoption at the residential scale can inform decision-makers to design policies that expand a state's renewable energy portfolio. The results suggest a need to place the sustainable consumer in a lived policy context, and consider the extent to which that context operates to shape household decisions regarding energy. The results also speak to a gap in who is involved in decision-making. Those individuals living in or near fuel poverty (1) have less power in legislation regarding renewable energy technologies (Kramer and Tyler, 1996) and (2) have limited means to invest in renewable energy systems (Sovacool et al, 2013).To reconcile with procedural and affirmative energy justice concepts, the first solution is to supplement Michigan's RPS program with state incentives such as tax credits, tax exemptions, rebates, and/or subsidies that extend to low-fixed income households. This 
provides equal access to alternative technologies for all Michigan residents. Additionally, to ensure fair participation, the state could model Wisconsin Forestry Council's creation of an advisory committee (Herrick et al, 2009). This committee includes all relevant stakeholders affected by issues related to biomass harvesting and use. An interesting component to this specific committee is the revolving door policy on stakeholder participants. Groups who feel their needs and opinions are not being recognized by legislation can join the committee's deliberations. A creation of an energy advisory committee in Michigan would allow relevant stakeholders, including industry, non-profit organizations, environmental organizations, and local governments the capacity to deliberate and voice specific needs. The significance of including local governments in an advisory committee is their capacity to represent local resident's needs in energy deliberations.

Considering prohibitive energy justice issues provides another avenue to begin to help communities adapt and shift to acquire basic energy needs. The third case study (Chapter 4) illustrates a violation of the prohibitive energy justice principle. Again, expanding the focus at the national scale, this paper shows the externalities associated with energy generation through conventional fuels, specifically the harms to human life through the combustion of coal for energy generation. The U.S. energy system is currently centralized and fossil fuel dependent. The overarching solution is to promote the use of renewables in a distributed generation style electrical grid system (Zweible et al, 2008, Duan et al, 2016). This will begin a transition to replace heavy conventional fossil fuel use. Promoting renewable energy technology can result from implementing policy instruments such as a carbon tax or carbon cap and trade system. Legislation could 
tax carbon dioxide emissions from heavy fossil fuel users to incentivize this shift to renewable energy generation. A carbon tax does not automatically result in decreased carbon dioxide emissions, as those industries that have the means to comply with a tax may not take steps to reduce their use. Cap and trade seems to provide a more practical solution; by placing targets on carbon dioxide emissions, heavy fossil fuel users have flexibility in how they decrease carbon dioxide emissions. A major caveat to carbon cap and trade is the difficulty in pinpointing the carbon emission source. Renewable energy adoption could correspond to a decrease in negative environmental (air pollution, degradation, climate change) and human (morbidity, mortality, electric grid failure) impacts associated with continued reliance on a centralized, fossil fuel dependent electrical system. Instituting federal regulations, sanctions, or incentives discussed above can function to decrease the reliance on fossil fuels while simultaneously promoting a transition to renewable energy sources.

Borrowing from Hall (1993), considering an energy justice framework in U.S. energy policy decision-making has the potential to cause first, second, and third order shifts at the federal level (Hall, 1993). First and second order policy shifts can be seen through changes in policy instruments and the settings of those instruments. Utilizing an energy justice framework could result in different policy instruments and targets that expand to all energy users, including military (Chapter 2), industry (Chapter 4), and residential (Chapter 3). However, a third order change results when the policy goals shift. By using an energy justice framework, U.S. energy policy can become less about maximizing profits and more concerned with equity and equality in distributing access to 
energy systems that maximize social goods while minimizing environmental and social harms.

\subsection{Future Work}

Energy is the main way we produce and obtain basic goods and needs for our existence. Because energy is such a dominating force in our society, we cannot overlook the ends to justify the means. Energy problems that inform energy policy decisionmaking can assist energy planners and consumers in making more informed energy choices to mitigate and prevent the negative consequences (i.e. harm to humans and the environment) that hinder our ability to obtain these basic needs and enjoy the indispensible goods of security and welfare.

Each of these case studies presents opportunities for future research projects. One avenue would consider a military transition to dominant renewable energy systems (following chapter 2). This would include devising potential renewable energy capacity for domestic military bases corresponding to current energy load and usage. Treating the military as a first level for transition could provide the groundwork for other U.S. sectors (critical infrastructure, industry, and residential) to follow suit in renewable energy adoption. Chapter 3 presented adoption levels in Michigan as a function of socioeconomic, political, and policy indicators. Future research could construct and analyze true measures of fuel poverty among Michigan residents. Understanding and reporting accurate measures of fuel poverty can act as a catalyst to instituting state incentives for renewable technology adoption. Building on the applications in this thesis allows for specific examinations of U.S. energy policies the context of an energy justice 
framework, opening the door for possibilities to change and improve policy through energy justice guided policy development. 


\subsection{References}

Bochner, Francesca F. "Water, Wind, and Fire: A Call for A Federal Renewable Portfolio Standard." Duke Envtl. L. \& Pol'y F. 25 (2014): 201.

Caney, Simon. "Cosmopolitan justice, responsibility, and global climate change." Leiden journal of international law 18, no. 04 (2005): 747-775.

Duan, Hong-Bo, Gu-Peng Zhang, Lei Zhu, Ying Fan, and Shou-Yang Wang. "How will diffusion of PV solar contribute to China' s emissions-peaking and climate responses?." Renewable and Sustainable Energy Reviews 53 (2016): 1076-1085.

Elliot, E.D. "Why the United States does not have a renewable energy policy." $\mathrm{PhD}$ diss., Yale Law School, 2013.

Epstein, P., Buonocore, J., Eckerle, K., Hendryx, M., Stout, B., Heinberg, R., Clapp, R., May, B., Reinhart, N., Ahern, M., Doshi, S., Glustrom, L. "Full cost accounting for the life cycle of coal." Ecological Economics Reviews 1219 (2011): 73-98.

Goldthau, A. and Sovacool, B. "The uniqueness of the energy security, justice, and governance problem.” Energy Policy 41 (2012):232-240.

Hall, S.M., Hards, S., Bulkeley, H. "New approaches to energy: equity, justice, and vulnerability. Introduction to the special issue." Local Environment 18, 4 (2013): 413-421.

Herrick, Sarah, Joe Kovach, Eunice Padley, Carmen Wagner, and Darrell Zastrow. "Wisconsin's forestland woody biomass harvesting guidelines." WI DNR Division of Forestry and Wisconsin Council on Forestry, Madison, WI(2009).

Sovacool, Benjamin K., Christopher Cooper, Morgan Bazilian, Katie Johnson, David Zoppo, Shannon Clarke, Jay Eidsness, Meredith Crafton, Thiyagarajan Velumail, and Hilal A. Raza. "What moves and works: Broadening the consideration of energy poverty." Energy Policy 42 (2012): 715-719.

Sovacool, B.K. "The cultural barriers to renewable energy and energy efficiency in the U.S.," Technology in Society 31, 4(2009): 365-373.

Sovacool, Benjamin K., Sidortsov, Roman, Jones, Benjamin. Energy Security, equality, and justice. Routledge, 2013.

Sovacool, B.K., Heffron, R., McCauley, D., Goldthau, A. "Energy decisions reframed as justice and ethical concerns." Nature Energy 1 (2016): 16024 
Zweibel, Ken, James Mason, and Vasilis Fthenakis. "A solar grand plan." Scientific American 298, no. 1 (2008): 64-73. 